\title{
Evaluation of Parent-Child Interaction Therapy and a Standard Parenting Program within a Women's State Prison Facility
}

\author{
Ashley B. Tempel \\ West Virginia University
}

Follow this and additional works at: https://researchrepository.wvu.edu/etd

\footnotetext{
Recommended Citation

Tempel, Ashley B., "Evaluation of Parent-Child Interaction Therapy and a Standard Parenting Program within a Women's State Prison Facility" (2012). Graduate Theses, Dissertations, and Problem Reports. 4929.

https://researchrepository.wvu.edu/etd/4929

This Dissertation is protected by copyright and/or related rights. It has been brought to you by the The Research Repository @ WVU with permission from the rights-holder(s). You are free to use this Dissertation in any way that is permitted by the copyright and related rights legislation that applies to your use. For other uses you must obtain permission from the rights-holder(s) directly, unless additional rights are indicated by a Creative Commons license in the record and/ or on the work itself. This Dissertation has been accepted for inclusion in WVU Graduate Theses, Dissertations, and Problem Reports collection by an authorized administrator of The Research Repository @ WVU. For more information, please contact researchrepository@mail.wvu.edu.
} 
Evaluation of Parent-Child Interaction Therapy and a Standard Parenting Program within a Women's State Prison Facility

\author{
Ashley B. Tempel \\ Dissertation submitted to the \\ Eberly College of Arts and Sciences \\ at West Virginia University \\ in partial fulfillment of the requirements \\ for the degree of \\ Doctor of Philosophy \\ in \\ Psychology
}

Cheryl B. McNeil, Ph.D., Chair

William Fremouw, Ph.D.

Thomas Horacek, Ph.D.

Katherine Karraker, Ph.D.

Elisa Krackow, Ph.D.

Department of Psychology

Morgantown, West Virginia

2012

Keywords: maternal incarceration, prison, correctional facility, parenting programs, ParentChild Interaction Therapy, Partnerships in Parenting 


\begin{abstract}
Evaluation of Parent-Child Interaction Therapy and a Standard Parenting Program within a Women's State Prison Facility
\end{abstract}

\title{
Ashley B. Tempel
}

A majority of inmates in state and federal prisons across the U.S. have been reported to be parents of minors (Glaze \& Maruschak, 2008). It is estimated that twice as many American children (i.e., 2\% or over 1.7 million) compared to children of other industrialized countries have incarcerated parents (Murray, 2007). Approximately 336, 000 households with minor children are believed to be directly affected by parental imprisonment (Mumola, 2000). Parent training provided through correctional programming has potential to impact a large number of American families that are affected by parental incarceration. However, correctional parenting programs often vary across facilities and there are no empirically supported "best practices" for parenting programs provided to mothers during incarceration. The current study examines a standard parenting class offered within a correctional facility and a parent-training class modeled from Parent-Child Interaction Therapy, a program with an existing evidence base for improving parenting outcomes with community populations. Eighty-two women incarcerated in a female, state prison facility were randomized to one of the two intervention groups. Participants had a mean age of 30.83 years $(S D=5.88)$. The average minor child age was 6.76 years $(S D=4.37)$.The majority of mothers were white, nonHispanic (93\%), had not graduated from high school (i.e., less than a $12^{\text {th }}$ grade education; 63.4\%) and were unemployed or receiving disability benefits at the time of incarceration $(56.1 \%)$. Participants reported being responsible for the care of at least one of their children $(71.0 \%)$ and seeing their children every day prior to incarceration $(71.0 \%)$. At pre-treatment, mothers reported that they talked about their child every day (64.6\%), wrote letters to their child at least once a week $(57.3 \%)$, talked with their child on the phone at least once a week $(48.8 \%)$, but were not having facility visitation with their children $(76.8 \%)$. Participants in both treatment groups were matched to intervention dose of weekly, 1.5-hour group parenting classes that each consisted of 10-15 participants. Treatment groups were combined for pre-treatment, post-treatment, and follow-up assessments that included group administration of self-report measures and individual behavior observations of analogue parenting interactions. Study findings suggest similar changes in parenting knowledge, parenting stress, and child abuse potential following both facility-based parenting programs. In addition, these findings suggest that mothers completing PCIT reported higher levels of demonstrated parenting skills and treatment satisfaction than mothers in the standard program. Each study finding as well as methodological limitations, possible implications, and future directions are discussed. 



\section{Acknowledgments}

My heartfelt thank you is owed to many individuals for their contributions to the development of this study. Without the collaboration of all involved, the completion of such a project would not have been possible. First, I thank Dr. Cheryl McNeil, for being not only a graduate mentor but an academic "parent." Your unrelenting support has allowed for my growth both as a professional and person. Secondly, I thank the members of my dissertation committee; Drs. William Fremouw, Katherine Karraker, Elisa Krackow, and Thomas Horacek. I appreciate your thoughtful contributions which significantly shaped the conceptualization and implementation of this project. I also thank my research colleagues and friends- Karishma Chengappa, Amanda Costello, Lauren Scudder, Sydney Metheny, Alex Siler, Michelle Treadwell, and Camille Uncapher. I value your dependability and loyalty. You dedicated thousands of miles to car rides, contributed countless hours to facility assessment days, scored lengthy questionnaires, and endured hours of coding and data entry--all for the sake of this project. You were the oil in the machine--thank you tremendously for your efforts.

I would also like to express my sincere gratitude to the staff of the West Virginia Department of Corrections, the staff of Lakin Correctional Facility, and the West Virginia Department of Education. In particular, I thank Commissioner Rubenstein, Brad Douglas, Jennifer Ballard, Lori Nohe, Craig Roberts, Kari Rice, Lori Loomis, and Lisa Chambers. Your dedication to serving the communities of West Virginia and improving the lives of families is apparent in your work. Your welcoming support of research to inform your practices is a model for others. Additionally, I thank the mothers involved in the parenting project for your openness in sharing your experience with me. Your willingness to grow as parents has informed future programming for other mothers and families. Thank you for allowing me to learn with you.

I would like to share my gratitude to my close family and friends for their support throughout this long endeavor. I am fortunate to have many people who have provided laughter and support along the way. I thank my parents and brothers for being steadfast and showing me very early on that a sense of humor and strong work ethic can take you far. I am so grateful for Tyler, whose confidence, encouragement, and passion for taking on challenges motivate me daily. It is with great appreciation that I dedicate this document to all of you. 


\section{TABLE OF CONTENTS}

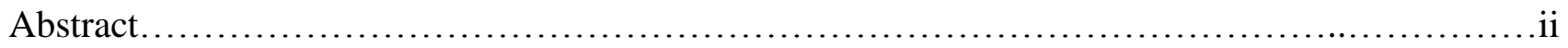

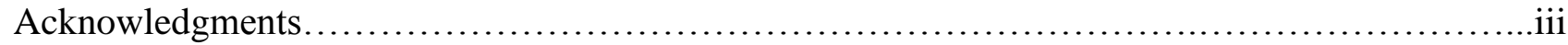

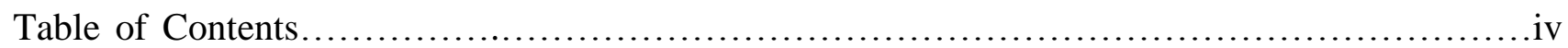

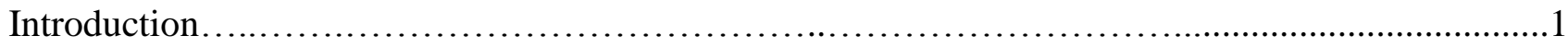

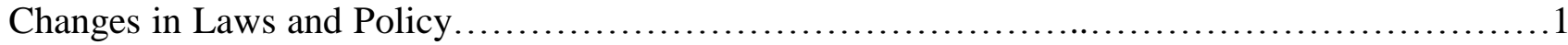

Characteristics of the Female Prison Population........................................................2

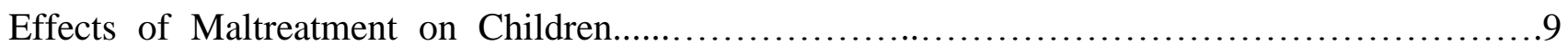

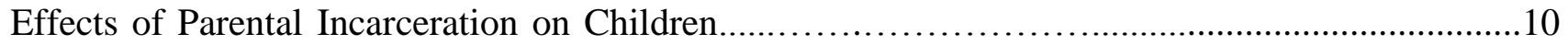

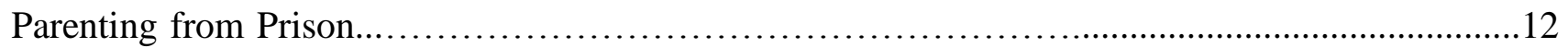

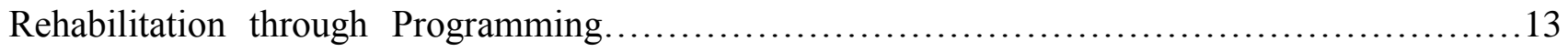

Prevalence of Parenting Problems in Prison Facilities .....................................14

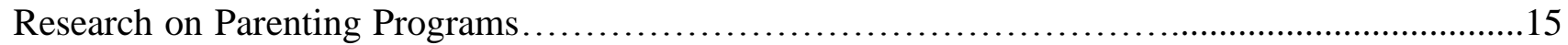

Evidence-Based Parent-training Programs for Community Settings...........................................22

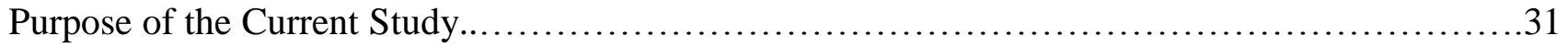

Study Hypotheses......................................................................

Method.......................................................................... 40

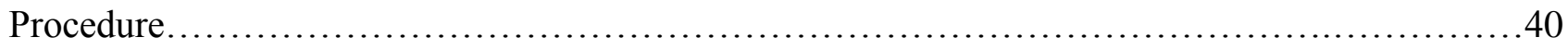

Measures.......................................................................... 47

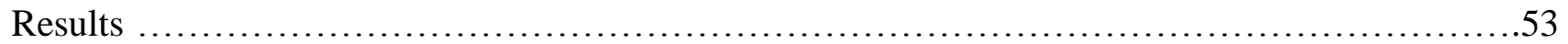

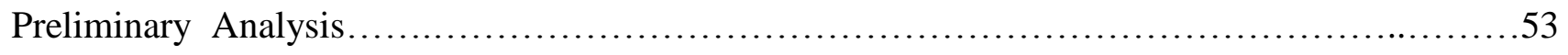

Descriptive Statistics..............................................................53

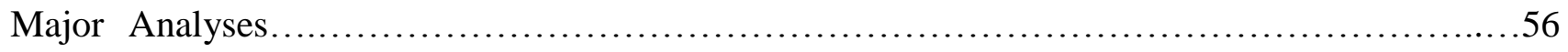

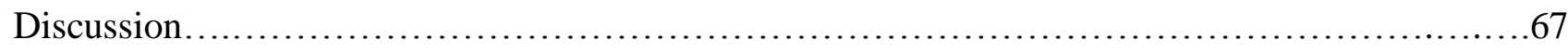

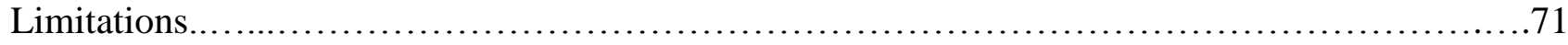

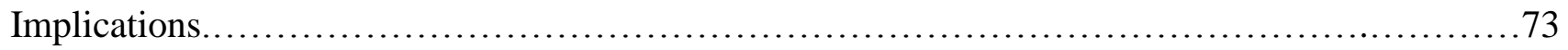

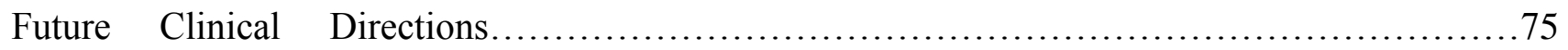

Future Research Directions..........................................................76

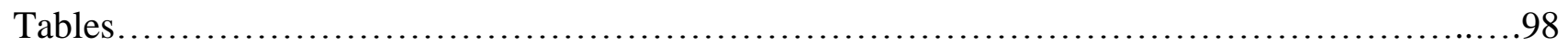

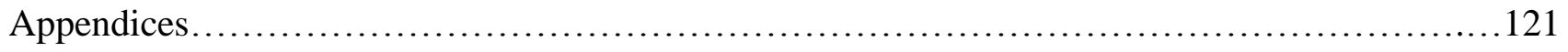


Evaluation of Parent-Child Interaction Therapy and a Standard Parenting Program within a Women's State Prison Facility

The United States has the highest incarceration rate in the world (i.e., 1 in 100 adults; Pew Center on the states, 2008). In 2008, over 7.3 million people were in jail, prison, or on probation or parole (i.e., 1 in every 31 U.S. adults; Glaze \& Maruschak, 2008). More than 1.6 million of these individuals were held under the jurisdiction of state and federal prison facilities (Glaze \& Maruschak, 2008; West, 2010). Recent rates suggest that 1 in 20 individuals in the U.S. population will serve time in a state or federal prison system during their lifetime, and 1 in 198 will serve a sentence of more than one year (West, 2010). If incarceration rates remain unchanged, $6.6 \%$ of U.S. residents born in 2001 will go to prison during their lifetime (Bonzcar, 2003). Men are over 14 times more likely than women to be in prison at least once during their lifetime; however the incarcerated female population grew substantially over the past 30 years (Sabol \& Couture, 2008; West, 2010). In the past decade alone, the number of incarcerated females has increased more than $20 \%$ (West, 2010). Approximately 101, 250 women are incarcerated in state prisons (West, 2010). These increases are thought to be a result of increased recidivism rates and changes in policies and laws disproportionately affecting the female population.

\section{Change in Laws and Policy}

Although the rate of female incarceration has shown dramatic growth in recent years, this does not necessarily suggest an increase in women's criminality. For example, legal and political movements such as mandatory drug sentencing and the tough on crime movements resulted in greater enforcement and increased penalties (Belknap, 2001). The rising rate of incarcerated women is believed to have been influenced by two specific areas of policy reform: poverty-related and drugrelated offenses. 


\section{Poverty-related offenses.}

The increased proportion of matriarchal households living at or below the poverty line places women and children in the majority of individuals living in poverty. This increase has been suggested to subsequently impact the rate of female criminality as women report law-breaking as a way of supporting their families. More specifically, $80 \%$ of women in prison report incomes of less than $\$ 2,000$ the year prior to arrest, and $92 \%$ report incomes of less than $\$ 10,000$ (Gray, 2001). A majority of incarcerated women report being unemployed, and 30\% report receiving financial support through the welfare system at the time of their arrest (Greenfeld \& Snell, 1999). Increases in the number of females living in poverty may specifically contribute to increased female involvement in economically based crimes such as forgery, counterfeiting, fraud, and embezzlement (e.g., Belknap, 2001). Furthermore, poverty-related environmental stressors associated with limited resources may lead many women who are impoverished prior to incarceration to remain in poverty following release (Holtfreter, Reisig, \& Morash, 2004).

\section{Drug-related offenses.}

The number of females serving time for drug-related offenses increased greatly between 1986 and 1991 and accounted for half of the increase of the female prison population during this time (Bureau of Justice Statistics, 1994). An estimated 60\% of women in state prisons in 1998 reported illegal drug use in the month prior to their arrests and approximately $33 \%$ reported drug use at the time of their offense. In a sample of incarcerated mothers, $33 \%$ also reported being incarcerated for crimes committed to support their drug habits (e.g., uttering, prostitution; Greenfield \& Snell, 1999).

\section{Characteristics of the Female Prison Population}

Compared to non-incarcerated females, women offenders are reported to be poorer, less educated, younger mothers, with lower-level employment and parenting skills (e.g., Clement, 1993). 
Many of these women have family histories of incarceration, domestic violence, mental illness, abuse, neglect, and drug use. They report prior histories of rape, incest, medical disabilities, physical and sexual abuse, and homelessness (e.g., Beck, 2000; Glaze \& Maruschak, 2008; Greenfeld \& Snell, 1999; Mumola \& Karberg, 2006; West, 2010). Victimization of incarcerated women is generally reported to occur across the lifespan, in numerous circumstances, and by multiple acquaintances (e.g., Bloom \& Owen, 1995; Greenfeld \& Snell, 1999). For example, 60\% of incarcerated women report that their parents had histories of substance abuse or had perpetrated physical or sexual abuse against them as children. Additionally, 30-70\% of incarcerated women indicate being abused by intimate partners (American Correctional Association, 1990). An estimated $73 \%$ of women in state facilities have mental health difficulties, and a majority of female inmates report polysubstance abuse and dependence (James \& Glaze, 2006).

\section{Prevalence of maternal incarceration.}

The high rate of female incarceration has powerful implications for American children and families. A majority of female inmates are in child-rearing age and are mothers of young children (Glaze \& Maruschak, 2008). At initial prison intake, $4 \%$ of women are reported to be pregnant (Maruschak, 2008). Estimates suggest that 60-70\% of women incarcerated in state prisons across the past 20 years have been mothers of minor children (Glaze \& Maruschak, 2008; Mumola, 2000). At last estimate in 2007, there were 65, 600 incarcerated mothers with children below age 18 . As incarcerated mothers typically have multiple children, maternal incarceration is estimated to affect approximately 150,000 minor children (Glaze \& Maruschak, 2008). Twenty-two percent of these children are younger than 5 years, and the majority of minor children are younger than 10 years old (Glaze \& Maruschak, 2008).

Seventy two percent of incarcerated mothers report living with their children prior to incarceration. Upon incarceration there is a dramatic decline in the level of contact that mothers have 
with their children, which leads to an increased likelihood of significant family disruption and negative outcomes for children (Gentry, 2003; Glaze \& Maruschak, 2008; Murray, Farrington, \& Sekol, 2012). Incarcerated mothers report high importance of their maternal roles; however they also indicate limited parenting knowledge and skills and high levels of parental stress related to their parenting competence (e.g., Houck \& Loper, 2002; Showers, 1993). Although many incarcerated mothers report lacking the skills and knowledge to appropriately care for a child, a majority are primary caregivers of their children and attempt and are granted reunification with their children upon release from prison (Mumola, 2000).

\section{Limited social supports.}

Further reduction in the limited social supports and resources of incarcerated mothers commonly occurs during imprisonment. More than $40 \%$ of female state inmates with minor children report living in single-parent households in the month prior to their arrest, which is more than three times those living in two-parent households (Glaze \& Maruschak, 2008). Mothers' existing supports may be lost due to factors such as divorce or abandonment from significant others. Problems during incarceration commonly tax interpersonal relationships and exacerbate existing difficulties.

\section{Maternal mental health.}

Incarcerated mothers report mental health concerns that likely make parenting difficult. For example, incarcerated mothers report high levels of internalizing disorders such as depression and anxiety disorders (Wright, Salisbury, \& Van Voorhis, 2007). Mothers report specific feelings of despair and depression (e.g., Houck \& Loper, 2002), grieving due to the loss of their children (e.g., Hairston \& Lockett, 1985), anxiety over fear of losing custody (e.g., Dodge \& Pogrebin, 2001), guilt and lowered self-esteem related to their role as a parent and their parenting abilities (e.g., Hutchinson, Moore, Propper, Mariaskin, 2008), and fears regarding their inability to control the safety and wellbeing of their children during their incarceration (e.g., Block \& Potthast, 1998). 
Across the literature mothers report fears that their children will be exposed to high risk behaviors such as physical, emotional, or sexual abuse; sexual activity; substance use; juvenile delinquency; or future imprisonment as a result of the maternal incarceration (e.g., Bloom \& Steinhart, 1993;

Browne, 1989; Hairston, 1991; Thompson \& Harm, 1995). Issues related to their parental rights and involvements in the child welfare system are commonly considered daily stressors among incarcerated mothers. Although a majority of incarcerated mothers report plans to reunify with their children upon release, stressors such as a lack of father support, foster care placement, or parole requirements make reunification and restoration of parental rights difficult. Incarcerated mothers, whose children are placed in formal foster care, rather than with family or friends, are at increased risk of losing permanent rights to their children (Hayward \& DePanfilis, 2007).

Inmate mothers are likely to have serious drug histories and to have committed their crimes while under the influence of drugs (Beck, 2000; Mumola, 2000). Mothers with substance abuse problems have been shown to demonstrate particular difficulties balancing the role of parenting and substance abuse or dependence. Side effects of the substance and energy depletion from substance seeking often make parenting difficult and may greatly affect parents' disciplinary choices and childrearing styles (Surratt, 2003). Parents with substance-abuse problems have been shown to demonstrate less effective discipline than parents without substance-abuse difficulties (Tarter, Blackson, Martin, Loeber, \& Moss, 1993) and have been reported to be limited in their ability to attend to their children's behaviors and to appropriately respond (Surratt, 2003). Substance abuse paired with environmental stressors has been related to harsh parenting practices. Parents using substances and also having limited support and resources may react with harsh discipline or provide little attention to their children. These factors have been found to lead to increased levels of child abuse and neglect in parents that abuse substances (e.g., Grella \& Greenwell, 2006). 


\section{Parenting stress.}

Incarcerated mothers experience high levels of family and socioeconomic stressors prior to incarceration, which place them at a high level of parenting-related stress during and prior to incarceration (Green, Miranda, Daroowalia, \& Siddique., 2005). High levels of parenting stress have been associated with parental depression (Rodgers-Farmer, 1999), less effective parenting behaviors (Rodgers, 1998), and poor child outcomes (Anthony et al., 2005; Crnic, Gaze, \& Hoffman, 2005), and have been considered to be a marker for intervention in high-risk families (Ortega, Beauchemin, \& Kaniskan, 2008). Although parent-reported parental attachment (i.e., affection or regard) remains similar to other parents, parenting stress, particularly stress related to sense of parenting competence, has been shown to be elevated in incarcerated parents relative to general samples described in the Parenting Stress Index manual (PSI; Abidin, 1995; Houck \& Loper, 2002; Loper, 2009).

Inmate mothers report similar anxiety levels as inmate nonmothers at prison entry; however, mothers maintain elevated levels of distress while nonmothers' levels reduce by 6 months following prison entry (Fogel \& Martin, 1992). Incarcerated mothers with higher levels of parenting stress, specifically stress related to sense of competency, report poor adjustment during incarceration such as higher levels of depression and anxiety, increased violence, and more frequent institutional infractions (Houck \& Loper, 2002; Loper, 2009). Elevated levels of maternal distress are often attributed to disruptions in the parent-child relationship. Mothers report separation from their children as their primary concern during incarceration (e.g., Ferraro \& Moe, 2003; Forsyth, 2003). They also report anxiety related to reunification or disintegration of the parent-child relationship (Bloom \& Steinhart, 1993; Datesman \& Cales, 1983) and fear that their children may resent them or may have bonded strongly with their alternate caregiver (Baunanch, 1985). 
Although incarcerated mothers generally report positive attitudes related to their relationship with their children that is equivalent to mothers who are not incarcerated, they may face additional parenting-related stressors due to infrequent visitation and contact with their children, loss of control of their children's wellbeing, and loss of their maternal identity. Numerous barriers to visitation (e.g., caregiver resistance, geographical barriers) lessen parent-child contact, make mothering from prison difficult, and affect maternal functioning in the facility. Although parent-child contact has been associated with reduced parenting stress and prisoner adjustment (Houck \& Loper, 2002), only $42 \%$ of mothers in state prisons report having visitation from their child during incarceration (Glaze \& Maruschak, 2008). The specific relation between the quality and type of contact (e.g., talking about child, letter writing, phone calls, and visitation) has been reported to have varying impact on maternal functioning (Houck \& Loper, 2002).

\section{Parent-child relationship.}

Maternal incarceration may be particularly disruptive as mothers often serve a primary role in early childcare. Limited contact with their children while in prison disrupts parent-child relationships and lowers mothers' authority and confidence to make decisions regarding parenting. The frequent pairing of limited parenting skills and drug use in a majority of incarcerated mothers leads to inconsistent parenting and adds risk for further disruption of the parent-child relationship (Tuerk \& Loper, 2006). Facilitation of positive parent-child interactions may strengthen parent-child relationships, and subsequently enhance child development and long-term resilience (i.e., positive outcomes in adverse situations). Specific parenting behaviors (e.g., attending, praise) have been identified across the literature as important components in enhancing the quality of parent-child relationships (e.g., increased positive talk, increased positive touch; Hart \& Risley, 1995).

The relationships between incarcerated women and their children are not homogeneous; mother-child relationships are reported to range from neglectful or abusive to warm and nurturing 
(e.g., Block \& Potthast, 1998). However, parental incarceration is considered a risk factor for child abuse and neglect (Murray et al., 2012), and children of incarcerated parents are more likely to experience child maltreatment than children of non-incarcerated parents (Murray et al., 2012).

Higher levels of child maltreatment in families experiencing parental incarceration may be largely related to self-reported parenting skill deficits, problematic family histories, limited exposure to appropriate parenting models, and added stressors related to incarceration (e.g., Beck, 2000; Glaze \& Maruschak, 2008; Greenfeld \& Snell, 1999; Mumola \& Karberg, 2006; West, 2010). The majority of parents report increased stressors and difficulty in discipline following release from prison (Fritsch \& Burkhead, 1981; Murray et al., 2012).

\section{Harsh parenting practices.}

An estimated 709,500 children in the United States are victims of child maltreatment each year (U.S. Department of Health and Human Services Report, 2008). Younger children (0-7 years) have the highest victimization rates and are more likely to experience a recurrence of maltreatment. Specifically, children 7 years and younger suffer the most severe injuries and account for $89.9 \%$ of maltreatment-related fatalities (U.S. Department of Health \& Human Services, 2008).

Biological parents are involved in a majority of child maltreatment cases, and biological mothers are most commonly reported. Physical abuse reports account for $48 \%$ of child maltreatment cases. Of these, $81.2 \%$ indicate involvement of biological parents. Biological mothers are involved in 56.2\% of cases (U.S. Department of Health \& Human Services, 2008). Physical abuse by mothers appears to rarely be premeditated and often occurs during child discipline (Budd, Heilman, Kane, 2000; McNeil \& Hembree-Kigin, 2010).

Parent-child interactions in families with a history of abuse are set apart by the absence of positive interactions compared to obvious displays of open conflict and aggression (Bousha \& Twentyman, 1984). Parents with a history of abuse tend to be less positive and affectionate when 
interacting with children (Bousha \& Twentyman, 1984; Crittenden, 1982; Frodi \& Lamb, 1980; Kavanaugh, Yongblade, Reid, \& Fagot, 1988; Shipman \& Zeman, 1999) and respond less often to children during parent-child interactions compared to parents without a history of child maltreatment (Kavanaugh et al., 1988). Parents with a history of abuse have also been shown to demonstrate more negative interactions (verbal and nonverbal; Bousha \& Twentyman, 1984). Specifically, verbal interactions are characterized by higher levels of parental verbal aggression and power assertion techniques such as whining, yelling, criticizing, threatening, screaming (Lahey, Conger, Atkeson, \& Treiber, 1984; Oldershaw, Walters, \& Hall, 1986), and physical aggression (bite, kick, grab; Bousha $\&$ Twentyman, 1984). These parents use less rational guidance (e.g., reasoning with the child in response to misbehavior) and more inconsistent discipline strategies (Bousha \& Twentyman, 1984). Parents with a history of maltreatment also report more negative expectations of their child's behavior (Schellenbach, Monroe, \& Merluzzi, 1991) and have a greater acceptance of corporal punishment as an effective means of child discipline (e.g., Kelly, Grace, \& Elliot, 1990). The literature suggests that families with a history of or at risk for child maltreatment may have difficulty with problem solving and other cognitive skills (Nayak \& Milner, 1998) and would likely benefit from a concrete, skill-building treatment approach such as behavioral parent training (Azar \& Wolfe, 1998; Chaffin et al., 2004; Hackman, Chaffin, Funderburk, \& Silovsky, 2009).

\section{Effects of Maltreatment on Children}

Children with a history of child maltreatment generally have difficulty securing positive caregiver and peer relationships (Crittenden \& Ainsworth, 1989; Hoffman-Plotkin \& Twentyman, 1984; Azar \& Wolfe, 1998). They exhibit higher rates of disruptive behavior problems, antisocial behavior, adult psychopathology, educational problems, unemployment, low-paying jobs, physical health concerns, and perpetrated child maltreatment, than children with no history of child maltreatment (e.g., Eckenrode, Laird, \& Doris, 1993, Kendall-Tackett, 2004, Wilson, Rack, Shi, 
Norris, 2008). The behavioral concerns for children with a history of child maltreatment have been documented across settings and with peers, siblings, and adults (e.g., Keiley, Howe, Dodge, Bates, \& Pettit, 2001; Wolfe \& Mosk, 1983).

\section{Effects of Parental Incarceration on Children}

To date, there is a paucity of research in the area of specific child outcomes following parental incarceration. There are no data that begin at the time of parental incarceration and follow children throughout development or the time of parental reunification and no national organization is responsible for monitoring or tracking outcomes of children of incarcerated parents. However, the existing examinations of the literature provide snapshots of the impact of parental incarceration on children. In a prospective longitudinal study gathered as part of a population-based randomized controlled trial, past parental incarceration was associated to lower family income, parental education, parental socioeconomic status, parental health, and with higher levels of parental depression, inappropriate and inconsistent discipline, and youth problem behaviors and serious delinquency (Kjellstrand \& Eddy, 2011). Research has suggested a growing recognition that experience with the criminal justice system is intergenerational, placing children of incarcerated parents at greater risk than their peers for future involvement with the correctional system (e.g., American Correctional Association, 1990). Children with incarcerated parents are three to six times more likely than their peers to become involved in crime (Eddy \& Reid, 2003) and five to six times more likely than their peers to become incarcerated themselves (Barnhill \& Dressel, 1991). Prior research estimates that as many as one-third of juvenile offenders have a parent who is or has been incarcerated (Muse, 1994).

Following the onset of parental incarceration, child behavior changes are reported such as increases in anger, anxiety, aggression, Attention-Deficit/Hyperactivity Disorder, traumatic stress symptoms, poor social skills, school difficulties, clinginess, shame and guilt, depressed mood, 
withdrawn behaviors, sleep difficulties, teen pregnancy, and substance abuse (Cunningham, 2001; Hairston, 1991; King, 2001; Kinner, Alati, Najman, \& Williams, 2007; Miller, 2006; Murray et al., 2012; Snyder, Carlo, \& Mullins, 2001; Thompson \& Harm, 1995; Tudball, 2000; Tuerk \& Loper, 2006). Behavioral difficulties are reported to be even more elevated in children who have witnessed a parental arrest (Cunningham, 2001; Miller, 2006; Tudball, 2000; Tuerk \& Loper, 2006). Roughly one fifth of children of incarcerated parents are reported to be present during parental arrest. Of these, half are between the ages of 3 and 7 years (Brown \& Bloom, 2009). The specific link between parental incarceration and poor child outcomes is unclear (e.g., Eddy \& Reid, 2003), but findings suggest that parental incarceration may pose an additional risk for children to display behavioral difficulties (Murray et al., 2012).

Research indicates that children with incarcerated mothers may face comparatively greater stress and risks in their environments than children of incarcerated fathers (Johnson \& Waldfogel, 2002). During maternal incarceration children have been found to have increased separation-related stress. These findings are believed to be because mothers are often the sole parental figure, and children are typically moved more often and among more caregivers throughout maternal incarceration (Bloom \& Owen, 1995; Nieto, 2002). During maternal incarceration, children are five times more likely to enter foster placement than during paternal incarceration (Glaze \& Maruschak, 2008) and more commonly experience separation from siblings, peers, and other significant relationships (Thompson \& Harm, 1995).

The subsequent disruption in a child's routine following maternal incarceration, as well as increased financial pressure, difficulties encountered maintaining parent-child relationships, and changes in primary caregivers have also been identified as contributors to behavior change (Kaplan \& Owen, 2004; King, 2001; Miller, 2006; Tudball, 2000; Woodward, 2003). Elevated levels of behavioral difficulties are more commonly reported in children whose mother was the primary 
caregiver prior to incarceration (Woodward, 2003). One study found that $62 \%$ of mothers in prison report evidence of behavior problems among their children after the mother left home for prison (Fritsch \& Burkhead, 1981; Showers, 1993). Another study examining both parent and caregiver report found that $70 \%$ of mothers and $52 \%$ of caregivers reported that the daughters of incarcerated mothers presented with emotional (e.g., depression, sadness, anger), behavioral (withdrawal, crying, bed-wetting, fighting, disobedience), and school performance (e.g., lowered grades, disobedience, suspension) problems following maternal incarceration (Block \& Potthast, 1998).

Parenting style is also associated with delinquency and adult criminal life styles (Patterson, Crosby, \& Vuchinich, 1992), and positive and consistent parenting is often discussed as a key element in breaking the intergenerational transmission of problem behaviors (Patterson, 1982; Patterson, Reid, \& Dishion, 1992; Reid, Patterson, \& Snyder, 2002). Paternal arrest has been shown to be a better predictor than paternal imprisonment of alcohol, tobacco, and cannabis use in young adults (Kinner et al., 2007). These findings suggest that parental modeling of antisocial behavior may be related to findings that second and third generations of the same family are displaying similar high risk behaviors. For example, parental modeling has been shown more highly associated with child conduct problems and substance use than parental absence (Baunach, 1985). As environmental stressors and risks related to parental illegal behavior (e.g., poverty) are difficult to alter, early intervention strategies targeting parent behaviors commonly have the goal of altering parenting skills and later negative parent and child outcomes (e.g., teen pregnancy; juvenile delinquency; Thompson \& Harm; 2000; Widom, 2000).

\section{Parenting from Prison}

Whether or not to allow incarcerated mothers to parent while in correctional facilities is a controversial debate concerning imprisonment in the U.S. (Belknap, 2007). In contrast, parenting within prison is the norm internationally (Kauffman, 2006). In a multi-national survey published by 
the Alliance of Non- Governmental Organizations of Crime Prevention and Criminal Justice, only 4 of 70 nations (i.e., Suriname, Liberia, the Bahamas, and the U.S.) routinely separated imprisoned mothers from their infants (Kauffman, 2006). While older children are more commonly separated from their mothers during maternal incarceration, there remains an international majority supporting mothers' maternal role with their minor children even during maternal imprisonment. Regardless of the seemingly discrepant correctional procedures related to family functioning during imprisonment, a survey of public attitudes toward prisoner amenities in the U.S. indicated that the majority (i.e., 93\%) of the citizens that responded endorsed keeping prisoner-family visits and family telephone calls (i.e., 83\%; Applegate, 2001).

In the U.S., debate derives from conflicting views regarding the nature and societal purpose of imprisonment. Although goals to reduce recidivism and increase law abiding behavior are consistent among individuals with different views, the ways in which these goals are addressed may be much different. For example, while some may consider the loss of family contact a legitimate consequence for crime, others may suggest that when dealing with mothers, this forfeiture may unjustly affect the short- and long-term outcomes of children of incarcerated mothers (Clement, 1993). Some suggest that women are generally more suitable for community-based alternatives than incarceration because the majority of women have committed nonviolent offenses, are primary caretakers of their children, have medical needs for drug treatment, and have mental health needs for counseling. Further understanding of the impact of maternal incarceration on criminality, recidivism, and mother and child mental health and behavioral outcomes may be beneficial in guiding laws, policies, and facility procedures.

\section{Rehabilitation through Programming}

Currently the U.S. spends billions of dollars annually at the state and federal levels to accommodate prison populations (Pew Center on the States, 2008). Meta-analyses examining 
correctional interventions have demonstrated the utility of correctional programming in altering post-prison outcomes. Inmates who take any type of correctional classes are less likely (e.g., 23\%) to return to prison than inmates who do not participate in programming during incarceration (Gordon \& Weldon, 2003; Schmidt, 2002). Family interventions (e.g., parenting education and parenting programs) are demonstrated to be one of the most promising types of programs. Recidivism rates are shown to be much lower for inmates completing programs aimed at improving parenting skills than for nonparticipating inmates (Palmer, 1996; Schmidt, 2002; Showers, 1993). Positive behavioral changes are also associated with engagement in some prison parenting education programs.

Examination of mediating and moderating factors of program outcomes are still needed; however family supports and family contact during incarceration appear to be related to not only short-term reductions in recidivism but also facilitating the development of community and family life success (e.g., finding employment, Bales \& Mears, 2008; Lattimore, Steffey, \& Visher, 2010).

Increased efforts to acknowledge the role of rehabilitative programming have resulted in policies to protect the rights and enhance the current and future care of children of incarcerated parents. For example, resources such as the Children of Incarcerated Parents Bill of Rights (Phillips, 2008) offer suggestions regarding broad program procedures and characteristics. Findings supporting the use of prison as rehabilitation suggest that prison parenting programs have utility in altering parent outcomes by increasing parenting skills, lowering parental stress levels, and reducing risk of harsh parenting practices.

\section{Prevalence of Parenting Programs in Prison Facilities}

An increase in the prison population has required the correctional system to house more inmates and build new facilities. However, prison parenting programs have not yet expanded to meet this subsequent demand for programming. For example, in 1985, 97\% of the 57 state prison facilities had classes on parenting (Boudouris, 1985). At latest report, only $45 \%$ of the 1719 state prison 
facilities offered parent-training programs (Stephen, 2008). The majority of U.S. jurisdictions appear to offer parenting in at least some of their correctional institutions (Clement, 1993); however the number of facilities in a particular state offering parent-training may be few and the number of participating parents is likely to be very small. Although approximately $60 \%$ of parents in prison have engaged in self-help or improvement classes during incarceration, only an estimated $12 \%$ indicate involvement in parenting classes. Mothers are more likely than fathers to participate in parenting classes (i.e., 30\%; Glaze \& Maruschak, 2008). This finding may largely be because facilities housing female inmates (e.g., 90.2\%) or coed inmates (e.g., 55\%) are more likely to offer parenting programs (Hughes \& Harrison-Thompson, 2002).

The range of parenting-related services provided in correctional facilities is broad (e.g., prison nurseries, child visitation, parenting classes, and therapeutic services), however prison-based general parenting-education classes have been most commonly used to provide parent-training to incarcerated individuals (Hughes \& Harrison-Thompson, 2002). In 2001, a National Institute of Justice survey identifying innovative programs for women in correctional settings found only 21 programs specifically designed for parent education and another 21 categorized as innovative child visitation programs across all U.S. states. Eight states had a nursery program (i.e., children 18 months and younger) in at least one of their facilities (Carlson, 2001; Porterfield, 2007). A more recent review of prison parenting programs described in the literature and through surveying organizations on a national level yielded 28 parenting educational programs (Eddy et al., 2008).

\section{Research on Parenting Programs}

Facility parenting-educational programs are typically group based, meet once a week for several hours, and last for several months (Clement, 1993; Eddy et al., 2008). Most programs are not established based on the recent empirical literature on parenting but are developed in-house and in relative isolation by a parenting instructor (Eddy et al., 2008). Typical facility-based parenting 
programs provide information about generic communication skills (100\%), parenting techniques (96\%), and child development (68\%). They may also provide special parent-child visitation opportunities (57\%) and emphasize parenting during incarceration (54\%; Eddy et al., 2008). Anger and stress management (25\%) and parent-child interaction laboratories (7\%) are less commonly noted. Very few programs in prisons currently offer a parenting model that combines classroom instruction with an interactional component where mothers practice parenting skills (Block \& Potthast, 1998; Sandifer, 2008; Wilczak \& Markstrom, 1999).

Although parenting educational programs have generally been offered, there remains a lack of consistency among programs in terms of length, depth, and content. There are currently no commonly accepted "best practices" and national standards to guide facilities regarding curriculum, method, and elements of evaluation. Most prison parenting programs have overarching goals of improving parent and child outcomes; however these goals are often broadly stated. Regardless of similar program aims, additional aspects of these programs such as design, intervention method, and assessment differ and make comparison difficult. For example, the existing programs appear to be taught largely by volunteers and with instructors varying in expertise and training backgrounds (Clement, 1993; Hughes \& Harrison-Thompson, 2002). Studies examining programs often display limitations such as inadequate sample sizes, nonrandom assignment, lack of control groups, and subjective assessment measures.

These difficulties have led to little systematic knowledge about programs' impact on incarcerated parents and their families. For example, Koons, Burrow, Morash, and Bynum (1997) identified 67 papers describing parenting programs; however treatment outcomes were examined for only 12 programs. A review of the recent literature found only 17 evaluations of parenting programs involving incarcerated women. Of these, few had a comparison (i.e., three studies) or waitlist control group (i.e., three studies), and only one study noted the use of randomization to condition. 
The interventions used varied from general parenting discussion groups to multicomponent programs (e.g., mothers' support and discussion group, multiple-week didactic parenting class, therapeutic visitation program). The reported duration of programs ranged from 1 to 24 weeks and varied from one session per week to full-day trainings. Complete programs ranged from 5 to 72 hours. All studies included the pre- and post-treatment measurement of parental self-reports on constructs believed to indirectly affect parenting such as parenting self-esteem levels, attitudes toward parenting, or institutional adjustment. Most found at least one significant pre-post positive effect; however when a comparison or waitlist control group was included studies often reported that treatment group changes were similar to the control group. No studies included a follow-up assessment to examine whether intervention gains were maintained over time. No studies included structured observation and measurement of child or parent behaviors (e.g., parent-child relationship or parenting skill). Although increased regulation of parenting education may enhance outcomes, more quality evaluations of parenting programs are first needed. See Table 1 for a summary of studies examining facility-based parenting class outcomes involving mothers.

\section{Programming and parental skills.}

Prison programs have aimed at improving parenting skills to promote healthy parent-child relationships through increased contact and facilitation of family interactions and to ease re-entry of the incarcerated parent into a parental role following release (Hairston, 1998; Lange, 1997). This aim may be of particular importance for incarcerated mothers who likely return to a caregiver role upon release (Loper, 2009). Positive parenting skills exist at low levels in natural observations of mothers in other at-risk samples (Hackman et al., 2009; Tempel, Wagner, \& McNeil, in press). Studies examining parent-child contact during incarceration have found that the type and quality of these interactions may greatly predict parent and child behavioral outcomes (Poehlman, Dallaire, Loper, \& Shear, 2010). In families with children between the age of 2.5-7.5 years, Poehlmann (2005) found 
higher levels of parent-child interaction without intervention to be associated with greater difficulties. Studies finding that parents in correctional facilities do not possess adequate parenting skills during parent-child contact have long suggested the need for alternative treatment delivery. Furthermore, play has been suggested to be important and acceptable approach in strengthening relationships between inmate mothers and their children (e.g., Block \& Potthast, 1998; Bloom \& Steinhart, 1993). Current programs reporting the greatest success target normal interactions between mothers and their children (e.g., Block \& Potthast, 1998). For example, interactions involving structured activities such as camp settings, Girl Scout meetings, arts and crafts, reading, and other everyday activities have demonstrated some success.

\section{Programming and parental knowledge.}

Many correctional facilities provide parenting education as a means to improve parenting knowledge and skills, with the assumption that these changes may enhance family functioning (Kennon, Makintosh, \& Myers, 2009; Pollock, 2002). Previous evaluations of parenting classes for adolescent and adult offenders have revealed changes in parenting knowledge and attitudes across time (e.g., Halsey, Johnson, Kaur, \& Harland, 2004; Harrison, 1997; Showers, 1993). Specifically, short-term outcome measures of parenting knowledge and attitudes have consistently demonstrated positive effects immediately after intervention (Moore \& Clement, 1998; Showers, 1993; Surratt, 2003; Thompson \& Harm, 2000). The terms "knowledge" and "skill" appear to be used interchangeably throughout the literature (e.g., Sandifer, 2008). For the current review, "knowledge" is used to describe parent-reported level of information regarding child development and behavior management and "skill" is used to describe observed parenting behavior.

Group parent training has been found to enhance parental knowledge related to child development and parenting-related legal knowledge. For example, Fulton, Murphy, \& Anderson (1991) found pre-post increases in child development knowledge following a pre-parent intervention 
for adolescents, as measured by the infancy subscale of the Knowledge Inventory of Child Development and Behavior: Infancy to School-Age. In a later study, Showers (1993) found that participants receiving child behavior management cards (i.e., index cards with child behavior strategies to be used to study) demonstrated significantly more knowledge about child development and nonviolent behavior management than those participants who did not receive these cards. Wilczak and Markstrom (1999) showed not only that knowledge about parenting and child development was enhanced but that inmate fathers also became more confident parents. They also found changes in belief that parenting practices directly affected child behavior and that parents had the ability to manage parent-child relationship difficulties. Sandifer (2008) reported no significant pre-post change in parental knowledge related to child development using the Adult-Adolescent Parenting Inventory- second edition (AAPI-II) Inappropriate Expectations Scale. Kennon et al. (2009) found that parenting knowledge related to legal rights also increased following programming that involved a training component addressing legal concerns related to parenting during incarceration. These findings suggest the efficacy of parenting interventions for altering parents' levels of broad categories of parenting-related knowledge following short-term interventions during incarceration.

\section{Programming and parental stress.}

The impact of parenting programs during incarceration on parenting stress has also been examined (e.g., Loper \& Tuerk, 2011). The PSI (Abidin, 1995) or a modified version of this measure has most commonly been used to assess parenting stress among incarcerated populations. Higher levels of stress regarding parenting competency has been most strongly associated with elevated mental health symptoms and higher levels of institutional rule breaking among incarcerated mothers (Houck \& Loper, 2002; Loper, 2009). Pre- to post- treatment differences have been found for both child and parent stress outcomes (Loper \& Tuerk, 2011). The use of a waitlist control group 
illustrated the impact of the intervention itself as the immediate treatment and waitlist control group demonstrated similar change following exposure to treatment (Loper \& Tuerk, 2011).

\section{Programming and child abuse potential.}

An abundance of studies of parenting programs have included pre- and post-treatment measures to examine changes in parenting attitudes (Browne, 1989; Gat, 2000; Harm, Thompson, \& Chambers, 1998; Harrison, 1997; Moore \& Clement, 1998; Showers, 1993; Thompson \& Harm, 2000; Wilczak \& Markstrom, 1999). The Adult -Adolescent Parenting Inventory (Bavolek, 1984) has been the most frequently used measure among studies within the prison literature. The Child Abuse Potential Inventory (Milner, 1986) has not been discussed in the literature with this population. Several studies have examined facility parenting program outcomes related to child maltreatment and suggest that child abuse potential may be significantly altered through group parenting programs. Parenting education has also been associated with increased parental report of non-violent approaches to child behavior management (Fulton et al., 1991; Showers, 1993). In their examination of Mothers Inside Loving Kids (MILK), Browne (1989) examined females in a community alternative to incarceration at pre-and post-treatment and found no significant pre-post differences on domains of the Adult-Adolescent Parenting Inventory- first edition (AAPI). Moore and Clement (1998) found no significant differences on the AAPI- II subscales for mothers completing the series of two-hour parenting classes over the course of nine weeks compared to those receiving a waitlist control condition. Following a 15-week parenting program, Harm, Thompson, and Chambers (1998) found that parents with a history of substance abuse and abuse as a child were similar to parents without abuse histories in change (i.e., increase in scores) in inappropriate expectations of child. They found no pre-post changes in parents' belief in corporal punishment in both groups. Using the same sample but examining all parents completing treatment as one treatment group, Thompson and Harm (2000) found a decrease (i.e., increases in scores) in inappropriate 
expectations of children, parent-reported corporal punishment, and parent-child role reversal on the AAPI-II. Mothers who received visitation with their child at least once per month demonstrated improvement (i.e., increases in scores) on empathy for their children's needs. Surratt (2003) examined three groups of mothers in a substance abuse offender village within a state prison system (i.e., those who had received no treatment, were currently in treatment, and who had completed treatment) and found that attendance at parenting classes predicted decreased (i.e., increases in scores) belief in corporal punishment using the AAPI-II. Examining another parenting program, Sandifer (2008) found decreased (i.e., increases in scores) belief in corporal punishment and parentchild role reversal as well as an increase (i.e., increase in scores) in parental empathy following a 12week, group treatment with didactic and interactive components. These findings suggest the effectiveness of facility parenting programs in altering parent-reported measures related to child maltreatment.

\section{Recommendations from the current literature.}

Empirical evidence documenting the efficacy of prison parenting education programs is limited; however the literature consists of various suggestions on how to address the needs of families of incarcerated mothers (e.g., Baunanch, 1985; Loper \& Tuerk, 2006; Morash, Bynum, \& Koons, 1998). As early as 1985, Baunanch concluded that parenting programs to address parenting skills and responsible decision making are necessities. Later authors such as Loper and Tuerk (2006) recommended parenting program objectives: 1) promote contact between parent and child, 2) consider the impact education levels might have on ability to comprehend course materials, 3) address institutional obstacles, 4) impart parenting skills in the form of teaching child behavior management techniques and child development knowledge, 5) consider that it may be necessary to concretely teach communication skills, 6) adapt programs to meet the different needs of female and male inmates, and 7) monitor intervention through appropriate standardized instruments. 
Eddy et al. (2009) reviewed findings from discussion groups examining inmate interest in components of parenting programming. Each group reported the highest level of interest in components specific to parenting from prison (e.g., writing an appropriate and encouraging letter to children of various ages, learning to make a phone call go well, or increasing the quality of parentchild interactions during prison visitation). Within each communication mode inmates were most interested in aspects of appropriate limit setting and discipline. The second area of highest interest for all groups was elements affecting the family and parent-child relationships when transitioning from prison back to the community (Eddy et al., 2008).

\section{Evidence-Based Parent-Training Programs for Community Settings}

Several training interventions designed for non-incarcerated parents have well-documented evidence of effectiveness and efficacy (e.g., Eyberg et al., 2005; Sanders et al., 2003; WebsterStratton, 2001). However, these programs may not easily translate to a correctional setting (Loper \& Tuerk, 2006). Standard programs require some adaptation to make them suitable for use within prison settings due to security practices and other custodial limitations. For example, these parenting programs function under the assumption that parents reside with their children and will have opportunity to practice learned skills during daily interactions.

Behavioral parent-training leads to improved child outcomes through reducing harsh parenting practices and increasing the amount of positive parent behavior during parent-child interactions. Within community samples, mother-child dyads receiving behavioral parent training have demonstrated greater improvements relative to standard community programs (e.g., Wolfe et al., 1988). Three programs are identified as "best practices" for families with a history of or at-risk for child abuse (Kauffman Best Practices Project, 2004): Abuse-Focused Cognitive Behavior Therapy (AF-CBT; Kolko, Iselin, \& Gully, 2011), Parent-Child Interaction Therapy (PCIT; Eyberg, 1999), and Trauma-Focused Cognitive Behavior Therapy (TF-CBT; Cohen \& Mannarino, 1993). 
These programs demonstrate empirical support for the reduction of recidivism rates of child maltreatment. In a recent meta-analysis of controlled prevention- and treatment-focused parenttraining studies, parental practice of new skills during parent-training sessions was associated with better parent and child outcomes (Kaminski et al., 2008). Of specific interest for this review is PCIT, which focuses on enhancing the parent-child relationship through increasing quality parent-child interactions.

\section{Parent-Child Interaction Therapy.}

Parent-Child Interaction Therapy (PCIT) is a long-established evidence-based intervention used in the treatment of externalizing behavior problems among children 3-6 years of age as well as the enhancement of parenting practices in families of children between 4-12 years with a history of child maltreatment. The efficacy of PCIT is demonstrated through an extensive research and clinical history (e.g., Herschell, Calzada, Eyberg, McNeil, 2002; McNeil \& Hembree-Kigin, 2010). PCIT is aimed at modifying a broad range of behavioral, emotional, and family problems (Eyberg, Dabbs, \& Nearly, 2001; McNeil \& Hembree-Kigin, 2010), including temper tantrums, aggression, defiance, low self-esteem, and parent-child relationship concerns. PCIT has been influenced by Baumrind's (1967) theory demonstrating children's dual needs for parental nurturance and limits to achieve optimal outcomes. The PCIT program consists of several unique features: (a) traditional playtherapy skills are taught to enhance the quality of the parent-child relationship, (b) parental problemsolving skills are coached to develop direct strategies for continued management of problem behaviors, and (c) parents are coded and coached to assist in reaching a level of mastery of both play-therapy and discipline skills (Eyberg, 1988).

\section{PCIT outcome literature.}

The positive treatment effects of standard PCIT are generalizable across severity levels, treatment orders, settings, family members, and treatment populations. Research findings support 
generalizablility across varying severity levels of disruptive behavior (Funderburk et al., 1998) and levels of parental psychological functioning (Eyberg \& Robinson, 1982). Treatment effects are also found to generalize to the home (Boggs, 1990), school setting (McNeil, Eyberg, Eisenstadt, Newcomb, \& Funderburk, 1991), and parent-child interactions with untreated siblings (Brestan, Eyberg, Boggs, \& Algina, 1997; Eyberg \& Robinson, 1982). Efficacy studies demonstrate important changes in parents' interactions following treatment such as increased reflective listening, physical proximity, and positive verbal reinforcement, and decreased levels of parenting stress, use of corporal punishment, and use of high rates of parental commands, criticism, and sarcasm (Chaffin et al., 2004; Eisenstadt, Eyberg, McNeil, Newcomb, \& Funderburk, 1993; Schuhmann, Foote, Eyberg, Boggs, \& Algina, 1998; Timmer, Urquiza, Zebell, \& McGrath, 2005). The efficacy of PCIT is seen in treatment with diverse co-occurring child concerns such as Attention-Deficit/Hyperactivity Disorder (Nixon, 2001), internalizing disorders (Pincus, Eyberg, \& Choate, 2005), chronic illness (Bagner, Fernandez, \& Eyberg, 2004), developmental disabilities (McDiarmid \& Bagner, 2005), and child maltreatment (Chaffin et al., 2004; Fricker-Elhai, Ruggerio, \& Smith, 2005). Furthermore, PCIT follow-up examinations suggest that treatment gains are maintained at four months (Schuhmann et al., 1998), 1 year (e.g., Funderburk et al., 1998), two years (Eyberg et al., 2001), and 3 to 6 years (Hood \& Eyberg, 2003).

Beyond the efficacy findings that imply that PCIT successfully assists in the enhancement of parenting skills and the management of child problem behaviors, parents also report high levels of satisfaction concerning the content and course of PCIT treatment (Chaffin et al., 2004; McNeil, Hershell, Gurwitch, \& Clemens-Mowrer, 2005; Schuhmann et al., 1998; Timmer et al., 2005). The reported satisfaction is thought to be a result of decreases in parenting-related distress as well as increases in parents' levels of confidence in their ability to manage child problem behaviors (Chaffin et al., 2004; McNeil et al., 2005; Schuhmann et al., 1998; Timmer et al., 2005). 


\section{PCIT with child maltreatment.}

PCIT is considered a "best practice" for the treatment of child abuse by the Kauffman Best Practices Project (2004) and the National Child Traumatic Stress Network, and has also been indicated as a "supported and acceptable" treatment by the National Crime Victims Research and Treatment Center and the Center for Sexual Assault and Traumatic Stress. As a treatment approach, PCIT is used to enhance caregiving behaviors with adults who serve as caregivers for young children and specifically does not target parents who were actively involved in the sexual abuse of a child or have had all parental rights terminated. When working with families with a history or elevated risk of child maltreatment, PCIT therapists emphasize the role of the parent during parent-child interactions (e.g., Timmer et al., 2005; Urquiza \& McNeil, 1996). PCIT is particularly appropriate to address abuse occurring in the context of child discipline (e.g., Borrego, Urquiza, Rasmussen, \& Zebell, 1999; Chaffin et al., 2004). It is common for parents with a history of child abuse and neglect to have too high or too low expectations of child behavior. In PCIT with child maltreatment populations, coaching targets the reduction of negative parental behaviors during parent-child interactions and the appropriateness of parents' expectations of the child based on the child's developmental level.

Chaffin et al. (2004) is a large treatment outcome study examining PCIT in families with a history of child maltreatment. This study examined 110 parent-child dyads in three treatment groups: a) PCIT, b) PCIT and wraparound services, and c) standard community treatment. All conditions demonstrated increasing positive parent behaviors; however, only PCIT and PCIT with enhanced services conditions were associated with reductions in negative parent behaviors. PCIT demonstrated clinically and statistically significant reductions in re-abuse rates compared to families receiving standard community treatment. Moreover, at 2-year follow-up, only $19 \%$ of participants in the PCITonly condition had a re-abuse report, whereas $36 \%$ of participants in the PCIT with enhanced 
services condition, and $49 \%$ of participants in the community treatment group had a re-report of abuse. These findings suggest that PCIT reduced re-report rates more when provided alone than in combination with other service components; the authors speculated that additional services may have placed too much demand on families or diluted the focus on PCIT treatment. No differences were found among groups for re-report rates of neglect, indicating that PCIT may influence recidivism rates of child abuse but not affect neglect outcomes. Given the nature of neglect, it is possible that changes in parental neglect behaviors may be less likely to be changed following PCIT or may be difficult to detect.

\section{Modifications for PCIT with child maltreatment.}

Modifications have been recommended for PCIT treatment with families with a history of maltreatment. McNeil and Hembree-Kigin (2010) describe a series of modifications made to the PCIT protocol. Specific modifications included a focus on the parent; teaching relaxation skills; practicing discipline procedures extensively with the therapist in role-play; implementing discipline with the child only after the parent has demonstrated good self- control during practice procedures; and direct coaching of parents on sensitivity, self-control, developmental milestones, and developing appropriate expectations for their child. Modifications such as adding motivational components (e.g., motivational interviewing, phone engagement) to standard PCIT treatment have also been effective in increasing treatment retention rates in child maltreatment populations (e.g., Chaffin, Funderburk, Bard, \& McCoy, 2008).

\section{PCIT in a group format.}

PCIT in a group format was introduced around 1999 (i.e., Auerbach, Nixon, Forest, Goodley, \& Gemke), and several PCIT group models have been demonstrated to be effective across unique settings (e.g., Berkovits, O’Brien, Carter, \& Eyberg, 2010; McNeil et al., 2005; Niec et al., 2005). Group PCIT has been proposed to be useful in settings with an abundance of referrals and limited 
instructor access (e.g., Niec et al., 2005). Existing group formats vary in the number of group participants, session length, number of sessions, mastery requirements, and modes of coaching (e.g., in room, wait room, viewing room). Of these, relatively few studies have empirically examined group PCIT within an applied setting (e.g., Berkovits et al., 2010).

Group formats have demonstrated clinical and statistical significance in altering child behavior outcomes. In a case-study examination of group PCIT in a university clinic setting, Niec et al. (2005) found a reduction in reports of three of four children's externalizing problem behaviors as well as in parental difficulty managing problem behaviors and parenting-related stress between preand post-treatment. Parents received 16 therapy sessions and 1 individual family booster session. Treatment was conducted with four families, using two therapists, an observation room, and a bugin-the-ear communication device for live coaching and feedback during parent-child interactions. In this study, treatment progression was not determined based on parental attainment of standard PCIT mastery criteria. Instead progression was outlined by the predetermined group session curriculum.

Group formats have also served as effective prevention models, demonstrating utility in changing both parent and child behaviors. One of the first examinations of group PCIT was conducted using a workshop format to enhance parenting among foster parents (McNeil et al., 2005). This two-day workshop model did not allow for at-home practice of skills between parents and their children. Clinically and statistically significant changes were found in both parent report of child behavior intensity and problem scores on the Eyberg Child Behavior Inventory at the one-month post-treatment follow-up. Additionally, a pre-parent education model was developed in a twosession group training format based on PCIT skills for undergraduate students (Lee, Wilsie, \& Brestan-Knight, 2011). Study findings suggested the feasibility of teaching parenting strategies as a preventative model as undergraduate non-parents were able to increase their behavior management knowledge and observed use of praise during parenting role plays of child-led play interactions. 
Berkovits et al. (2010) conducted a comparison of two preventative PCIT-based interventions (i.e., Primary Care PCIT and PCIT Anticipatory Guidance). Children within this study had externalizing behavior scores falling below the clinical level. In Primary Care PCIT, parents received a four-session preventative intervention including the coaching and coding of parent-child interactions in groups and conducted with 17 families in weekly sessions held in the waiting room of a primary care physician's office. In PCIT Anticipatory Guidance, families were enrolled in selfguided treatment in which 13 parents received PCIT materials and resources. Parent-reported parental locus of control, parenting stress, and child externalizing behavior problems decreased similarly between pre-and post-treatment with targeted treatment gains maintained at a 6-month follow-up for parents in both adapted models of PCIT. Additionally, no differences were found between the two groups in parental treatment satisfaction at post-treatment or 6-month follow-up. These findings suggest that less intensive, alternative PCIT treatment models may be suitable as preventative treatment approaches.

Eyberg et al. (2009) developed a group PCIT manual in which treatment progression is based on $50 \%$ of group members meeting mastery skills prior to completion of Child-Directed Interaction (CDI) and Parent-Directed Interaction (PDI) treatment stages. Preliminary observational data of preto post-treatment parent-child interactions showed an increase in parent praise $(d=2.73, N=11)$ and a reduction in parental criticism $(d=1.90, N=11)$. Furthermore, parent-report measures also reflected treatment acceptability in group PCIT as mothers and fathers indicated high therapy satisfaction $(M=44$ on a 50 - point scale, $N=20)$.

Group PCIT includes in-session parent practice during both a relationship enhancement phase known as Child-Directed Interaction (CDI) and a behavior management phase known as ParentDirected Interaction (PDI). 


\section{Child-Directed Interaction (CDI).}

An importance is placed on positive parent-child interactions during the early years of childhood when children are most responsive to parental attention. CDI is based on attachment theory and aims to provide a secure attachment (i.e., affection or regard) through the active restructuring and enhancement of the parent-child relationship. Parents are taught to allow their child to lead the play activity and are taught skills to establish positive interaction patterns. Specifically, parents are trained in the use of selective attention methods as a form of behavior management by responding to appropriate play using positive attention while consistently not attending to unharmful, attention-seeking, and inappropriate behaviors. Enhancement of these skills is obtained through in vivo coaching, coding, and feedback of parenting behavior. Coaching during PCIT in a group format typically occurs using an observation room and bug-in-the-ear communication device to provide in-vivo coaching and feedback while parents interact with their children (Niec et al., 2005); however in-room coaching procedures have also been shown to be effective (e.g., Herschell et al., 2002).

\section{PRIDE skills.}

Parents are directly instructed in how to follow their child's lead during play by using the PRIDE skills: Praising the child (i.e., labeled praise, unlabeled praise), Reflecting the child's statements (i.e., paraphrasing, active listening), Imitating the child's play, Describing the child's actions (i.e., behavioral description, information description), and using Enthusiasm throughout play. When using the PRIDE skills, parents also learn to avoid questions, commands, and criticism. Together, these CDI skills are found to improve the quality of parent-child interactions and increase appropriate child behavior.

Parent-Directed Interaction (PDI).

PDI emphasizes teaching parents predictable, consistent and safe limit-setting and discipline 
strategies. Parents continue to use selective attention skills to differentiate between appropriate and inappropriate behavior, yet are also taught to issue effective commands and to provide consistent consequences for both child compliance and noncompliance.

\section{Effective command giving and discipline.}

During PDI, parents are taught to provide effective commands that are direct, positively stated, one at a time, specific, age-appropriate, polite and respectful, and only given when necessary. Effective command giving and follow-through is found to reduce child noncompliance through teaching children listening skills (Thomas \& Zimmer-Gembeck, 2011). A timeout sequence is taught to parents and included in the command sequence to provide a safe and consistent discipline strategy.

\section{Coding.}

Behavioral observations, conducted within 5-minute situations, are used to evaluate and guide treatment. During the child-directed and parent-directed interaction coding situations; parents demonstrate the taught parenting skills independent of therapist assistance. During CDI, clinicians code parents in their use of the PRIDE skills. Specific emphasis is placed on attaining 10 Labeled Praises, 10 Reflections, and 10 Behavioral Descriptions; while providing three or fewer commands, questions, and criticisms, and ignoring unharmful inappropriate child behavior during the 5-minute parent-child play situation. Parents are taught to provide a high frequency of the taught parenting skills during the 5-minute period as a way of overpracticing skills in session and in turn increasing generalization to other settings. During PDI, parents are coded on the use of the command sequence and safe discipline while continuing to use skills learned during CDI. Parents work to provide approximately one command per minute with at least $75 \%$ appropriate follow through.

\section{Coaching and feedback.}

Parents are coached weekly throughout treatment. Through coaching, therapists convey 
developmentally appropriate expectations for child behavior and highlight the direct and indirect effects that parental behaviors have on child behavior. During these coaching sessions, parents are taught to fill the role of their child's play "therapist" as they receive direct coaching and practice of communication and behavior management skills (Eyberg, 1988). To assist with both the attainment and generalization of learned skills, parents are asked to practice the skills throughout the week during a daily 5-minute special playtime. For a more complete description of PCIT see (Eyberg, Nelson, \& Boggs, 2008; McNeil \& Hembree-Kigin, 2010).

\section{Purpose of the Current Study}

With approximately five percent of the population incarcerated during their lifetime, a significant proportion of U.S. adults receive services through correctional programming. The effectiveness of programming may have large implications for ensuring individual and familial wellbeing. Specific to the goals of this research, the enhancement of parenting-related skill and knowledge as well as the reduction of parenting-related stress and child abuse potential may alter future functioning on several levels. The current literature remains limited in the number of examinations of treatment outcomes following parenting programming in women's correctional facilities. In addition to the limited number of empirical examinations, the lack of consistency in methodology of studied outcome leaves much to be known about best-practice methods for this population.

In community settings, PCIT has an extensive empirical history and has subsequently incorporated research findings in the continual modification and advancement of the treatment intervention. As one of the few evidence-based parent-child training programs for the enhancement of parent-child interactions and the reduction and prevention of harsh parenting practices, PCIT continues to be a leading early intervention. Specifically, the emphasis during PCIT on the direct coaching of parents within a group format for at-risk or physically abusive parents may be more 
effective than traditional parenting discussion groups because PCIT is concrete (and thus suitable for parents at different functioning levels), active, non-blaming, and relatively short in duration. The generalization of PCIT parenting outcomes in brief formats (e.g., group PCIT in primary care, preparent training format), with untreated children (i.e., parenting behaviors with untreated siblings), and across time (i.e., 1 month to 6 year follow-up) suggests that a PCIT-based parent-training program may also have utility as a prevention model during parental incarceration. Empirical investigation of PCIT within a state prison provides some understanding of treatment effectiveness and utility in correctional settings. Specifically, the current study investigates whether PCIT provides additional benefit when compared to the standard parenting program outcomes on parent-reported levels of parenting knowledge, parenting stress, child abuse potential, and treatment acceptability as well as observed levels of facilitative parenting skills.

\section{Hypothesis 1}

Parental incarceration has been associated with higher levels of inappropriate and inconsistent discipline and youth problem behaviors (Kjellstrand \& Eddy, 2011). PCIT places an emphasis on skill building and direct coaching, monitoring, and feedback during parenting interactions. Prior research suggests significant differences (i.e., large effect sizes) in skill level following PCIT in comparison to standard community parenting programs. Although treatment progress was not contingent on skill acquisition, parental skill, as measured by the Dyadic ParentChild Interaction Coding System, third edition (DPICS-III), was hypothesized to improve significantly more in the PCIT treatment condition than in the treatment as usual (TAU) standard parenting class condition across time (i.e., pre-treatment, post-treatment, and 7-week treatment follow-up). Four 2 X 3 (group X time) mixed design analyses of covariance (ANCOVAs) were computed to examine specific hypotheses related to change in parenting skills between mothers in the PCIT condition and the TAU condition at pre-treatment, post-treatment, and follow-up. Due to 
preliminary analyses, maternal education level was entered as the covariate. Planned simple comparisons were used to examine specific changes following significant effects.

\section{Hypothesis 1a.}

Positive parental attending has been associated with positive parent-child outcomes such as the quality of the parent-child relationship, child behavioral functioning, language development, and academic performance (e.g., Hart \& Risley, 1995). Based on an extensive prior knowledge of large increases in positive parenting skills following PCIT compared to standard community-based programs (Foley \& McNeil, 2010; Schuhmann et al., 1998), DPICS-III positive mastery skills (i.e., labeled praise, reflection, and behavioral description) were hypothesized to increase significantly more in the PCIT treatment condition than in the TAU treatment condition across time. Specific to hypothesis 1a, a 2 X 3 (group X time) mixed design ANCOVA was used to examine the change in positive mastery skills between conditions at pre-treatment, post-treatment, and follow-up assessments. Planned simple comparisons were used to examine specific changes following significant effects.

\section{Hypothesis $1 b$.}

Parental reliance on high levels of negative attention has been associated with greater risk for disruptions in the parent-child relationship and parent and child stress (e.g., Patterson, 1982). Based on prior literature suggesting greater reductions in negative parenting mastery skills following PCIT compared to community treatments (e.g., Chaffin et al., 2004), negative mastery skills (i.e., questions, negative talk, and commands) were hypothesized to decrease significantly more in the PCIT treatment condition than in the TAU condition across time. Specific to hypothesis $1 \mathrm{~b}$, a 2 X 3 (group X time) mixed design ANCOVA was used to examine the change in negative parent talk between conditions at pre-treatment, post-treatment, and follow-up assessments. Planned simple comparisons were used to examine specific changes following significant effects. 


\section{Hypothesis 1c.}

Use of ineffective commands leads to less opportunity for successful child compliance and may result in frustration for parents and children during parent-directed parenting interactions (Schuhmann et al., 1998). Drawing from previous examinations of significant increases in parentprovided effective command sequences following PCIT (Schuhmann et al., 1998), parent-provided effective command sequences, as measured by the DPICS-III, were hypothesized to increase significantly more in the PCIT treatment condition than in the TAU treatment condition across time. Specific to hypothesis 1c, a 2 X 3 (group X time) mixed design ANCOVA was used to examine the change in the percentage of effective command sequences between conditions at pre-treatment, posttreatment, and follow-up assessments. Planned simple comparisons were used to examine changes following significant effects.

\section{Hypothesis 1d.}

Parent identification of child compliance behavior and subsequent positive attending to child compliance is believed to increase appropriate compliance to parental instructions, in turn enhancing successful limit setting and consequences for families during discipline. Prior studies also indicate that parent-provided labeled praise contingent on child compliance behaviors increase across the course of PCIT (e.g., Schuhmann et al., 1998; Timmer et al., 2006), therefore the percentage of parent-provided labeled praise contingent on compliance, as measured by DPICS-III, was hypothesized to increase more in the PCIT treatment condition than in the TAU treatment condition across time. Specific to hypothesis 1d, a $2 \mathrm{X} 3$ (group X time) mixed design ANCOVA was used to examine the change in labeled praise contingent on compliance between conditions at pre-treatment, post-treatment, and follow-up assessment. Planned simple comparisons were used to examine changes following significant effects.

\section{Hypothesis 2}


Parenting knowledge regarding child development and behavior management are commonly addressed as educational topics in community-based parenting education programs (Eddy et al., 2008). PCIT does not formally address this topic through lecture-based material. Therefore, parental knowledge, as measured by the Inappropriate Expectations scale on the Adult-Adolescent Parenting Inventory- second edition (AAPI-II; an increase in scores indicates a decrease in inappropriate expectations), was hypothesized to increase significantly more in the TAU treatment condition than the PCIT condition across time. Additionally, parenting knowledge based on the Partnerships in Parenting post-treatment parenting questionnaire was hypothesized to be more similar to teacherreported ideal parenting expectations. Two (group X time) mixed design ANCOVAs were computed to examine the parental knowledge hypotheses at pre-treatment, post-treatment, and treatment follow-up. Maternal education level was entered as the covariate. Planned simple comparisons were proposed to examine changes following significant effects.

\section{Hypothesis 2a.}

The facility parenting class curriculum was developed based on the Partnerships in Parenting curriculum which contains specific didactic lessons on parenting expectations and child development. This formal component of didactic instruction on child developmental expectations is not addressed in PCIT treatment. Therefore, parental knowledge, as measured by the Inappropriate Expectations scale on the AAPI-II, was hypothesized to increase significantly more in the TAU treatment condition than the PCIT condition across time. One 2 X 3 (group X time) mixed ANCOVA was computed to examine the parental knowledge hypothesis at pre-treatment, posttreatment, and treatment follow-up. Planned simple comparisons were used to examine specific changes following significant effects.

\section{Hypothesis $2 b$.}

The standard facility parenting class was developed based on the Partnerships in Parenting 
curriculum. While PCIT treatment includes some material included in the standard parenting program, other topics are not addressed. Program component knowledge, as measured by the lead teacher's reported ideal responding to items on the Partnerships in Parenting Topics Knowledge questionnaire, was hypothesized to be more similar to the lead teacher-reported ideal for the TAU treatment condition than the PCIT condition across time. One 2 X 2 (group X time) mixed ANCOVA was computed to examine program knowledge at post-treatment and treatment follow-up. Planned simple comparisons were used to examine specific changes following significant effects.

\section{Hypothesis 3}

PCIT has demonstrated reductions in levels of parenting stress following intervention (e.g., Borrego et al., 1999; Timmer et al., 2005). Active roleplaying and problem-solving throughout the course of PCIT was hypothesized to lead to reductions in parenting-related stress compared to didactic instruction. Parental stress, as measured by the Parenting-Stress Index, was hypothesized to decrease significantly more in the PCIT condition than the TAU standard parenting class condition across time. Two 2 X 3 (group X time) mixed design ANCOVAs were used to examine specific hypotheses at pre-treatment, post-treatment, and treatment follow-up. Maternal education level was entered as the covariate. Planned simple comparisons were used to examine specific changes following significant effects.

\section{Hypothesis 3a.}

Parenting stress is related to adverse parent functioning. Prior research suggests that incarcerated mothers are at particular risk for higher levels of stress during incarceration compared to nonmothers, and this is likely due to their parenting role (Houck \& Loper, 2002). Total parental stress, as measured by the total score on the Parenting-Stress Index, was hypothesized to decrease more in the PCIT condition than the TAU condition across time. Specific to hypothesis $3 \mathrm{a}$, a 2 X 3 (group X time) mixed design ANCOVA was used to examine the change in total parental stress at 
pre-treatment, post-treatment, and treatment follow-up. Planned simple comparisons were used to examine specific changes following significant effects.

\section{Hypothesis $3 b$.}

Parenting stress related to sense of competence has been highlighted in the literature as specifically related to factors of parental adjustment during incarceration (Loper \& Tuerk, 2011). Competency-related parenting stress has been shown to be related to the quality and type of parenting interactions during incarceration (e.g., Poehlmann et al., 2011; Tuerk \& Loper, 2006). It is conceptualized that increased practice of parenting skills may foster reduced levels of stress specific to parenting competence. Parenting stress related to sense of competence, as measured by the Sense of Competence scale on the Parenting Stress Index, was hypothesized to decrease significantly more in the PCIT condition than the TAU condition across time. Specific to hypothesis $3 \mathrm{~b}$, a 2 X 3 (group $\mathrm{X}$ time) mixed design ANCOVA was computed to examine the change in parenting stress related to sense of competence between conditions at pre-treatment, post-treatment, and treatment follow-up. Planned simple comparisons were used to examine specific changes following significant effects.

\section{Hypothesis 4}

PCIT is an evidence-based treatment for the reduction of harsh parenting practices. Parents demonstrate reductions in high risk parenting attitudes and child welfare re-abuse reports following PCIT (e.g., Chaffin et al., 2004). Studies examining changes in potential for child abuse following standard facility parenting programs have shown changes in parenting attitudes but have not demonstrated decreased rates of future abuse reports. Child abuse potential, as measured by the abuse scale on the Child Abuse Potential Inventory (CAP) and the Lack of Empathetic Regard and Belief in Corporal Punishment scales of the AAPI-II, was hypothesized to decrease significantly more in the PCIT condition than the TAU condition across time. Three 2 X 3 (group X time) mixed design ANCOVAs were computed to examine child abuse potential hypotheses between conditions 
across time. Maternal education level was entered as the covariate. Planned simple comparisons were used to examine specific changes following significant effects.

\section{Hypothesis 4a.}

Parents completing PCIT have shown reductions in CAP abuse scale scores and these reductions have been shown to predict reductions in re-abuse reports following treatment (e.g., Chaffin et al., 2004). No studies have examined CAP pre-post changes after correctional parenting programs. Total abuse potential, as measured by the Abuse scale on the CAP, was hypothesized to decrease significantly more in the PCIT condition than the TAU condition across time. Specific to hypothesis 4a, a 2 X 3 (group X time) mixed design ANCOVA was computed to examine the change in total abuse potential by condition at pre-treatment, post-treatment, and follow-up. Planned simple comparisons were used to examine specific changes following significant effects.

\section{Hypothesis $4 \mathrm{~b}$.}

Parent ability to demonstrate empathy toward the needs of children by being sensitive and responsive to the child needs is considered a foundation to effective and nurturing parenting. Although prior studies have not examined parental empathy following PCIT, parents have been found to be more responsive and to attend better to child behavioral needs (e.g., Borrego et al., 1999 ; Hackman et al., 2009). Studies examining standard facility parenting programs compared to comparison treatments or waitlist controls have found limited support for differences in parentreported empathy. Empathetic regard for child, as measured by the Lack of Empathetic Regard scale on the AAPI-II (i.e., increase in scores indicate increase in empathetic regard), was hypothesized to increase significantly more in the PCIT condition than the TAU condition across time. Specific to hypothesis 4b, a 2 X 3 (group X time) mixed design ANCOVA was computed to examine the change in lack of empathy between conditions at pre-treatment, post-treatment, and follow-up. Maternal education level was entered as the covariate. Planned simple comparisons were used to 
examine specific changes following significant effects.

\section{Hypothesis 4c.}

Previous studies examining prison parenting education suggest mixed findings on program effectiveness in reducing parental belief in corporal punishment. However, PCIT has been shown superior to didactic community interventions in reducing child welfare involvement due to harsh parenting behaviors (e.g., Chaffin et al., 2004; Hackman et al., 2004). Throughout treatment parents learn and implement non-corporal punishment techniques such as removal of attention and timeout from reinforcement. Therefore, parental belief in corporal punishment, as measured by the Parental Belief in Use of Corporal Punishment scale on the AAPI-II, was hypothesized to decrease significantly more in the PCIT condition than in the TAU condition across time. Specific to hypothesis 4c, a 2 X 3 (group X time) mixed ANCOVA was used to examine the change in belief in corporal punishment between conditions at pre-treatment, post-treatment, and follow-up. Planned simple comparisons were used to examine specific changes following significant effects.

\section{Hypothesis 5}

Across studies, PCIT has been shown to be an acceptable treatment, and satisfaction is reported to be high across implementation formats (e.g., Berkovits et al., 2010; Brestan, Jacobs, Rayfield, \& Eyberg, 1999; Schuhmann et al., 1998). Treatment acceptability, as measured by the total score on the Therapy Attitude Inventory, was hypothesized to be significantly higher in the PCIT condition compared to the TAU following treatment. Specific to hypothesis 5, a 2 X 2 (group $\mathrm{X}$ time) mixed ANCOVA was used to examine the treatment acceptability between conditions at post-treatment and follow-up. Maternal education was entered as the covariate. 


\section{Method}

\section{Participants}

Eighty-four women incarcerated in a female, state prison facility were selected for the current study. For study inclusion, the women were required to meet the following criteria: (a) eighteen years or older, (b) recommended for parenting services through the standard Individualized Recovery/ Resiliency Plan (IRRP) process conducted by the Department of Corrections staff at facility intake, (c) mother of child between the ages of 2 to 12 years, (d) all parental rights had not been terminated for future children, (e) parole eligibility did not occur before study group completion, and (f) availability during time that parenting classes were offered. Study exclusion criteria were established that individuals would be excluded from sample if they (g) were not fluent English speakers or (h) had participated in the standard parenting program at the facility within the past year. However, no women met the exclusion criteria. A power analysis (G*Power 3; Faul, Erdfelder, Lang, \& Buchner, 2007), utilizing methods advocated by Cohen (1998) was conducted using a power criterion of .80. It was determined that a sample of 73 mothers would have reasonable power to detect large to moderate effect sizes in this research project. Cohen (1988) defines effect sizes using partial eta squared $\left(\eta \rho^{2}\right)$ as $.01=$ small effect size, $.06=$ moderate effect size, $.14=$ large effect size. Previous research examining the effect sizes of PCIT have demonstrated large effect sizes with reference to parent behavior and functioning $(d=0.76-5.67$; Thomas $\&$ Zimmer-

Gembeck, 2007). However, due to the preliminary nature of the current examination and comparison to the current "gold standard" at the facility, smaller effects were expected.

\section{Procedure}

The current study was a randomized-controlled trial using a treatment comparison design. The Institutional Review Board at West Virginia University reviewed and approved the study protocol prior to participant recruitment. Data collection began January 2011 and ended in August 
2011. Participants were selected from a list of women waiting for participation in parenting classes at one women's state correctional facility. In accordance with facility policy, priority for inclusion in each pre-treatment wave of parenting groups was given to women based on their listed parole eligibility date. Prior to the written consent at pre-treatment assessment, consent forms were numbered with a participant identification number. Inmates self-selected participant identification numbers based on their chosen seat at the initial pre-treatment consent process. Participant identification numbers were randomly assigned to one of two treatment conditions: (a) Parent-Child Interaction Therapy (PCIT) or (b) treatment as usual (TAU) by a clerical staff member uninvolved with the collection of study data or the implementation of the parenting classes. Each treatment condition consisted of three waves of treatment groups throughout the course of the study (see Appendix A). The treatment groups were comprised of 10-15 participants, to match standard facility procedures prior to the current study, and group enrollment was closed upon the start of each group. Each PCIT group was matched to one TAU group by time of class across seven weeks. They were also matched in the number of group participants with the exception of the last wave of treatment in which an odd number of participants led to one additional participant in the PCIT group. Additionally, one TAU participant was incorrectly sent to the first PCIT class by staff uninvolved in the current study. Since this participant missed the first TAU class material and was exposed to the first PCIT class she was kept in the PCIT intervention group. The TAU condition consisted of 40 total participants (i.e., 3 classes of 10-15 mothers) who received once weekly, 1.5-hour group parenting classes (as adapted by the Department of Education at Lakin Correctional Center). The TAU group was led by an experienced instructor, with 2 years of experience providing group parenting education classes at the facility. One or two inmates who had previously graduated from the TAU parenting class assisted the instructor. The PCIT condition included 42 participants (i.e., 3 classes of 10-15 mothers). One graduate student PCIT therapist, with 3 years of PCIT experience, 
conducted each PCIT group. An undergraduate or graduate research assistant trained in the DPICSIII also attended each PCIT session to assist in DPICS-III coding of skills and to allow for quality assurance through completion of a treatment integrity checklist (Eyberg et al., 2009). The ParentChild Interaction Therapy (PCIT) condition was matched to the TAU group format and consisted of seven, 1.5-hour, weekly, group PCIT sessions. The PCIT format consisted of 3 CDI and 4 PDI sessions and adhered as closely as possible to the existing group PCIT protocol (Eyberg et al., 2009). Modifications made to the protocol were documented (see Table 2).

Procedures to prevent coercion of participants were considered. First, participants were informed that they were able to withdraw from the research project at any time without penalty. Secondly, both groups received a standard parenting class certificate for participation, and no incentives were provided unique to study participation. For example, study participation was not documented in inmates' facility profiles to ensure that participation did not influence sentencing. Furthermore, inmates did not receive tangible rewards such as food or money for participation.

Participants in both treatment groups were combined for study assessments across the three time points: 1-week pre-treatment, 1-week post-treatment, and 7-weeks follow-up. Assessments at each time point included group administration of self-report measures and individual behavior observations in an analogue situation of two structured parenting interactions (i.e., child-directed play and parent-directed play). All self-report measures across assessment periods were provided to participants in a group format and research assistants were available to assist with individual questions or clarification. Mothers were asked to answer items related to child behavior based on one of their own children who was 12 years or younger and demonstrated the most behavioral difficulties. During each one-on-one behavior observation coding situation, a research assistant, who was uninformed of each participant's treatment condition, played the role of a child between the age of 3-6 years. Participants were asked to "interact as they typically would with their own child or a 
child of this age." All research assistants involved in primary coding of assessment observations remained uninformed of participant's treatment group throughout the course of the study. Pretreatment assessment forms were presented in the following order: Participant Information Form, Adult-Adolescent Parenting Inventory-II, Child Abuse Potential Inventory, Parenting Stress Index, and Partnerships in Parenting Form. The Dyadic Parent-Child Interaction Coding System-III was utilized during individual parenting observations. These measures were completed by participants in approximately 60 to 80 minutes (i.e., approximately 60-70 minutes of self-report measures and 10 minutes of behavior observations). Post-treatment and follow-up assessments were given in the following order: Participant Information Form, Adult-Adolescent Parenting Inventory-II, Child Abuse Potential Inventory, Parenting Stress Index, Partnerships in Parenting, and Therapy Attitude Inventory. The Dyadic Parent-Child Interaction Coding System-III was utilized during individual parenting observations. These measures were also completed by participants in approximately 70 to 80 minutes.

\section{Treatment as usual condition.}

The standard parenting curriculum at Lakin Correctional Center has been adapted from the Partnerships in Parenting manual researched and compiled by Norma Bartholomew and Dr. Danica Knight (2002). This structured workshop series was designed for eight weekly meetings of about 2 hours each. The curriculum used at the facility was a modified version of the standard curriculum. Classes cover broad parenting issues and were divided into several topic categories. During the first 20 minutes of each session, TAU group members completed icebreaker activities and discussed previous class topics. In the next 30 minutes, the TAU instructor led group members in a discussion regarding the daily topic. Various methods for applying each topic to participants' lives were discussed. In the last 10 minutes of each session the instructor led a session wrap-up (For a more detailed outline of treatment see Appendix B). 


\section{Parent-Child Interaction Therapy condition.}

Treatment followed the group PCIT protocol (Eyberg et al., 2009), with the modifications

described. Several modified group formats have been examined (e.g., Berkovits et al., 2010; Foley \& McNeil, 2010; Niec et al., 2005). Similar to modifications made by previous authors, the following modifications were used to accommodate the demands of the correctional environment. First, PCIT participants received a pre-determined number and duration of treatment sessions. Second, participant's advancement from CDI to PDI to completion of the PCIT program was not based upon mastery criteria. Examined group PCIT formats vary in requirement of the mastery criteria (e.g., Eyberg et al., 2009, Niec et al., 2005). While mastery skills remained a key component of treatment, the group was not required to meet $50 \%$ mastery due to the preliminary nature of treatment in this environment. All participants progressed in treatment at the same time, regardless of skill mastery (e.g., Foley \& McNeil, 2010; Niec et al., 2005). Third, in-room, direct observation coding and coaching of PCIT skills was utilized (e.g., Foley \& McNeil, 2010).

In addition, a few modifications were made to meet the unique needs of parents in the correctional setting. First, parents received treatment without their children. This modification was necessary as a majority of incarcerated women did not receive weekly visits from their children. Second, out-of-session practice activities consisted largely of daily coloring practice with a selected inmate partner. This modification was necessary as participants did not have access to toys outside of the PCIT group time. Colored pencils and paper used during out-of-session practice were lent to participants and requested to be returned by participants at each PCIT group session. Out-of-session practice was documented by participant self-report but was not specifically examined as part of the current study. Third, out-of-session practice may also have been completed in the form of over-thephone or written letter practice of PCIT skills with their child, as many mothers wished to practice their skills with their own children and did not have direct visitation with their children throughout 
the course of the study. Fourth, dolls were used for timeout coaching, coding, and in-session practice during Parent-Directed Interaction stage due to rules restricting contact such as touching among inmates, staff, and non-familial visitors.

Each PCIT session was conducted in one-and-a-half hour time periods. The first 10 minutes of each session consisted of assessing caregiver attendance and questions related to prior material or out-of-session practice and providing an overview of the PCIT session. The next 70 minutes of each session consisted of PCIT mastery coding and in-session coding and coaching of individual PCIT group members. The final 10 minutes of each session was used to discuss one of the optional session worksheet topics (e.g., Parents are Models, Finding Supports) and to assign weekly out-of-session practice. During in-session coaching and coding practice, participants were divided into small groups (e.g., five groups of three participants, four groups of three to four participants) and also interacted in whole group practice (e.g., group members identified as coders, child, and parent, while therapist coded or coached). Within each group, participants rotated between the role of parent, child, coach, or coder. The PCIT instructor rotated throughout the groups to provide group members an opportunity for in-session coding and coaching of skills. Participants were coded each session by a research assistant for 2.5- 5 minutes using the Dyadic Parent-Child Interaction Coding System-III to assess and receive feedback on their progress toward mastery of PCIT skills. Each participant also engaged in group coaching activities focused on skills needed to progress toward CDI skill mastery. Participants were provided with coding sheets and were taught to code other PCIT participants on their PCIT mastery skills. Each session consisted of a review of that week's treatment plan (charted skills coding and one-to-two sentence written feedback) followed by a wrap-up of the day's session. As a component of therapy, participants were asked to practice, for 5 minutes a day, the PCIT skills that they learned in-session with other group members out-of-session, during child phone contact, or during supervised child visitations at the facility. Colored pencils and blank paper were provided to 
participants and requested to be returned at each group session. Out-of-session practice was monitored only by participant self-report but allowed participants to practice their PCIT skills on a daily basis. For participants to receive a class participation certificate they were required to attend and participate in a majority of sessions (as determined by existing Department of Corrections policy), however attendance was not a concern for any participant completing the study.

\section{Treatment fidelity and quality assurance.}

Several study elements were included to ensure treatment fidelity and integrity (Herschell, 2010). The primary therapist for the TAU condition had previous experience with the standard parenting program (i.e., developed protocol and administered TAU within the facility for two years) and provided an outline that described content covered during each session. The primary therapist in the PCIT condition had similar previous PCIT experience (i.e., participated on a clinical team specializing in PCIT for one year, conducted individual and group PCIT with Head Start families for one year, and supervised clinicians conducting PCIT as a graduate student supervisor on a clinical team specializing in PCIT) and adhered to a detailed group PCIT manual and treatment integrity checklist (Eyberg et al., 2009), which provides specific content to be covered during each session.

\section{Treatment integrity.}

The PCIT therapist received weekly, one-hour, individual supervision throughout the duration of the study from a licensed clinical psychologist who is a certified master trainer in PCIT and possesses extensive experience in both providing and supervising PCIT. These meetings supported the maintenance of treatment integrity (Nixon, Sweeney, \& Erickson, 2004). During supervision, the therapist reviewed and discussed session content and received instruction regarding how to improve therapy and ensure treatment integrity. Furthermore, a research assistant assessed integrity for PCIT utilizing session-by-session protocol adherence checklists (Bagner \& Eyberg, 2007; Chaffin et al., 2004; Schuhmann et al., 1998). Treatment integrity checklists were completed 
during $20 \%$ of the treatment sessions. Integrity percentages were determined for each treatment session by dividing the number of session components accurately completed by the total number of session components that could be accurately completed and multiplying that number by 100 . Furthermore, a treatment integrity plan was established that if treatment integrity dropped below $80 \%$ for any PCIT session, the therapist would meet with the supervising psychologist, a master PCIT trainer, to be retrained and to establish a corrective plan. However, treatment integrity remained high, 93\%, across all PCIT sessions and no PCIT sessions fell below the established integrity cutoff. Treatment integrity in the TAU condition was reported by the primary TAU therapist, who submitted a description of intervention material and topics addressed during each session (see Appendix C).

Before coding live, raters were trained using the DPICS-III Workbook and were quizzed on each behavior measured in the study. They were required to achieve a score of $80 \%$ or higher on each quiz. Additionally, the raters were required to achieve inter-rater reliability on a criterion tape demonstrated by kappas of .7 or higher for each behavior on three consecutive coding observations. If at any time before establishing three consecutive coding observations with kappas of .7 or higher, codes were reviewed and coders were required to complete three consecutive observations with kappas of .7 or higher. During training, all coders were compared for interrater reliability with the graduate student researcher.

\section{Measures}

\section{Participant Information Form (see Appendix D).}

The Participant Information Form was designed for description of parent-reported demographic (e.g., parent age, education, child age) and parent-child contact information (e.g., type of contact, frequency of contact). This form was developed from correspondence with Elana Tuerk, Ph.D., and included demographic and contact characteristic variables previously examined in the 
parenting programs literature (e.g., Tuerk \& Loper, 2006).

\section{Participant File Review.}

A file review using the West Virginia public online offender search locator (as found at Www.wvdoc.com) as well as a review of available participant facility files was used to collect basic demographic information. This review included only demographic items not included in the Participant Information form. The online offender search locator was used to provide demographic variables such as sentence length at pre-treatment, time left until parole eligibility, and offenses. The facility file review was completed to collect further information related to participant cognitive and achievement functioning, behavioral characteristics during incarceration, and facility risk and mental health classifications.

\section{Child Abuse Potential Inventory (CAP).}

The CAP (Milner, 1986) is a 160-item assessment developed to estimate risk for committing child physical abuse, which includes an abuse potential scale and several validity subscales. This study examined the Abuse Scale score. The Abuse scale is a 77-item measure that combines six subscales: rigidity; distress; unhappiness; and problems with child, family, and others. Items are rated as 'agree' or 'disagree.' The Abuse Scale has been reported to have high internal consistency $(\mathrm{KR}-20=.92$ to .95$)$, test-retest reliability (.83 at 1 month, .75 at 3 month) and good discriminant and predictive validity between abusive and non-abusive adults (i.e., Chaffin \& Valle, 2003; Milner, 1986, 1994; Milner \& Wimberly, 1980).

\section{Adult-Adolescent Parenting Inventory-second edition (AAPI-II).}

The AAPI-II (Bavolek \& Keene, 1999) is a 40-item assessment of parenting and childrearing attitudes of adult and adolescent parent and pre-parent populations. The AAPI-II uses a continuous scale to classify individuals' parenting-related knowledge. Participants respond to statements using a 5-point Likert-type scale. This study specifically looks at the Inappropriate 
Expectations of Children, Parental Lack of Empathy toward Children's Needs, and Strong Parental Belief in the Use of Corporal Punishment scales.

The Inappropriate Expectations of Children scale consists of 7 items related to parents' understandings of child growth and development. This subscale specifically examines the degree to which parental expectations exceed developmental capabilities of children. Parents with low scores on the Inappropriate Expectations of Children scale tend to be demanding and controlling and are not emotionally supportive of children. This subscale demonstrates high internal reliability (Cronbach's Alpha= .89).

The Parental Lack of Empathy toward Children's Needs scale is made up of 10 items that examine parental understanding and value of children's needs. High scores suggest general empathy and value found in the parental role. For individuals scoring low on this scale, parenting demands often lessen the worth of having children (Bavolek \& Keene, 1999). This subscale demonstrates high internal reliability (Cronbach's Alpha= .93).

The Strong Parental Belief in the Use of Corporal Punishment scale consists of 11 items that assess attitudes toward various methods of discipline. High scores indicate use of alternative strategies to corporal punishment and a general dislike for spanking children. Those with low scores express a strong, often exclusive, preference for spanking and fear as the best way to teach children respect and "right from wrong." This subscale demonstrates high internal reliability (Cronbach's Alpha = .96).

\section{Parenting Stress Index, Third Edition (PSI).}

The PSI (Abidin, 1995) is a 120-item assessment of stressors particular to parenting. This measure yields data on potential sources of stress related to family through the parent's perception of his or her functioning in the parental role, issues of the parent-child relationship, child development issues, life stress, and degree of support from the other parent. The PSI yields 17 scores including 
seven Child Domain scores, eight Parent Domain scores, and a Total Stress score, plus an optional Life Stress score. Participants indicated the degree to which she agreed or disagreed with each statement on a 5-point Likert scale ranging from 1 (Strongly agree) to 5 (Strongly disagree). Scores on the PSI remain stable over time, as indicated by correlation coefficients of .91 across a 1- to 3month interval (Abidin) to .70 over a 1-year interval (Hamilton, 1980 as cited in Abidin).

The current study examined the Total Stress score as well as one particular scale from the Parent Domain of the Sense of Competence subscale. Parental sense of competence has previously been shown to be particularly predictive of parental functioning during incarceration ( e.g., Houck \& Loper, 2002). The Sense of Competence subscale was used to examine parental stress hypotheses. This scale is composed of 13 questions that evaluate the participant's comfort in making parental decisions and disciplining child behavior. In normative sample, alpha reliability for the Sense of Competence subscale was .83 (Abidin).

\section{Therapy Attitude Inventory (TAI).}

The Therapy Attitude Inventory (TAI; Eyberg \& Johnson, 1974) consists of 10 items, on a 5point Likert-type scale, designed to assess parental satisfaction with therapy following the completion of parent training (i.e., total score ranges from 10 to 50). Higher total scores indicate higher levels of satisfaction regarding treatment and improvement of previously identified child behavior problems. Specific items ask parents to rate various components of the treatment including confidence in implementing intervention components and general impressions of treatment. The TAI has demonstrated strong internal consistency (Cronbach's Alpha $=.91)$ and test-retest reliability $(r=$ .85; Brestan et al., 1999). For the present study, the TAI was administered at post -treatment and follow-up. 


\section{Partnerships in Parenting Pre-Post Questionnaire.}

The Partnerships in Parenting questionnaire (Bartholomew \& Knight, 2001) is a 28-item assessment of parenting and child-rearing attitudes developed to examine changes in participants of the Partnerships in Parenting program at pre-treatment and post-treatment. The Partnerships in Parenting has been used qualitatively during clinical administration. Neither standardization nor norms have been published. Participants respond to statements using a 7-point scale. For the current study, participant scores for each item were compared to the teacher-reported ideal participant response. Participants' difference from the ideal response was summed for all items to reach a total score on the Partnerships in Parenting questionnaire.

\section{Dyadic Parent-Child Interaction Coding System-III (DPICS-III).}

The Dyadic Parent-Child Interaction Coding System-III (Eyberg et al., 2005) is the most recently revised and expanded version of the DPICS behavioral coding system, which has been designed and psychometrically assessed for the measurement of interaction quality within play interactions of parents and children 3 through 6 years of age. The DPICS-III consists of behavioral categories to measure all parent and child verbalizations, vocalizations (i.e., yell, whine, and laugh), physical behaviors (i.e., positive and negative touch), and responses (e.g., compliance to command). The psychometric properties for the DPICS have been studied exclusively (see Eyberg et al., 2005, for an overview). In the original standardization of the DPICS all coding was live coding. Reliability and validity studies of the DPICS during live coding situations have demonstrated adequate results (for a table of kappas for individual parent and child categories during live coding see Eyberg et al., 2010). DPICS coding occurred live for the current study, and composite scores (e.g., Parental Positive Mastery Skills, Parental Negative Mastery Skills) were used.

The DPICS-III was used to examine parent behavior. Specifically, parent skill level was examined during one child-directed and one parent-directed interaction with each participant at pre- 
treatment, post- treatment, and follow-up. During the child-directed interaction, parent categories of positive and negative mastery skills were coded. During the parent-directed interaction, parental use of effective command sequences and labeled praise following child compliance were coded. Coders used two standardized forms to record all parent observational data (see Appendix E \& F). Interrater reliability for parent behavior was attained for $20 \%$ of assessment interactions over the course of the study. Kappas of .6 or higher were required for inclusion of data within the study. No kappas fell below this criterion cutoff. During CDI, kappas were examined for parent positive mastery skills (K $=.90)$ and negative mastery skills $(\mathrm{K}=.87)$. During PDI, kappas were examined for parental effective command sequences $(K=.86)$ and labeled praises following compliance $(K=.82)$. Coders continued to participate in coding practice through PCIT lab excerpts and coding of PCIT clinic-based sessions throughout the course of assessments.

\section{Child play behavior checklist (see Appendix G \& H)}

A child behavior script was used to ensure specific child behaviors occurred during parentchild role play interactions during the assessment of both child-led and parent-led interactions. Research assistants playing the role of a child followed a child behavior checklist during each behavior observation assessment. Specific child behaviors such as tantrumming, screaming, laughing, complying with commands, using manners, or banging toys are examples of behaviors on the checklist that were demonstrated by research assistants. Research assistants were not required to complete child behaviors in a specific order during role plays.

The DPICS-III was used during pre-treatment, post treatment, and follow-up assessments for the manipulation integrity checklist of child play behavior in $20 \%$ of the structured behavior observation assessments. A treatment integrity plan was established that if treatment integrity dropped below $80 \%$, then the researcher would retrain the research assistant until mastery was met on child play behavior. Treatment integrity was observed at $95 \%$ across observations. 


\section{Results}

\section{Preliminary Analyses}

Data were collected from a total of 82 mothers; however only the data from the 73 participants who completed a parenting intervention were included in the following data analyses. Each of the included participants completed the pre-treatment assessment, a parenting program, and one or both of the assessments following the program. Consistent with accepted methods of examination in treatment outcome research designs across multiple time points, intent to treat analyses were used (Mazumadar, Liu, Houck, \& Reynolds, 1999). If a participant completed the intervention but only one assessment period following treatment (i.e., post-treatment or follow-up assessments), data were held constant across assessments following the intervention (i.e., posttreatment and follow-up). To address missing data, research assistants reviewed materials prior to participants leaving each assessment. If missing data existed, participants were asked if the item was intentionally left blank. Missing data were minimal with the majority of participants omitting no items. If a caregiver omitted more than $10 \%$ of responses on any given measure, data for that measure alone were not allowed to be considered in further analyses; however, no participants met this criterion. Data were initially screened for the presence of outliers and problems of skew or kurtosis. Additionally, homogeneity of variance was assessed for each variable. These explorations indicated that parenting skills had one outlier which may have affected the distribution of participants' responses. After reviewing the data, these scores were included in the dataset as removal did not significantly influence the mean of the dependent variable.

\section{Descriptive Statistics}

Eighty-four women were selected for the current study; however eighty-two women (42 in PCIT, 40 in TAU) were enrolled. Demographic characteristics for all enrolled participants are presented in Table 3. All women were currently incarcerated at a state correctional facility housing 
approximately 500 women at all levels of security classification. Of the two women who did not complete the initial pre-treatment assessment, one refused participation due to the research involvement and one woman refused participation because her female partner did not meet criteria for inclusion.

Participants had a mean age of 30.83 years $(S D=5.88)$. Approximately ninety-three percent were white, non-Hispanic, 3.7\% were African American, and 3.7\% were biracial. Related to relationship status, $36.6 \%$ were single, never married, $36.6 \%$ were divorced or separated, $11.0 \%$ were married, $8.5 \%$ had unmarried partners and $4.9 \%$ were widowed. The majority of mothers had not graduated from high school (i.e., less than a $12^{\text {th }}$ grade education; 63.4\%), were unemployed or receiving disability benefits at the time of incarceration $(56.1 \%)$, and reported they were uncertain of their household income at the time of their offense $(45.1 \%)$. Twenty one women $(25.6 \%)$ reported an annual household income of below \$15,000, and ten women (12.2\%) reported an income between $\$ 15,000$ and $\$ 25,000$. According to the U.S. Census Bureau's poverty line criteria for a family of five in 2011 (i.e., \$26, 434), only $17.1 \%$ of participants identified living in households above this estimated poverty line.

Participants had an average of 2.30 children $(S D=1.31)$, and the average minor child age of all participants' children (i.e., not only the reported target children) was 6.76 years $(S D=4.37)$. The majority of participants reported being responsible for the care of at least one of their children (71.0 $\%$ ) and seeing their children every day prior to incarceration $(71.0 \%)$. At pre-treatment, mothers reported that they talked about their child every day (64.6\%), wrote letters to their child at least once a week $(57.3 \%)$, talked with their child on the phone at least once a week (48.8\%), and were not having facility visitation with their children (76.8\%). Multiple caregivers were listed as the current primary caregivers of mothers' multiple children. Approximately $16 \%$ of mothers indicated more than one primary caregiver of their children at pre-treatment. Primary caregivers during maternal 
incarceration were most commonly grandmothers (47.9\%); however children were also cared for by fathers $(26.0 \%)$, other family members $(10.4 \%)$, nonfamily member adults chosen by the courts (8.3\%), and other arrangements (7.3\%). For further information about parent-child contact for all participants see Table 4. Mean scores on CAP subscales are provided in Table 5.

\section{Participant File Review.}

Following study completion, a file review was completed to examine additional demographic variables. File review information was collected by an assigned facility staff member with security clearance and permission from the Associate Warden of Programs for specific file access. Of the 82 participants, 56 files (68.3\%) were available for review. Files unable to be reviewed were reported to be due to participant movement to new facilities or parole. Participants' scores on the Beta III, a brief test of nonverbal cognitive abilities, suggested mean intellectual functioning in the average range (i.e., $M=96.33, S D=11.65)$. Examination of achievement scores based on the Test of Achievement Basic Education suggest grade equivalent functioning between $7^{\text {th }}-9^{\text {th }}$ grade levels in mathematics $(M=7.95, S D=3.29)$, reading $(M=9.15, S D=3.81)$, and language skills $(M=8.86$, $S D=3.53$ ). At facility entry, most participants had a facility risk categorization of community or low risk $(55.36 \%)$ and a mental health score of low risk (53.57\%). Prior to participation in the current parenting program, participants had completed three prison programs $(S D=2.68)$. Behavioral characteristics such as prior offenses $(M=10.39, S D=11.87)$, days previously incarcerated $(M=$ 102.70, $S D=391.54)$, and days previously spent in segregation due to facility violations $(M=46.94$, $S D=131.06)$ varied greatly across participants.

Testing the adequacy of the randomization procedures, pre-treatment between-group differences were examined for participant characteristics (i.e., annual household income, frequency of contact with child prior to incarceration, frequency of phone contact in past 6 weeks, frequency of visitation contact in past 6 weeks, mother education level, and mother age). Significant differences 
between groups were found only for mother's educational level, $t(68)=-2.36, p=.02$; therefore maternal education level was entered as a covariate in all major analyses. The selected participant characteristics and pre-treatment scores on all outcome variables were also examined between participants that completed treatment and those who did not complete treatment; the only difference found was that participants who completed treatment were older than those not completing their respective parenting program, $t(79)=-2.13, p=.02$. The relation between treatment wave and study outcome variables was also examined for each group and treatment wave was not found to be significantly related to scores on any major analyses.

\section{Major Analyses}

Hypothesis 1. Parenting Skills, as indicated by the Dyadic Parent-Child Interaction Coding System ( $3^{\text {rd }}$ edition; Eyberg et al., 2005), will be related to treatment condition. It was hypothesized that 1a) Positive Mastery Skills would increase, 1b) Negative Mastery Skills would decrease, 1c) Percentage of Effective Command Sequences would increase, and 1d) Percentage of ComplianceContingent Labeled Praises would increase more in the PCIT condition compared to the TAU condition following the intervention.

Hypothesis 1a, Positive Mastery Skills. An independent samples $t$-test was conducted to determine whether there was a significant difference between the PCIT and TAU conditions at pretreatment on the level of Positive Mastery Skills. Analysis indicated no significant difference in Positive Mastery Skills between treatment conditions at pre-treatment, $t(71)=1.11, p=.52$. Subsequently, a mixed between-within subjects analysis of covariance was conducted to compare the effectiveness of the two interventions in increasing positive mastery skills in parents across time. The between-subjects variable was the type of intervention (PCIT, TAU), and the within-subjects variables consisted of Positive Mastery Skills on the pre-treatment, post-treatment, and follow-up assessment. Mother's education level was used as a covariate in this analysis. Descriptive statistics 
are shown in Table 6. Preliminary checks were conducted to ensure that there was no violation of the assumptions of normality, linearity, homogeneity of variances, homogeneity of regression slopes, and reliable measurement of the covariate. Normality and homogeneity of variance were violated; therefore scores were square-root transformed. Once transformed, assumptions were met. After adjusting for maternal education level, there was a significant interaction between the type of intervention (i.e., PCIT, TAU) and the time of assessment (i.e., pre-treatment, post-treatment, and follow-up), $F(1,63)=15.82, p=.00, \eta \rho^{2}=.56$. The covariate, maternal education level, was not significantly related to Positive Mastery Skills. Planned contrasts revealed significantly higher levels of Positive Mastery Skills following PCIT compared to TAU at post treatment, $t(63)=8.51, p=.00$, $\eta \rho^{2}=.53$ and follow-up, $t(63)=10.49, p=.00, \eta \rho^{2}=.64$. As noted by Cohen (1988), interpretation of $\eta \rho^{2}$ indicates $.01=$ small effect size, $.06=$ moderate effect size, $.14=$ large effect size.

Hypothesis 1b, Negative Mastery Skills. An initial independent samples t-test was completed to examine whether there was a significant difference between the PCIT and TAU conditions at pretreatment on the level of Negative Mastery Skills. Analysis indicated no significant difference in Negative Mastery skills between treatment conditions at pre-treatment, $t(71)=.79, p=.44$. Subsequently, a mixed between-within subjects analysis of covariance was conducted to compare the effectiveness of the two interventions in decreasing Negative Mastery Skills in mothers across time. The independent variable was the type of intervention (PCIT, TAU), and the within-subjects variables consisted of Negative Mastery Skills on the pre-treatment, post-treatment, and follow-up assessments. Mother's education level was used as a covariate in this analysis. Descriptive statistics are shown in Table 7. Preliminary checks were conducted to ensure that there was no violation of the assumptions of normality, linearity, homogeneity of variances, homogeneity of regression slopes, and reliable measurement of the covariate. Normality and homogeneity of variance were violated; therefore scores were square-root transformed. Once transformed, assumptions were met. After 
adjusting for maternal education level, there was a significant interaction between the type of intervention (i.e., PCIT, TAU) and the time of assessment (i.e., pre-treatment, post-treatment, and follow-up), $F(1,63)=13.27, p=.001, \eta \rho^{2}=.17$. The covariate, maternal education level, was not significantly related to Negative Mastery Skills. Planned contrasts revealed significantly lower levels of Negative Mastery Skills following PCIT compared to TAU at post- treatment, $t(63)=-1.93, p$ $=.05, \eta \rho^{2}=.06$ and follow-up, $t(63)=-3.37, p=.001, \eta \rho^{2}=.15$.

Hypothesis 1c, Percentage of Effective Command Sequences. An initial independent samples $t$-test was completed to examine whether there was a significant difference between the PCIT and TAU conditions at pre-treatment on the Percentage of Effective Command Sequences. Analyses indicated no significant differences in Percentage of Effective Command Sequences between treatment conditions at pre-treatment, $t(71)=-.16, p=.88$. Subsequently, a mixed between-within subjects analysis of covariance was conducted to compare the effectiveness of the two interventions in increasing Percentage of Effective Command Sequences in mothers across time. The between-subjects variable was the type of intervention (PCIT, TAU), and the within-subjects variables consisted of Percentage of Effective Command Sequences on the pre-treatment, posttreatment, and follow-up assessments. Mother's education level was used as a covariate in this analysis. Descriptive statistics are shown in Table 8. Preliminary checks were conducted to ensure that there was no violation of the assumptions of normality, linearity, homogeneity of variances, homogeneity of regression slopes, and reliable measurement of the covariate. Normality and homogeneity of variance were violated; therefore scores were square-root transformed. Once transformed, assumptions were met. After adjusting for maternal education level, there was a significant interaction between the type of intervention (i.e., PCIT, TAU) and the time of assessment (i.e., pre-treatment, post-treatment, and follow-up), $F(1,63)=6.35, p=.014, \eta \rho^{2}=.09$. The covariate, maternal education level, was not significantly related to Percentage of Effective 
Command Sequences. Planned contrasts revealed significantly higher levels of the Percentage of Effective Command Sequences following PCIT compared to TAU at post treatment, $t(63)=2.23, p$ $=.03, \eta \rho^{2}=.07$.

Hypothesis 1d, Percentage Compliance-Contingent Labeled Praise. An initial $t$-test was completed to examine whether there was a significant difference between the PCIT and TAU conditions at pre-treatment on the level of Percentage Compliance-Contingent Labeled Praise. Analyses indicated no significant differences in skills between treatment conditions at pre-treatment, $t(71)=1.17, p=.25$. Subsequently, a mixed between-within subjects analysis of covariance was conducted to compare the effectiveness of the two interventions in increasing Percentage of Effective Command Sequences in mothers across time. The between-subjects variable was the type of intervention (PCIT, TAU), and the within-subjects variables consisted of Percentage of Compliance-Contingent Labeled Praise on the pre-treatment, post-treatment, and follow-up assessments. Mother's education level was used as a covariate in this analysis. Descriptive statistics are shown in Table 9. Preliminary checks were conducted to ensure that there was no violation of the assumptions of normality, linearity, homogeneity of variances, homogeneity of regression slopes, and reliable measurement of the covariate. Normality and homogeneity of variance was violated; therefore scores were square-root transformed. Once transformed, assumptions were met. After adjusting for maternal education level, there was a significant interaction between the type of intervention (i.e., PCIT, TAU) and the time of assessment (i.e., pre-treatment, post-treatment, and follow-up), $F(1,63)=15.46, p=.00, \eta \rho^{2}=.20$. The covariate, maternal education level, was not significantly related to Percentage of Compliance-Contingent Labeled Praise. Planned contrasts revealed significantly higher levels of the Percentage of Compliance-Contingent Labeled Praise following PCIT compared to TAU at post treatment, $t(63)=3.68, p=.00, \eta \rho^{2}=.18$ and follow-up, $t$ $(63)=4.16, p=.00, \eta \rho^{2}=.22$. 
Hypothesis 2. Parental Knowledge, as measured by the AAPI-II Inappropriate Expectations scale (Bavolek \& Keene, 1999) and the Partners in Parenting Pre-Post Questionnaire, will be related to treatment condition. It was hypothesized that 2a) scores on the AAPI-II Inappropriate Expectations scale would increase more (i.e., higher scores showing more appropriate expectations) in the TAU condition than in the PCIT condition, and 2b) responses on the Partnerships in Parenting Knowledge questionnaire would be more similar to the teacher-reported ideal responding across time for the TAU condition compared to the PCIT condition.

Hypothesis 2a, Parental Knowledge, Inappropriate Expectations. An initial independent samples $t$-test was completed to examine whether there was a significant difference between the PCIT and TAU conditions at pre-treatment on the level of Inappropriate Expectations on the AAPIII. Analyses indicated no significant difference in scores between treatment conditions at pretreatment, $t(71)=-.82, p=.41$. Descriptive statistics are shown in Table 10. Subsequently, a mixed between-within subjects analysis of covariance was conducted to compare the effectiveness of the two interventions in reducing Inappropriate Expectations in mothers (i.e., higher scores indicate reductions in Inappropriate Expectations). The between-subjects variable was the type of intervention (PCIT, TAU) and the within-subjects variables consisted of the pre-treatment, posttreatment, and follow-up Inappropriate Expectations scores. Mother's education level was used as a covariate in this analysis. Preliminary checks were conducted to ensure that there was no violation of the assumptions of normality, linearity, homogeneity of variances, homogeneity of regression slopes, and reliable measurement of the covariate. Normality and homogeneity of variance were violated; therefore scores were square-root transformed. Once transformed, assumptions were met. After adjusting for mother's education level, there was no significant interaction between the type of intervention (i.e., PCIT, TAU) and the time of assessment (i.e., pre-treatment, post-treatment, and follow-up), $F(1,63)=1.62, p=.21, \eta \rho^{2}=.02$. There was a significant main effect for time, $F(2$, 
$63)=4.94, p=.02 \eta \rho^{2}=.07$. Within-subjects contrasts for time suggest that Inappropriate

Expectations decreased (i.e., higher scores) at post-treatment and follow-up. The covariate, maternal education level, was not significantly related to Inappropriate Expectations.

Hypothesis 2b, Parent Knowledge, PIP Parenting Topics. An initial independent samples ttest was completed to examine whether there was a significant difference between the PCIT and TAU conditions at pre-treatment on Knowledge of PIP Parenting Topics scores (i.e., difference from the teacher-reported ideal for each item). Descriptive statistics are shown in Table 11. Analyses indicated a significant difference in skills between treatment conditions at pre-treatment, $t(71)=$ $2.82, p=.01$. Subsequently, a mixed between-within subjects analysis of covariance was conducted to assess the impact of the two interventions (PCIT, TAU) on participants' Knowledge of PIP Parenting Topics, across three two periods (post-treatment, and 7-week follow-up). A check of assumptions indicated that assumptions of normality and homogeneity of variance were violated; therefore scores were log transformed. Once transformed, assumptions were met. Mother's pretreatment Knowledge of PIP Parenting Topics score and mother's education level were used as the covariate in this analysis. Preliminary checks were conducted to ensure that there was no violation of the assumptions of normality, linearity, homogeneity of variances, homogeneity of regression slopes, and reliable measurement of the covariate. After adjusting for pre-treatment Knowledge of PIP Parenting Topics scores and mother's education level, there was no significant interaction between the type of intervention (i.e., PCIT, TAU) and the time of assessment (i.e., pre-treatment, posttreatment, and follow-up), $F(1,67)=.61, p=.44, \eta \rho^{2}=.01$. There was also no significant effect for time, $F(2,67)=1.19, p=.28, \eta \rho^{2}=.02$. There was a significant relation between pre-treatment scores and post-treatment and follow-up scores $\left(\eta \rho^{2}=.17\right)$, which suggests that pre-treatment scores accounted for $17 \%$ of the variance in post-treatment and follow-up scores. 
Hypothesis 3. Parenting Stress, as indicated by the Parenting Stress Index (Abidin, 1995), will be related to treatment condition. It was hypothesized that 3a) Total Parenting Stress would decrease and 3b) Competency-Related Stress would decrease more in the PCIT condition compared to the TAU condition following the intervention.

Hypothesis 3a, Total Stress. An initial independent samples $t$-test was completed to examine whether there was a significant difference between the PCIT and TAU conditions at pre-treatment on the level of PSI Total Stress. Analysis indicated no significant difference in scores between treatment conditions at pre-treatment, $t(71)=.99 p=.33$. Descriptive statistics are shown in Table 12. Subsequently, a mixed between-within subjects analysis of covariance was conducted to compare the effectiveness of the two interventions in reducing participants' total parenting stress. The between-subjects variable was the type of intervention (PCIT, TAU), and the within-subjects variables consisted of scores on the pre-treatment, post-treatment, and follow-up Total Stress scores. Mother's education level was used as a covariate in this analysis. Preliminary checks were conducted to ensure that there was no violation of the assumptions of normality, linearity, homogeneity of variances, homogeneity of regression slopes, and reliable measurement of the covariate. All assumptions were met. After adjusting for mother's education level, there was no significant interaction between the type of intervention (i.e., PCIT, TAU) and the time of assessment (i.e., pre-treatment, post-treatment, and follow-up), $F(1,67)=.37, p=.55, \eta \rho^{2}=.01$. The main effect for time was also not significant, $F(2,67)=2.11, p=.13, \eta \rho^{2}=.03$. There was a significant relation between maternal education level $\left(\eta \rho^{2}=.08\right)$ and Total Stress.

Hypothesis 3b, Parenting Competency-Related Stress. An initial independent samples $t$-test was completed to examine whether there were significant differences between the PCIT and TAU conditions at pre-treatment on level of competency-related parenting stress. Analyses indicated no significant differences in scores between treatment conditions at pre-treatment, $t(71)=1.63, p=.11$. 
Descriptive statistics are shown in Table 13. Subsequently, a mixed between-within subjects analysis of covariance was conducted to compare the effectiveness of the two interventions in decreasing PSI Competency-Related Stress in mothers across time. The between-subjects variable was the type of intervention (PCIT, TAU), and the within-subjects variables consisted of PSI Competency-Related Stress on the pre-treatment, post-treatment, and follow-up assessments. Mother's education level was used as a covariate in this analysis. Preliminary checks were conducted to ensure that there was no violation of the assumptions of normality, linearity, homogeneity of variances, homogeneity of regression slopes, and reliable measurement of the covariate. Normality and homogeneity of variance were violated; therefore scores were square-root transformed. Once transformed, assumptions were met. After adjusting for maternal education level, there was no significant interaction between the type of intervention (i.e., PCIT, TAU) and the time of assessment (i.e., pretreatment, post-treatment, and follow-up), $F(1,67)=3.00, p=.09, \eta \rho^{2}=.04$. The main effect for time was also not significant, $F(2,67)=1.92, p=.16, \eta \rho^{2}=.03$. The covariate, maternal education level, was not significantly related to PSI Competency-Related Stress.

Hypothesis 4. Child Abuse Potential, as indicated by the Abuse Scale on the CAP (Milner, 1986) and the Empathetic Regard and Belief in Corporal Punishment domains of the AAPI-II (Bavolek \& Keene, 1999, will be related to treatment condition. It was hypothesized that 4a) Total Abuse would decrease (i.e., lower scores indicate lower abuse potential), 4b) Lack of Empathetic Regard would decrease (i.e., higher scores indicate increased empathetic regard), and 4c) Belief in Corporal Punishment will reduce (i.e., higher scores indicate less belief in corporal punishment) in the PCIT condition compared to the TAU condition following the intervention.

Hypothesis 4a, Abuse Potential. The CAP Abuse score was examined in two ways: with and without elevated lie scores included. Findings were not altered with the removal of the elevated lie scores, therefore data from participants with elevated lie scores were included. See Table 14 for the 
percentages of scores meeting signal-detection cutoff. An initial $t$-test was completed to examine whether there was a significant difference between the PCIT and TAU conditions at pre-treatment on the level of abuse potential. Analysis indicated no significant difference in Abuse scores between treatment conditions at pre-treatment, $t(71)=-.09 p=.93$. Descriptive statistics are shown in Table 15. Subsequently, a mixed between-within subjects analysis of covariance was conducted to compare the effectiveness of the two interventions in reducing participants' Abuse Potential. The between-subjects variable was the type of intervention (PCIT, TAU), and the within-subjects variables consisted of scores on the pre-treatment, post-treatment, and follow-up CAP Abuse scores. Mother's education level was used as a covariate in this analysis. Preliminary checks were conducted to ensure that there was no violation of the assumptions of normality, linearity, homogeneity of variances, homogeneity of regression slopes, and reliable measurement of the covariate. All assumptions were met. After adjusting for mother's education level, there was no significant interaction between the type of intervention (i.e., PCIT, TAU) and the time of assessment (i.e., pre-treatment, post-treatment, and follow-up), $F(1,67)=.63, p=.43, \eta \rho^{2}=.01$. The main effect for time was also not significant, $F(2,67)=2.28, p=.11, \eta \rho^{2}=.03$. There was a significant relation between maternal education level $\left(\eta \rho^{2}=.06\right)$ and CAP Abuse.

Hypothesis 4b, Lack of Empathetic Regard. An initial independent samples $t$-test was completed to examine if there was a significant difference between the PCIT and TAU conditions at pre-treatment on the level of empathetic regard. Analysis indicated no significant difference in scores between treatment conditions at pre-treatment, $t(71)=-.31, p=.76$. Descriptive statistics are shown in Table 16. Subsequently, a mixed between-within subjects analysis of covariance was conducted to compare the effectiveness of the two interventions in reducing participants' Lack of Empathetic Regard (i.e., higher scores indicate less Lack of Empathetic Regard). The betweensubjects variable was the type of intervention (PCIT, TAU), and the within-subjects variables 
consisted of scores on the pre-treatment, post-treatment, and follow-up Lack of Empathetic Regard. Mother's education level was used as a covariate in this analysis. Preliminary checks were conducted to ensure that there was no violation of the assumptions of normality, linearity, homogeneity of variances, homogeneity of regression slopes, and reliable measurement of the covariate. All assumptions were met. After adjusting for mother's education level, there was no significant interaction between the type of intervention (i.e., PCIT, TAU) and the time of assessment (i.e., pre-treatment, post-treatment, and follow-up), $F(1,67)=.53, p=.47, \eta \rho^{2}=.01$. There was a significant main effect for time, $F(2,67)=4.68, p=.02, \eta \rho^{2}=.08$. Within-subjects contrasts for time suggest that Lack of Empathetic Regard decreased (i.e., higher scores) at post-treatment and follow-up. There was a significant relation between maternal education level $\left(\eta \rho^{2}=.06\right)$ and Lack of Empathetic Regard.

Hypothesis 4c, Belief in Corporal Punishment. An initial independent samples $t$-test was completed to examine whether there was a significant difference between the PCIT and TAU conditions at pre-treatment on the level of Belief in Corporal Punishment. Analyses indicated no significant difference in scores between treatment conditions at pre-treatment, $t(71)=-1.84, p=.07$. Descriptive statistics are shown in Table 17. Subsequently, a mixed between-within subjects analysis of covariance was conducted to compare the effectiveness of the two interventions in decreasing Belief in Corporal Punishment in mothers across time. The between-subjects variable was the type of intervention (PCIT, TAU), and the within-subjects variables consisted of Belief in Corporal Punishment on the pre-treatment, post-treatment, and follow-up assessments. Mother's education level was used as a covariate in this analysis. Preliminary checks were conducted to ensure that there was no violation of the assumptions of normality, linearity, homogeneity of variances, homogeneity of regression slopes, and reliable measurement of the covariate. Normality and homogeneity of variance were violated; therefore scores were square-root transformed. Once transformed, 
assumptions were met. After adjusting for maternal education level, there was no significant interaction between the type of intervention (i.e., PCIT, TAU) and the time of assessment (i.e., pretreatment, post-treatment, and follow-up), $F(1,67)=.03, p=.86, \eta \rho^{2}=.00$. The main effect for time was also not significant, $F(2,67)=1.31, p=.26, \eta \rho^{2}=.02$. The covariate, maternal education level, was not significantly related to Belief in Corporal Punishment.

Hypothesis 5. Treatment Acceptability, as indicated by the Total Score on the TAI (Eyberg \& Johnson, 1974), will be related to treatment condition. Specifically, it was hypothesized that treatment acceptability would be higher in the PCIT condition compared to the TAU condition following the intervention. Descriptive statistics are shown in Table 18. A mixed between-within subjects analysis of covariance was conducted to compare the effectiveness of the two interventions in Treatment Acceptability in mothers across time. The between-subjects variable was the type of intervention (PCIT, TAU), and the within-subjects variables consisted of TAI Total score on the post-treatment, and follow-up assessments. Mother's education level was used as a covariate in this analysis. Preliminary checks were conducted to ensure that there was no violation of the assumptions of normality, linearity, homogeneity of variances, homogeneity of regression slopes, and reliable measurement of the covariate. All assumptions were met. After adjusting for maternal education level, there was a significant interaction between the type of intervention (i.e., PCIT, TAU) and the time of assessment (i.e., pre-treatment, post-treatment, and follow-up), $F(1,67)=5.65, p=.02, \eta \rho^{2}$ $=.08$. The covariate, maternal education level, was not significantly related to Treatment Acceptability. Planned contrasts revealed that PCIT was significantly higher in Treatment Acceptability compared to TAU at post treatment, $t(67)=2.36, p=.02, \eta \rho^{2}=.08$ and follow-up $t$ $(67)=2.05, p=.05, \eta \rho^{2}=.06$. 


\section{Discussion}

This study aimed to explore the effectiveness of two facility-based group parenting programs

(i.e., PCIT and the standard facility-based parenting program based on the Partnerships in Parenting curriculum) in altering self-reported and observed parenting outcomes. Additionally, the study attempted to provide further knowledge of the implementation of group PCIT in a real-world setting, while adhering to restrictions characteristic of a correctional facility. As a result, PCIT was adapted to use role-plays and in-room coaching of parenting skills. To match the existing facility program and the standard practice of correctional parent- training programs, PCIT was conducted using a group format and was limited to seven sessions.

The current study findings suggest similar change following both facility-based parenting programs. In addition, these findings suggest that PCIT altered parent functioning in a correctional setting when using a group format, without children present, and without special equipment. Mothers completing PCIT reported higher levels of demonstrated parenting skills and treatment satisfaction than mothers in the standard program. Each study finding will be further discussed. Methodological limitations, possible implications, and future directions will also be explored while interpreting results.

\section{Parenting Skills}

Study hypotheses that mothers would demonstrate a greater increase in parenting skills following PCIT compared to the standard parent-training program were supported. The PCIT findings are consistent with prior research studies indicating increases in positive parenting behaviors (e.g., parent positive talk and effective limit setting) and reductions in negative parenting behaviors (e.g., negative talk) following PCIT. Mothers enrolled in PCIT demonstrated more positive mastery skills (i.e., labeled praise, reflection, behavioral descriptions) and fewer negative skills (e.g., questions, criticisms, and commands) following intervention compared to TAU. They 
also demonstrated higher percentages of effective commands and compliance-contingent labeled praise following treatment compared to mothers enrolled in the standard parenting program.

Although these are significant changes from pre-treatment, skills were not demonstrated at mastery level. For example, Parent Positive Mastery Skills were demonstrated at a level that was less than half the level required for CDI mastery (i.e., in the current study, the mean Positive Mastery Skills was approximately 11 and standard mastery requires 30). Furthermore, the rate of effective command sequences was much lower (i.e. approximately 10\%) than the $75 \%$ effectively stated command sequences required in standard PCIT services. At 10.5 hours of group intervention, dose was much less than standard individual-family PCIT. Each parent received far less than half the dedicated coaching time typical of standard PCIT, therefore lower levels of skill change are not surprising. Mothers in the standard facility program did not change across any measure on the demonstrated parenting skills following intervention (i.e., post-treatment and follow-up), which is consistent with other studies that suggest minimal skill change following didactic parenting interventions (e.g., Kaminski et al., 2008).

\section{Parenting Knowledge}

Study hypotheses that mothers would demonstrate higher levels of parenting knowledge (i.e., appropriate expectations of child development and behavior management and more knowledge of the parenting topics addressed in Partnerships in Parenting Program) following TAU compared to PCIT were not supported. Changes in inappropriate expectations and Knowledge of PIP Parenting Topics did not differ between groups. Inappropriate expectations were shown to decrease over time, suggesting similar improvement in both groups. However, Knowledge of PIP Parenting Topics remained stable across group and time for all mothers. 


\section{Parenting Stress}

Results indicated similar changes in parental stress between mothers completing PCIT and the standard parenting program. Previous PCIT outcome research specifically examining parent functioning has demonstrated decreases in parental stress from pre-treatment to post-treatment for parents of children with disruptive behavioral difficulties (e.g., Schuhmann et al., 1998) and families with a history of child maltreatment (e.g.,Timmer et al., 2006). Mothers in this study reported total parenting stress to be at a lower level than has been reported in some prior studies examining parenting stress outcomes in families receiving PCIT treatment (e.g., Capage, Bennett, \& McNeil, 2001; Schuhmann et al., 1998). However, the reported level of parenting competency-related stress was comparable to that found in Houck and Loper's (2002) examination of parenting stress during incarceration. As suggested by Houck and Loper, lower total stress scores for incarcerated mothers on the Parenting Stress Index may be a product of incarcerated mothers' difficulty in responding to some child behavior items due to limited parent-child contact. Further examination may support the use of specific subscales on the Parenting Stress Index as a more appropriate measure for evaluating stress during incarceration. Furthermore, teaching, modeling, and coaching mothers in a group format and without their children in treatment on the use of these skills did not decrease parental stress significantly more than didactic discussion of child behavior management strategies during the seven- session facility-based intervention. This study found less reduction in parenting stress scores than prior examinations of PCIT that have involved children in treatment. This may suggest that simply having parenting strategies may not allow caregivers to feel any more confident that they are prepared to manage inappropriate behaviors with their own children. Unique to the correctional population, mothers had limited opportunities to implement learned materials with their own children. As the seven session group format did not result in PCIT mastery-level parenting skills, the current format may also simply not be a large enough dose of intervention to result in a greater 
reduction in parenting stress. Lastly, it is possible that during incarceration mothers may be limited in resources or opportunities to successfully reduce stress and increase coping.

\section{Child Abuse Potential}

Study hypotheses that there would be a greater decrease in child abuse potential were not supported. Mothers in the PCIT group did not differ from the TAU group in CAP Abuse Potential or Lack of Empathetic Regard following treatment. Previous research has demonstrated that families with a history of child abuse and neglect who receive standard PCIT treatment services report fewer reabuse reports and decrease in potential for abuse from pre-treatment to post-treatment (Borrego et al., 1999; Timmer et al., 2005; Timmer et al., 2006), however prior examinations comparing treatment changes in PCIT to community programs have also found that parent-reported changes in parenting attitudes (e.g., CAP abuse scale score) do not appear to differ between treatments over time (e.g., Chaffin al., 2004). The current finding supports the practice of also examining behavioral outcomes such as reabuse reports or involvement in the child welfare system to gauge changes in abuse potential.

\section{Treatment Acceptability}

Treatment acceptability was found to be higher for mothers following PCIT compared to the standard facility program at post-treatment and at 7-week follow-up. These findings suggest that mothers enrolled in PCIT were more satisfied with treatment. Therefore, PCIT or a similar type of intervention (e.g., Webster-Stratton, 2001) may be an acceptable delivery format for incarcerated mothers. However, since the Therapy Attitude Inventory was only administered at post-treatment and follow-up, it is difficult to determine whether the novelty of the PCIT intervention at the facility influenced satisfaction scores. Compared to satisfaction following treatment in other studies (i.e., $M$ $=40$-43); Berkovits et al., 2010; Boggs et al., 2004), incarcerated mothers reported lower levels of satisfaction for both PCIT $(M=38.4)$ and TAU $(M=35.4)$ interventions. It is likely that the nature 
of the facility recommendation to complete parenting programing, group-based format, and lack of involvement of their children in the program contributed to decreased treatment satisfaction. As TAI treatment acceptability has previously been associated with treatment gains (Brestan et al., 1999), limited improvement in some areas of parent-child functioning may also account for lowered satisfaction. It is also possible that characteristics of a prison setting and population may be related to the mothers' overall satisfaction.

\section{Limitations}

Several limitations of the current study are important to note. First, treatment and assessment interactions relied on role-play situations and may be less characteristic of parental interactions with mothers' own children. Second, skill generalization to environments outside of the correctional setting was not assessed. Mothers may have used PCIT skills during sessions but may not actually implement skills across environments or with their own children. Using the DPICS-III coding system to assess mother-child interactions at home, school, and in the community would provide a wealth of information regarding caregivers' abilities to implement PCIT skills to reinforce their children's appropriate behaviors and manage their children's inappropriate behaviors in more natural environments following reunification. Third, treatment integrity was teacher-reported for the standard facility intervention. As a result, it is difficult to compare the standard facility program used during the current study to correctional parenting classes occurring across the country.

PCIT was modified significantly as it was not based on skill mastery, was conducted in a group setting, and had no child present. Additionally, the dose of coaching for any individual parent was much lower than would be the case for standard PCIT. The nature of the prevention program led this population to differ from others typically studied in PCIT research. More specifically, the participants' children were not required to have behavior problems and parents were not required to have a history of harsh parenting or child maltreatment, which may have added more variance in the 
study findings. The participants' children were also not involved in services throughout the course of the parenting program and the majority of mothers were not in direct contact with their children, which may account for limited changes in mother's self-report data (e.g., parenting-related stress, child abuse potential, parenting knowledge). Similarly, it appears that analyses may be underpowered to detect smaller effect sizes, which may have occurred due to the serious modifications, decreased dose of PCIT, and heterogeneity of the sample. PCIT had the benefit of a novelty effect with a new trainer and program in the prison that could have influenced satisfaction. In addition, the researcher was also the trainer and this could have had an effect of increased trainer motivation and enthusiasm during the PCIT intervention. Also, the 7-week follow-up was short; preferably the follow-up would have been extended longer to see if parenting skill changes were maintained over a longer period of time. The modification of PCIT by dose of treatment, format, and required resources suggests that analysis of cost effectiveness may be important in further discussion of the program's utility in a correctional setting. There were also some difficulties with practical implementation. For example, instructors had limited facility access, resources, and time. The PCIT training might be hard to manage for a single instructor who is less experienced in providing PCIT. Next, many of the measures were based on self-report. Characteristics of this particular population (e.g., low educational attainment) suggest that they may have difficulty presenting themselves in a realistic light, which may have influenced accurate reporting and the validity of paper and pencil measures. Specifically, the CAP, one outcome measure with validity indices, had a fairly high percentage of invalid profiles, which suggests the need for consideration of measures including validity measures as well as other types of assessment that do not solely rely on self-reports. Lastly, the measure of effectiveness for the TAU group was not standardized and did not seem to be sensitive to treatment effects in either group. There were no right or wrong answers and the measure 
had to be scored based on the lead teacher's opinion of what would be ideal parenting responses based on facility curriculum and goals for the parenting program.

\section{Implications}

The purpose of the study was to compare two parent-training interventions, PCIT and a standard facility-based program, conducted in a correctional setting. Preliminary findings suggest that PCIT is more effective than standard parent-training in increasing parent skills and is more acceptable than the standard program, even when conducted in a setting with restrictions requiring substantial modifications to the treatment format. These findings have important implications for the transportability of behavioral parent training programs such as PCIT into real-world settings. Results regarding PCIT's effectiveness at reducing child abuse potential, parenting stress, and increasing parenting-based knowledge are less clear. PCIT conducted in this investigation without specialized facilities or equipment had smaller effects, when compared to studies conducted in university environments or community-based settings in which parents are in physical contact with their children throughout treatment. This study relied largely on teaching parenting skills through active role-play and in-session coding. Numerous barriers to implementing these direct coaching methods were identified (e.g., staff profession, turnover rate, facility guidelines). However, other similar evidence-based behavioral parent training programs, such as Webster-Stratton's The Incredible Years, demonstrate similar effect sizes with community samples and may be more easily transported to the correctional environment.

Numerous topics discussed over the course of treatment were slightly different than what is typically seen with parents who have direct contact with their children (e.g., use of parenting skills during phone conversation or letter writing). Parents may also differ in needed treatment components based on their individual parenting-related characteristics, sentence length, and contact with children. Additional components such as indirect communication strategies and effective ways to 
manage parenting-related stress while parents are not in direct contact with their children may be helpful. Facility parenting programs should vary based on the goal of the intervention and specific parent characteristics. For example, many of the mothers had additional children who were a range of ages. Parenting programs specific to child age are important to address specific age-related difficulties. For example, mothers with older children also discussed parenting difficulties such as talking to youth about substance use and criminality. The age of children of incarcerated parents as well as the presence or absence of behavioral challenges in the children appear to be a major factor for group cohesion and relevancy of material. An average U.S. prison sentence is 3-7 years (U.S. Department of Justice, 2004), and previous findings imply the benefits of offering intervention throughout the course of incarceration. Similar to the current study, parenting programing is commonly offered to inmates based on their estimated release dates (Loper \& Tuerk, 2006). A majority of mothers report ongoing problems, which may need to be addressed earlier, rather than later, in the prison stay (e.g., difficulty in interactions during facility visitation and leaving children following visits). These findings further emphasize the value of additive components such as support groups, child contact programs, and community programs. For example, Eddy (2009) described the utility of additional components such as a parenting support group to balance inmates' needed time to talk and process outside of the components of instruction and skill building.

It is important to note that both treatment programs in this study produced similar results across parenting measures. However, the standard facility program consisted of many of the recommended components of intervention, such as addressing support structures and including multiple behavior management strategies regarding child behaviors. The facility-based program also provided mothers with out-of-session parenting exercises and encouraged parent-child contact. Further examination of active elements in the standard facility-based program may assist in improving current practices. 


\section{Future Clinical Directions}

The implementation of evidence-based practice in real-world settings is an important topic, however many community-based organizations are uninformed of the current empirical literature and research findings. A growing field is developing in implementation science. It is the role of the research community to disseminate findings in a manner that is applicable to community-based organizations to ensure that organizations provide the best services possible for families in their community. Researchers must work with professionals in applied settings to learn and better inform evidence-based practices. The response of correctional personnel to this research was uniformly positive, as they expressed great enthusiasm for examination of facility-based parenting programs designed for incarcerated mothers. Additional partnerships between universities and correctional institutions for the purpose of program evaluation may lead to important knowledge about enhancing parenting programs within prison populations.

Particular to the correctional setting, PCIT was able to be conducted in a format matched to the existing standard program and demonstrated equal to added benefits across measured outcomes. PCIT was cost and time-efficient which is an important consideration for community-based organizations with limited funding resources. Although further examination of PCIT-based training in a correctional facility is needed for clarification of the current findings, this study suggests that correctional facilities who elect to provide a PCIT-based group parenting intervention may wish to incorporate several program modifications not included in the current study: (a) treatment components that may include individual parent training, (b) a parent-child interaction component for families with facility visitation, and (c) reunification services for program graduates at the time of parole, (d) program content directly addressing parental imprisonment and (e) providing program content related to alternative types of parent-child contact. The standard facility program in this 
study includes program content directly addressing imprisonment and alternative types of parentchild contact, but may benefit from the addition of the remaining modifications.

\section{Future Research Directions}

The current study was small in scale, yet its findings suggest the utility of larger-scale longitudinal research studies to explore the impact of parent-training classes on parents during incarceration and following reunification with their children after facility release. The similarities between outcomes of both interventions highlight the importance of pre-post examinations of facility-based programs and adds caution to interpretation of study findings that have not included randomization or a comparison or no treatment control group.

Of particular interest would be a longer term follow-up study that assesses the retention of skills taught in PCIT during parent-child interactions with incarcerated mothers and their children. Chaffin et al. (2004) found that parenting skills predicted reabuse reports for families with a history of child abuse and neglect. A follow-up study examining retained parenting skills and child welfare involvement following reunification would add to this literature. Similarly, examination of whether parenting programs assist in reducing criminal re-offense rates would have broad implications.

In conclusion, the current study provides promising results regarding the use of evidencebased behavioral parent-training programs used in a group format when working with mothers during incarceration. The study also provided important information suggesting that positive outcomes can be obtained following PCIT in settings outside of a university-based lab and without the addition of a one-way mirror, communication device, or a specially constructed room. Finally, the research illuminates many of the methodological issues that need to be addressed to further our knowledge with regard to the potential importance of facility-based parenting programs in cases of maternal incarceration. 


\section{References}

Abidin, R. (1995). Parenting stress index: Professional manual ( $3^{\text {rd }}$ ed.). Lutz, FL: Psychological Assessment Resources, Inc.

American Correctional Association. (1990). The female offender: What does the future hold? Washington, DC: St. Mary's Press.

Anthony, L. G., Anthony, B. J., Glanville, D. N., Naiman, D. Q., Wandersm, C., \& Shaffer, S. (2005). The relationships between parenting stress, parenting behavior and preschoolers' social competence and behavior problems in the classroom. Infant and Child Development, $14,133-154$.

Applegate, B. (2001). Penal austerity: Perceived utility, desert and public attitudes toward prison amenities. American Journal of Criminal Justice, 25, 253-268.

Azar, S. T., \& Wolfe, D. A. (1998). Child abuse and neglect. In E. G. Mash \& R. A. Barkley (Eds.), Behavioral treatment of childhood disorders (2nd ed., pp. 501-544). New York: Guilford.

Auerbach, V., Nixon, R., Forrest, K., Gooley, S., \& Gemke, G. (1999). Group intervention program for oppositional, noncompliant and aggressive preschoolers. Clinical Psychologist, 3, 30-34.

Bagner, D. M., \& Eyeberg. S. M. (2007). Parent-child interaction therapy for disruptive behavior in children with mental retardation: A randomized controlled trial. Journal of Clinical Child and Adolescent Psychology, 36, 418-429.

Bagner, D. M., Fernandez, M. A., \& Eyberg, S. M. (2004). Parent-child interaction therapy and chronic illness: A case study. Journal of Clinical Psychology in Medical Settings, 11, 1-6. 
Bales, W. D., \& Mears, D. P. (2008). Inmate social ties and the transition to society: Does visitation reduce recidivism? Journal of Research in Crime and Delinquency, 45, 287-321.

Barnhill, S. (1991). Three generations at risk. Atlanta, GA: Aid to Imprisoned Mothers.

Bartholomew, N. G., Knight, D. K., Chatham, L. R., \& Simpson, D. D. (2002). Partners in Parenting: A DATAR/FIRST CHOICE treatment manual, Fort Worth, Texas: Texas Christian University.

Baumrind, D. (1967). Child care practices anteceding three patterns of preschool behavior. Genetic Psychology Monographs, 75(1), 43-88.

Baunanch, P. J. (1985). Mothers in prison. New Brunswick, NJ: Transaction Books.

Bavolek, S. J. (1984). Handbook for the Adult-Adolescent Parenting Inventory. Eau Claire, Wisconsin: Family Development Associates, Inc.

Bavolek, S. J. \& Keene, R. G. (1999). Adult-Adolescent Parenting Inventory-AAPI-2:

Administration and development handbook. Park City, UT: Family Development Resources, Inc.

Beck, A. J. (2000). Prisoners in 1999. (Report No. 183476). Washington, DC: U.S. Department of Justice. Bureau of Justice Statistics.

Belknap, J. (2007). The invisible woman: Gender, crime, and justice (3rd Ed.),Belmont, CA: Thomson Wadsworth Publishing Company.

Berkovits, M. D., O’Brien, K. A., Carter, G.C., \& Eyberg, S. M. (2010). Early identification and intervention for behavior problems in primary care: A comparison of two abbreviated versions of Parent-Child Interaction Therapy, Behavior Therapy, 41, 375-387.

Block K. J., \& Potthast, M. J. (1998). Girl scouts beyond bars: Facilitating parent-child contact in correctional settings. Child Welfare League of America, 27, 561-578. 
Bloom, B. \& Owen, B. (1995) Profiling the needs of California's female prisoners: A needs assessment. Washington, DC: National Institute of Corrections.

Bloom, B., \& Steinhart, D. (1993). Why punish the children? A reappraisal of the children of incarcerated mothers in America. San Fransico: National Council on Crime and Delinquency.

Boggs, S. R. (1990, August).Generalization of treatment to the home setting: Direct observation analysis. In. S.M. Eyberg (chair), Parent-child interaction therapy (PCIT) outcome studies: Multiple method assessment. Symposium presented at the meeting of the American Psychological Association, Boston

Boggs, S. R., Eyberg, S. M., Edwards, D. I., Rayfield, A., Jacobs, J., Bagner, D., \& Hood, K. K. (2004). Outcomes of Parent-Child Interaction Therapy. A comparison of treatment completers and study dropouts one to three years later. Child \& Family Behavior Therapy, 26, 1-22.

Bonczar, T. P. (2003). Prevalence of imprisonment in the U.S. population, 1974-2001. Bureau of Justice Statistics Special Report. NCJ 197976.

Borrego, J., Jr., Urquiza, A. J., Rasmussen, R. A., Zebell, N. (1999). Parent-child interaction therapy with a family at high risk for physical abuse. Child Maltreatment, 4, 331-342.

Boudin, K. (1998). Lessons from a mother's program in prison: A psychosocial approach supports women and their children. Women \& Therapy, 21, 103-125.

Boudouris, J. (1985). Prisons and kids: Programs for inmate parents. American Correctional Association, 3-59.

Bousha, D. M., and Twentyman, C. T. (1984). Mother-child interactional style in abuse, neglect, and control groups: Naturalistic observations in the home. Journal of Abnormal Psychology, 93, 106-114. 
Brestan, E. V., Eyberg, S. M., Boggs, S. R., \& Algina, J. (1997). Parent-child interaction therapy: Parent perceptions of untreated siblings. Child \& Family Behavior Therapy, 19, 13-28.

Brestan, E., Jacobs, J., Rayfield, A., \& Eyberg, S. M. (1999). A consumer satisfaction measure for parent-child treatments and its relationship to measures of child behavior change. Behavior Therapy, 30, 17-30.

Brown, M., \& Bloom, B. (2009). Reentry and renegotiating motherhood: Maternal identity and success on parole. Crime \& Delinquency, 55, 313-336.

Browne, D. C. H., (1989). Incarcerated mothers and parenting. Journal of Family Violence, 4, 411-421.

Budd, K. S., Heilman, N. E., Kane, D. (2000). Psychosocial correlates of child abuse potential in multiply disadvantaged adolescent mothers. Child Abuse \& Neglect, 24, 611-625.

Bureau of Justice Statistics. (1994). Women in prison. Washington, DC: U.S.

Capage, L. C., Bennett, G. M., \& McNeil, C. B. (2001). A comparison between African American and Caucasian children referred for treatment of disruptive behavior disorders. Child \& Family Behavior Therapy, 23, 1-14. doi:10.1300/J019v23n01_01

Carlson, J. (2001). Prison nursery 2000: A five-year review of the prison nursery at the Nebraska correctional center for women. Journal of Offender Rehabilitation, 33, 75-97. doi:10.1300/J076v33n03.

Chaffin, M., Silovsky, J. F., Funderburk, B., Valle, L. A., Brestan, E. V., Balachova, T., Jackson, S., Lensgraf, J., \& Bonner, B. L. (2004). Parent-child interaction therapy with physically abusive parents: Efficacy for reducing future abuse reports. Journal of Consulting and Clinical Psychology, 72, 500-510.

Chaffin, M., \& Valle, L. A. (2003). Dynamic predictive validity of the Child Abuse Potential Inventory. Child Abuse and Neglect, 27, 463-482. 
Clement, M. (1993). Parenting in prison: A national survey of programs for incarcerated women. Journal of Offender Rehabilitation, 19, 89-100. doi:10.1300/J076v19n01.

Cohen, J. A. \& Mannarino, A. P. (1993). A treatment model for sexually abused preschoolers. Journal of Interpersonal Violence, 8, 115131.

Crittenden, P. M. (1982). Abusing, neglecting, problematic, and adequate dyads: Differentiating by patterns of interaction. Merrill-Palmer Quarterly, 27, 201-218.

Crittenden, P. M., Ainsworth, M. D. S. (1989). Child maltreatment and attachment theory. In: D Cicchetti and V. Carlson, (Eds.), Child maltreatment: Theory and research on the causes and consequences of child abuse and neglect (pp. 432-463). Cambridge, UK: Cambridge University Press.

Crnic, K., Gaze, C., \& Huffman, C. (2005) Cumulative parenting stress across the preschool period: Relations to maternal parenting and child behavior at age 5. Infant and Child Development, $14,117-132$.

Cunningham, A. (2001). Forgotten families: The impacts of imprisonment. Family Matters, 59,3538.

Datesman, S., \& Cales, G. (1983). I'm still the same mommy: Maintaining the mother/child relationship in prison. The Prison Journal, 63, 142-154.

Devall, E. (2004). Positive parenting for high-risk families. Journal of Family and Consumer Sciences, 96, 22-28.

Dodge, M., \& Pogrebin, M. (2001). Collateral costs of imprisonment for women: Complications of reintegration. The Prison Journal, 81, 42-54.

Eckenrode, J., Laird, M., \& Doris, J. (1993) School performance and disciplinary problems among abused and neglected children. Developmental Psychology, 29, 53-62. 
Eddy J. M., \& Reid, J. B. (2003). The adolescent children of incarcerated parents: A developmental perspective. In J. Travis, \& M. Waul (Eds.), Prisoners once removed: The impact of incarceration on children, families, and communities (pp. 233-258). Washington, DC: Urban Institute Press.

Eddy, J., Martinez, C., Schiffmann, T., Newton, R., Olin, L., Leve, L., \& ... Shortt, J. (2008). Development of a multisystemic parent management training intervention for incarcerated parents, their children and families. Clinical Psychologist, 12, 86-98.

Eddy, B., Powell, M., Szubka, M., McCool, M., \& Kuntz, S. (2001). Challenges in research with incarcerated parents and importance in violence prevention. American Journal of Preventive Medicine, 20, 56-62. doi:10.1016/S0749-3797(00)00273-7.

Eisenstadt, T. H., Eyberg, S. M., McNeil, C. B., Newcomb, K., \& Funderburk, B. (1993). Parentchild interaction therapy with behavior problem children: Relative effectiveness of two stages and overall treatment outcome. Journal of Clinical Child Psychology, 22, 42-51.

Eyberg, S. M. (1988). PCIT: integration of traditional and behavioral concerns. Child and Family Behavior Therapy, 10, 33-46.

Eyberg, S. M. (1999). Parent-Child Interaction Therapy: Integrity Checklists and Session Materials. Retrieved April 2, 2008, from www.pcit.org.

Eyberg, S. M., Dabbs, M., \& Neary, E. M. (2001). Individual child and family-based treatments for Attention Deficit Hyperactivity Disorder. In B. L. Maria (Ed.). Advanced therapy in child neurology (2nd ed.). Houston: Decker.

Eyberg, S. M., Edwards, D., Boggs, S.R., \& Foote, R. (1998). Maintaining the treatment effects of parent training: The role of booster sessions and other maintenance strategies. Clinical Psychology: Science and Practice, 5, 544-554. 
Eyberg, S. M., \& Johnson, S. M. (1974). Multiple assessment of behavior modification with families: Effects of contingency contradicting and order of treated problems. Journal of Consulting and Clinical Psychology, 42, 594-606.

Eyberg, S. M., Lewis, C. A., Butler, A. M., Chase, R., Fussell, R., Nelson, M., Bussing, R., \& Boggs, S. R. (2009). Manual for group Parent-Child Interaction Therapy. University of Florida.

Eyberg, S. M., Nelson, M. M., \& Boggs, S. R. (2008). Evidence-based psychosocial treatments for children and adolescents with disruptive behavior. Journal of Clinical Child \& Adolescent Psychology, 37, 215-237.

Eyberg, S. M., Nelson, M. M., Duke, M., \& Boggs, S. R. (2005). Manual for the Dyadic ParentChild Interaction Coding System Third Edition. University of Florida.

Eyberg, S. M., \& Robinson, E. (1982). Parent-child interaction training: Effects on family functioning. Journal of Clinical Child Psychology, 11, 130-137.

Faul, F., Erdfelder, E., Lang, A. G., \& Buchner, A. (2007). G*Power 3: A flexible statistical power analysis program for the social, behavioral, and biomedical sciences. Behavior Research Methods, 39, 175-191.

Feinman, C. (1994). Women in the criminal justice system $\left(3^{r d}\right.$ Ed.). Westport, CT: Prager.

Ferraro, K. J., \& Moe, A. M. (2003). Mothering, crime, and incarceration. Journal of Contemporary Ethnography, 32. 9-40.

Forsyth, C. J. (2003). Pondering the discourse of prison mamas: A research note. Deviant Behavior, 24, 269-280.

Fogel, C. I., \& Martin, S. L. (1992). The mental health of incarcerated women. Western Journal of Nursing Research, 14, 30-47. 
Foley, K. \& McNeil, C. B. (2010). A comparison of parent-child interaction therapy and treatment as usual with families with a history of child abuse and neglect and intimate partner violence. Manuscript in preparation.

Fricker-Elhai, A., Ruggiero, K., \& Smith, D. (2005). Parent-child interaction therapy with two maltreated siblings in foster care. Clinical Case Studies, 4, 13-39. doi:10.1177/1534650103259671.

Fritsch, T. A., \& Burkhead, J. D. (1981). Behavioral reactions of children to parental absence due to imprisonment. Family Relations, 30, 83-88.

Frodi A. M., \& Lamb, M. E. (1980). Child abusers' responses to infant smiles and cries. Child Development, 51, 238-241.

Fulton, A. M., Murphy, K. R., \& Anderson, S. L. (1991). Increasing adolescent mothers' knowledge of child development: An intervention program. Adolescence, 26, 73-81.

Funderburk, B. W., Eyberg, S. M., Newcomb, K., McNeil, C. B., Hembree-Kigin, T. \& Capage, L. (1998). Parent-child interaction therapy with behavior problem children: Maintenance of treatment effects in the school setting. Child \& Family Behavior Therapy, 20, 17-38.

Gat, I. (2000). Incarcerated mothers: Effects of the Mother/Offspring Life Development Program (MOLD) on recidivism, prosocial moral development, empathy, hope, and parent-child attachment. Lincoln, NE: University of Nebraska.

Gentry, P. M., (2003). Damage to family relationships as a collateral consequence of parental incarceration. Fordham Urban Law Journal, 30, 1671-1684.

Glaze, L. E., \& Maruschak, L. M. (2008). Parents in prison and their minor children. Bureau of Justice Statistics Special Report, NCJ 22984.

Gonzalez, P., Romero, T., \& Cerbana, C. B. (2007). Parent education program for incarcerated mothers in Colorado. Journal of Correctional Education, 58, 357-373. 
Gordon, H. R., \& Weldon, B. (2003). The impact of career and technical education programs on adult offenders: Learning behind bars. The Journal of Correctional Education, 54, 200-209.

Gray, J. P. (2001). Why our drug laws have failed and what we can do about it. Philadeelphia: Temple University Press.

Green, B. L., Miranda J., Daroowalia, A., \& Siddique, J. (2005). Trauma exposure, mental health functioning, and program needs of women in jail. Crime \& Delinquency, 51, 133-151.

Greenfeld, L. A., \& Snell, T. L. (1999). Women offenders. Bureau of Justice Statistics Special Report, Women offenders (No. 175688). Washington, DC: U.S. Department of Justice Office of Justice Programs.

Grella, C. E., \& Greenwell, L. (2006). Parental status and attitudes toward parenting among substance-abusing female offenders. The Prison Journal, 86, 89-113.

Hackman, M., Chaffin, M., Funderburk, B., \& Silovsky, J. F. (2009). Change trajectories for parentchild interaction sequences during parent-child interaction therapy for child physical abuse. Child Abuse \& Neglect, 33, 461-470. doi: 10.1016/j.chiabu.2008.08.003.

Hairston, C. F. (1998). Family ties during imprisonment: Do they influence future criminal activity? Federal Probation, 52, 48-52.

Hairston, C. F. (1991). Family ties during imprisonment: Important to whom and for what? Journal of Offender Rehabilitation, 24, 135-152.

Hairston, C. F., \& Lockett, P. (1985). Parents in prison: A child abuse and neglect prevention strategy. Child Abuse \& Neglect, 9, 471-477.

Halsey, K., Johnson, A., Kaur, S. \& Harland, J. (2004) A World Apart? National Foundation for Evaluation of Family Learning Programmes in Prison. Summary of Key Findings.

Harm, N., Thompson, P., \& Chambers, H. (1998). The effectiveness of parent education for substance abusing women offenders. Alcoholism Treatment Quarterly, 16, 63-77. 
Harrison, K. (1997). Parental training for incarcerated fathers: Effects on attitudes, self-esteem, and children's self-perceptions. Journal of Social Psychology, 137, 588-594.

Hart, B., \& Risley, T. R. (1995). Meaningful differences in the everyday experience of young American children. Baltimore, MD: Paul H. Brookes Publishing Co.

Hayward, R. A., \& DePanfilis, D. (2007). Foster children with an incarcerated parent: Predictors of reunification. Children \& Youth Services Review, 29, 1320-1334.

Herschell, A. D. (2010). Fidelity in the field: Developing infrastructure and fine-tuning measurement. Clinical Pscyhology: Science and Practice, 17, 254-257.

Herschell, A. D., Calzada, E. J., Eyberg, S. M., \& McNeil, C. B. (2002). Parent-child interaction therapy: New directions in research. Cognitive and Behavioral Practice, 9, 9-16.

Hoffman-Plotkin, D., \& Twentyman, C. T. (1984). A multimodal assessment of behavioral and cognitive deficits in abused and neglected preschoolers. Child Development, 55, 794-802.

Hood, K., \& Eyberg, S. M. (2003). Outcomes of parent-child interaction therapy: Mothers' reports on maintenance three to six years after treatment. Journal of Clinical Child and Adolescent Psychology, 32, 419-429.

Holtfreter, K., Reisig, M., \& Morash, M. (2004). The Effects of Economic Marginalization on Recidivism among Women Offenders. Criminology and Public Policy, 185-208.

Houck, K., \& Loper, A. (2002). The relationship of parenting stress to adjustment among mothers in prison. American Journal of Orthopsychiatry, 72, 548-558. doi:10.1037/0002-9432.72.4.548.

Hughes, M. J. \& Harrison-Thompson, J. (2002). Prison parenting programs: A national survey. The Social Policy Journal, 1, 57-74.

Hutchinson, K., Moore, G., Propper, C., \& Mariaskin, A. (2008). Incarcerated women's psychological functioning during pregnancy. Psychology of Women Quarterly, 32, 440-453. doi:10.1111/j.1471-6402.2008.00457.x. 
James, D. J., \& Glaze, L. E. (2006). Mental Health Problems of Prison and Jail Inmates. Bureau of statistics special report. NCJ 213600.

Johnson, E. I., \& Waldfogel, J. (2002). Parental incarceration: Recent trends and implications for child welfare. Social Service Review, 76, 460-479.

Kaminski, J. E., Valle, L. A., Filene, J. H., \& Boyle, C. L. (2008). A meta-analytic review of components associated with parent training program effectiveness. Journal of Abnormal Child Psychology, 36, 567-589.

Kaplan, C., Owens, J., (2004). Parental influences on vulnerability and resilience. In M. Hoghughi \& N. Long, (Eds.), Handbook of parenting: Theory and research for practice (pp. 72-87). London: Sage.

Kassebaum, P. A. (1999). Substance abuse treatment for women offenders, a guide to promising practices. Technical Assistance Publication Series 23, Washington, D. C: Center for Substance Abuse Treatment.

Kauffman, K. (2006). Prison nurseries: New beginnings and second chance. In: R, Immarigeon, (ed.), Women and girls in the criminal justice system: Policy issues and practice strategies. Kington, NJ: Civic Research Institute.

Kauffman Best Practices Project (2004). Closing the quality chasm in child abuse treatment: Identifying and disseminating best practices. The findings of the Kauffman Best Practices Project to help children heal from child abuse. Kaufman foundation.

Kavanaugh, K. A., Yongblade, L., Reid, J. B., \& Fagot, B. L. (1988). Interactions between children and abusive versus control parents. Journal of Clinical Child Psychology, 17, 137-142.

Keiley, M., Howe, T. R., Dodge, K. A., Bates, J. E., \& Pettit, G. S. (2001). The timing of child physical maltreatment: A cross-domain growth analysis of impact on adolescent externalizing and internalizing problems. Development and Psychopathology, 13, 891-912. 
Kelly, M. L., Grace, N., \& Elliot, S. N. (1990). Acceptability of positive and punitive discipline methods: Comparisons among abusive, potentially abusive, and nonabusive parents. Child Abuse and Neglect, 14, 219-226.

Kendall-Tackett, K., \& Becker-Blease, K. (2004). The importance of retrospective findings in child maltreatment research. Child Abuse \& Neglect, 28, 723-727.

Kennon, S. (2003). Developing the parenting skills of incarcerated parents: A program evaluation. Richmond: Virginia Commonwealth University.

Kennon, S. S., Mackintosh, V. H., \& Myers, B. J. (2009). Parenting education for incarcerated mothers. The Journal of Correctional Education, 60, 10-30.

King, D. (2001). Parents, children \& prison: Effects of parental imprisonment on children. Dublin: Centre for Social \& Educational Research, Dublin Institute of Technology.

Kinner, S. A., Alati, R., Najman, J. M., \& Williams, G. M. (2007). Do paternal arrest and imprisonment lead to child behavior problems and substance use? A longitudinal analysis. Journal of Child Psychology and Psychiatry, 48(11), 1148-1156.

Kjellstrand, J. M., \& Eddy, J. (2011). Parental incarceration during childhood, family context, and youth problem behavior across adolescence. Journal of Offender Rehabilitation, 50, 18-36.

Kolko, D. J., Iselin, A. R., \& Gully, K. J. (2011). Evaluation of the sustainability and clinical outcome of alternatives for families: A cognitive-behavioral therapy (AF-CBT) in a child protection center. Child Abuse \& Neglect, 35, 105-116. doi:10.1016/j.chiabu.2010.09.004

Koons, B., Burrow, J., Morash, M., \& Bynum, T. (1997). Expert and offender perceptions of program elements linked to successful outcomes for incarcerated women. Crime \& Delinquency, 43(4), 512-532. 
Lattimore, P. K., Steffey, D. M., \& Visher, C. A. (2010). Prisoner reentry in the first decade of the twenty-first century. Victims \& Offenders, 5(3), 253-267.

doi:10.1080/15564886.2010.485907

Lahey, B. B., Conger, R. D., Atkeson, B. M., \& Treiber, F. A. (1984). Parenting behavior and emotional status of physically abusive mothers. Journal of Consulting and Clinical Psychology, 52, 1062-1071.

Lange, S. (1997). Parent training in corrections: Mission, methods, materials and best practices. Education Resources Information Centre. Accessed: September 11, 2006, from http://eric.ed.gov/ERICWebPortal/Home.portal.

Lee, E. L., Wilsie, C. C., Brestan-Knight, E. (2011). Using parent-child interaction therapy to develop a pre-parent education module. Children and Youth Services Review, 33, 1254-1261.

Loper, A. B. (2006). How do mothers in prison differ from non-mothers? Journal of Child and Family Studies, 15, 83-95. doi:10.1007/s10826-005-9005-x.

Loper, A. B. (2009). Parenting stress, alliance, child contact, and adjustment of imprisoned mothers and fathers. Journal of Offender Rehabilitation, 48(6), 483.

Loper, A. B., \& Tuerk, E. H. (2006). Parenting programs for incarcerated parents: Current research and future direction. Criminal Justice Policy Review, 17, 407-427.

Loper, A. B., \& Tuerk, E. H. (2011). Improving the emotional adjustment and communication patterns of incarcerated mothers: Effectiveness of a prison parenting intervention. Journal of Child And Family Studies, 20, 89-101. doi:10.1007/s10826-010-9381-8.

Maruschak, L. M. (2008). Medical problems of prisoners. Washington, DC: Bureau of Justice Statistics; Retrived from http://www.uip.gov/hjs/pub/html/mpp/mpp.html/related 
Mazumdar, S., Liu, K. S., Houck, P. R., \& Reynolds, C. F., III (1999). Intent-to-treat analysis for longitudinal clinical trials: Coping with the challenge of missing values. Journal of Psychiatric Research, 33, 87-95.

McDiarmid, M. D., Bagner, D. M. (2005). Parent-child interaction therapy for children with disruptive behavior and developmental disabilities. Education and Treatment of Children, $28,130-141$.

McKeown, M. (1993). An evaluative study of the extended visits scheme. Issues in Criminological \& Legal Psychology. 30, 32-40.

McNeil, C. B., Eyberg, S. M., Eisenstadt, T., Newcomb, K., \& Funderburk, B. (1991). Parentchild interaction therapy with behavior problem children: Generalization of treatment effects to the school setting. Journal of Clinical Child Psychology, 20, 140-151.

McNeil, C. B., \& Hembree-Kigin, T. L. (2010). Parent-Child Interaction Therapy. (2 ${ }^{\text {nd }}$ ed) New York: Springer.

McNeil, C. B., Herschell, A. D., Gurwitch, R. H., \& Clemens-Mowrer, L. (2005). Training foster parents in parent-child interaction therapy. Education and Treatment of Children, 28, 182-196.

Miller, K. (2006). The impact of parental incarceration on children: An emerging need for effective interventions. Child and Adolescent Social Work Journal, 23(4), 472-486.

Milner, J. S. (1994) Assessing physical child abuse risk: The child abuse potential inventory. Clinical Psychology Review, 14, 547-583.

Milner, J. S., \& Wimberly, L. (1980). Prediction and explanation of child abuse. Journal of Clinical Psychology, 36, 875-884.

Milner, J. S., Gold, R. G., Ayoub, C., \& Jacewitz, M. M. (1984). Predictive validity of the child abuse potential inventory. Journal of Consulting and Clinical Psychology, 52, 879-884. 
Milner, J. S. (1986). The Child Abuse Potential Inventory: Manual (2 ${ }^{\text {nd }}$ ed.). Webster, NC: Psytec.

Moore, A. R., \& Clement, M. J. (1998). Effects of parenting training for incarcerated mothers. Journal of Offender Rehabilitation, 27, 57-72. doi: 10.1300/J076v27n01_05

Morash, M., Bynum, T. S., \& Koons, B. A. (1998). Women offenders: Programming needs and promising approaches, National Institute of Justice.

Mumola, C. J. (2000). Incarcerated parents and their children. Washington, D.C.: US Department of Justistice Bureau of Justice Statistics.

Mumola, C. J., \& Karberg, J. C. (2006). Drug use and dependence, state and federal prisoners. Washington, D.C.: US Department of Justice Bureau of Justice Statistics.

Muse, D. (1994). Parenting from prison. Mothering, 99-105.

Murray, J., Farrington, D. P., \& Sekol, I. (2012). Children's antisocial behavior, mental health, drug use, and educational performance after parental incarceration: A systematic review and metaanalysis. Psychological Bulletin, 138(2), 175-210. doi:10.1037/a0026407

Nayak, M., \& Milner, J. S. (1998). Neuropsychological functioning: comparison of mothers at highand low- risk for child abuse. Child Abuse \& Neglect, 22, 687-703.

Niec, L. N., Hemme, J. M., Yopp, J., \& Brestan, E. V. (2005). Parent-child interaction therapy: The rewards and challenges of a group format. Cognitive and Behavioral Practice, 12, 113-125.

Nieto, M. (2002). In danger of falling through the cracks: Children of arrested parents. California Research Bureau, California State Library, 1-68.

Nixon, R. D. V. (2001). Changes in hyperactivity and temperament in behaviorally disturbed preschoolers after parent-child interaction therapy (PCIT). Behavior Change, 18, 168176. 
Nixon, R. D. V., Sweeney, L., \& Erickson, D. V. (2004). Parent-Child Interaction Therapy: One-and two-year follow-up of standard and abbreviated treatments for oppositional preschoolers. Journal of Abnormal Child Psychology, 32, 263-271.

Oldershaw, L., Walters, G. C., \& Hall, D. K. (1986). Control strategies and nocompliance in abusive mother-child dyads: An observational study. Child Development, 57, 722-732.

Ortega, S., Beauchemin, A., \& Kaniskan, R. (2008). Building resiliency in families with young children exposed to violence: The Safe Start Initiative pilot study. Best Practices in Mental Health. 4, 48-64.

Palmer, T. (1996). Programmatic and nonprogrammatic aspects of successful intervention. In A Harland (Ed.). Choosing options that work: Defining the demand and evaluating the supply (pp. 131-182). Thousand Oaks, CA: Sage.

Patterson, G.R., (1982). Coercive family process. Eugene, OR: Castalia.

Patterson, G., Crosby, L., \& Vuchinich, S. (1992). Predicting risk for early police arrest. Journal of Quantitative Criminology, 8, 335-355.

Patterson, G., Reid, J., \& Dishon, T., (1992). Antisocial boys. Eugene: OR: Castalia.

Pew Center on the States (2008). One in 100: Behind Bars in America 2008. Retrieved 11 August 2011, from www.pewcenteronthestates.org/

Phillips, S. D. (2008) The Bill of Rights for Children of Incarcerated Parents Technical Assistance Project Contextual Factors. Chicago: University of Illinois, Chicago. Jane Addams College of Social Work.

Pincus, D. B., Eyberg, S. M., \& Choate, M. L. (2005). Adapting parent-child interaction therapy for young children with separation anxiety disorder. Education and Treatment of Children, 28, $163-181$. 
Poehlmann, J. (2005). Representations of attachment relationships in children of incarcerated mothers. Child Development, 76, 679-696. doi: 10.1111/j.1467-8624.2005.00871.x.

Poehlmann, J., Dallaire, D., Loper, A. B., \& Shear, L. D. (2010). Children's contact with their incarcerated parents: Research findings and recommendations. American Psychologist, 65, 575-598. doi: 10.1037/a0020279.

Pollock, J. M. (2002). Parenting programs in women's prisons. Women \& Criminal Justice, 14,131-154. doi: 154.10.1300/JO12v14n01_04.

Porterfield, M. W. (2007, March 16).West Virginia's prison nursery program receives worldwide attention. Beckley Register-Herald.

Quilty, S., Butler, T., \& Levy, M.H. (2005). The magnitude of experience of parental incarceration in Australia. Psychiatry, Psychology and Law, 12, 256-257.

Reid, J. B., Patterson, G. R., \& Snyder, J., (2002). Antisocial behavior in children and adolescents: A developmental analysis and model for intervention. Washington, DC: American Psychological Association.

Rodgers, A. (1998). Multiple sources of stress and parenting behavior. Child and Youth Services Review, 20, 525-546.

Sabol, W. J., \& Couture, H. (2008). Prison inmates at midyear 2007-statistical tables. Washington, D.C.: US Department of Justice Bureau of Justice Statistics. NCJ 221944.

Sabol, W. J., Minton, T. D., \& Harrison, P. M. (2007). Prision and jail inmates at mid-year 2006. Washington, D.C.: US Department of Justice Bureau of Justice Statistics. NCJ 217675.

Sanders, M. R., Cann, W., \& Markie-Dadds, C. (2003). The triple p-positive parenting program: A universal population-level approach to the prevention of child abuse. Child Abuse Review. $12,155-171$. 
Sandifer, J. L. (2008). Evaluating the efficacy of a parenting program for incarcerated mothers. The Prison Journal, 88, 423-445.

Schellenbach, C., Monroe, L., \& Merluzzi, T. (1991). The impact of stress on cognitive components of child abuse potential. Journal of Family Violence, 6, 61-80.

Schmidt, P. (2002). College programs for prisoners, long neglected, win new support. Chronicle of Higher Education, A26-A27.

Schuhmann, E. M., Foote, R., Eyberg, S. M., Boggs, S., \& Algina, J. (1998). Parent-child interaction therapy: Interim report of a randomized trial with short-term maintenance. Journal of Clinical Child Psychology, 27, 34-45.

Shipman, K. L., \& Zeman, J. (1999). Emotional understanding: A comparison of physically maltreating and nonmaltreating mother-child dyads. Journal of Clinical Child Psychology, 28, 407-417.

Showers, J. (1993). Assessing and remedying parenting knowledge among women inmates. Journal of Offender Rehabilitation, 20, 35-46. doi:10.1300/J076v20n01.

Snyder, Z. K., Carlo, T. A., \& Coats Mullins, M. M. (2001). Parenting from prison: An examination of a children's visitation program at a women's correctional facility. Marriage \& Family Review, 32, 33-61.

Snyder-Joy, Z. K., \& Carlo, T. A. (1998). Parenting through prison walls: Incarcerated mothers and children's visitation programs. In S. L. Miller (Ed.), Crime control and women: Feminist implications of criminal justice policy (pp. 130-150). Thousand Oaks, CA: Sage.

Stephen, J. J. (2008). Census of state and federal correctional facilities, 2005. Washington, D.C.: US Department of Justice Bureau of Justice Statistics. NCJ 222182.

Surratt, H. (2003). Parenting attitudes of drug-involved women inmates. The Prison Journal, 83, 206-220. doi:10.1177/0032885503083002006. 
Tarter R. E., Blackson T., Martin C., Loeber R., Moss H. B., (1993). Characteristics and correlates of child discipline practices in substance abuse and normal families. American Journal on Addictions. 2, 18-25.

Tempel, A. B., Wagner, S. W., \& McNeil, C. B. (in press). Behavioral parent training skills and child behavior: The utility of behavioral descriptions and reflections. Child and Family Behavior Therapy.

Thomas, R., Zimmer-Gembeck, M. J. (2007). Behavioral outcomes of parent-child interaction therapy and triple-p positive parenting program: A review and meta-analysis. Journal of Abnormal Child Psychology, 35, 475-495.

Thomas, R., Zimmer-Gembeck, M. J. (2011). Accumulating evidence for parent-child interaction therapy in the prevention of child maltreatment. Child Development, 82, 177-192.

Thompson, P. J., \& Harm, N. J. (1995). Parent education for mothers in prison. Pediatric Nursing, $21,552-556$.

Thompson, P., \& Harm, N. (2000). Parenting from prison: Helping children and mothers. Issues in Comprehensive Pediatric Nursing, 23, 61-81. doi:10.1080/01460860050121402.

Timmer, S. G., Urquiza, A. J., Zebell, N. M., McGrath, J. M. (2005). Parent-child interaction therapy: Application to maltreating parent-child dyads. Child Abuse \& Neglect, 29, 825-842.

Timmer, S. G., Urquiza, A. J., Hershell, A. D., McGrath, J. M., Zebell, N. M., Porter, A. L., \& Vargas, E. C. (2006). Parent-child interaction therapy: Application of an empirically supported treatment to maltreated children in foster care. Child Welfare League of America, 919-939.

Tudball, N. (2000). Doing it hard: A study of the needs of children and families of prisoners in Victoria, Victoria: The Victorian Association for the Care and Resettlement of Offenders (VARCO). 
Tuerk, E. H., \& Loper, A. B. (2006). Contact between incarcerated mothers and their children: Assessing parenting stress. Journal of Offender Rehabilitation, 43, 23-43.

Urquiza, A. J., McNeil, C. B. (1996). Parent-child interaction therapy: An intensive dyadic intervention for physically abusive families. Child Maltreatment, 1, 134-144.

U.S Department of Health and Human Services, Administration of Children, Youth, and Families (2010). Child maltreatment 2008. Washington, DC: U.S. Government Printing Office.

U.S. Department of Justice. (2004). Correctional populations. Washington, DC: Bureau of Justice Statistics.

Webster-Stratton, C. (2001). The incredible years: Parents, teachers, and children training series. Residential Treatment for Children \& Youth, 18, 31-45.

West, H. C. (2010). Prison inmates at midyear 2009-statistical tables. Washington, D.C.: US Department of Justice Bureau of Justice Statistics. NCJ 230113.

Widom, C. (2000). Childhood victimization: Early adversity, later psychopathology. National Institute of Justice Journal,1, 2-9.

Wierzbicki, M., \& Pekarik, G. (1993). A meta-analysis of psychotherapy dropout. Professional Psychology: Research and Practice, 24, 190-195.

Wilczak, G., \& Markstrom, C. (1999). The effects of parent educaton on parental locus of control and satisfaction of incarcerated fathers. International Journal of Offender Therapy and Comparative Criminology, 43, 90-102.

Wilson, K., Gonzalez, P., Romero, T., Henry, K., \& Cerbana, C. (2010). The effectiveness of parent education for incarcerated parents: An evaluation of parenting from prison. Journal of Correctional Education, 61(2), 114-132. 
Wilson, S. R., Rack, J. J., Shi, X., Norris, A. M. (2008). Comparing physically abusive, neglectful, and non-maltreating parents during interactions with their children: A meta-analysis of observational studies. Child Abuse \& Neglect, 32, 897-911.

Wolfe, D. A., Edwards, B., Manion, I., \& Koverola, C. (1988). Early intervention for parents at risk of child abuse and neglect: A preliminary report. Journal of Consulting and Clinical Psychology, 56, 40-47.

Wolfe, D, A. \& Mosk, M, D. (1983) Behavioral comparisons of children from abusive and distressed families. Journal of Consulting and Clinical Psychology, 51(5) 702-8.

Woodward, R. (2003). Families of prisoners: Literature review on issues and difficulties.

Wright, E. M., Salisbury, E. M., \& VanVoorhis, P. (2007). Predicting the prison misconducts of women offenders: The importance of gender-responsive needs. Journal of Contemporary Criminal Justice, 23, 310-340. 
Table 1

An Overview of Studies Evaluating Parenting Programs for Incarcerated Parents

\begin{tabular}{|c|c|c|c|c|}
\hline Author, Date & Participants & Program Summary & $\begin{array}{l}\text { Outcome } \\
\text { Measures }\end{array}$ & Main Findings \\
\hline $\begin{array}{l}\text { Black \& } \\
\text { Potthast, } \\
1998\end{array}$ & 16 females & $\begin{array}{l}\text { Girl Scouts Beyond Bars } \\
\text { "troop meetings" Provided } \\
\text { transportation, focused on } \\
\text { emotional involvement, } \\
\text { development of individual } \\
\text { personalities, and self - } \\
\text { esteem }\end{array}$ & $\begin{array}{l}\text { Hudson Parent- } \\
\text { Child } \\
\text { Contentment Scale } \\
\text { (HP-CCS) at pre- } \\
\text { and posttest } \\
\text { qualitative } \\
\text { assessment }\end{array}$ & $\begin{array}{l}\text { Increased visiting and } \\
\text { improvements in } \\
\text { parent-child } \\
\text { relationship, No } \\
\text { differences in means } \\
\text { of HP-CCS }\end{array}$ \\
\hline $\begin{array}{l}\text { Browne, } \\
1980\end{array}$ & $\begin{array}{l}29 \text { females in } \\
\text { structured } \\
\text { community } \\
\text { treatment } \\
\text { alternative } \\
\text { incarceration }\end{array}$ & $\begin{array}{l}\text { Class met twice a week for } 6 \\
\text { months } \\
\text { Inmates met } 5 \text { days a week } \\
\text { for } 3 \text { months. Focused on } \\
\text { mother's own traumatic } \\
\text { experiences, shame and guilt } \\
\text { about choices, and brief at } \\
\text { separation from children. }\end{array}$ & $\begin{array}{l}\text { Pre- and posttest } \\
\text { using AAPI and } \\
\text { Self-Esteem } \\
\text { Inventory }\end{array}$ & $\begin{array}{l}\text { Significant } \\
\text { differences of self- } \\
\text { esteem. }\end{array}$ \\
\hline Boudin, 1998 & 10 females & $\begin{array}{l}\text { Class met twice a week for } 6 \\
\text { months. } 5 \text { days a week for } 3 \\
\text { months. }\end{array}$ & $\begin{array}{l}\text { No measures } \\
\text { included }\end{array}$ & $\begin{array}{l}\text { Qualitative results } \\
\text { concerning parenting } \\
\text { difficulties }\end{array}$ \\
\hline Carlson, 2001 & $\begin{array}{l}37 \text { females } \\
\text { residing in } \\
\text { prison } \\
\text { nursery, } 18 \\
\text { months }\end{array}$ & $\begin{array}{l}\text { Parenting classes while } \\
\text { caring for child in nursery } \\
\text { program during } 18 \text { months }\end{array}$ & $\begin{array}{l}\text { Institutional } \\
\text { records, follow-up } \\
\text { survey }\end{array}$ & $\begin{array}{l}\text { Reduced misconduct } \\
\text { and recidivism by } \\
\text { participants. Positive } \\
\text { attitude endorsed on } \\
\text { survey. }\end{array}$ \\
\hline Devall, 2004 & $\begin{array}{l}323 \text { males } \\
\text { and females }\end{array}$ & $\begin{array}{l}\text { The program had } 7 \text { different } \\
\text { curriculums with number of } \\
\text { classes ranging from } 9-24 \text {, } \\
\text { for } 2.5 \text { hours once a week. } \\
\text { Topics included } \\
\text { communication and conflict } \\
\text { resolution, family rules, } \\
\text { rewards and punishment, } \\
\text { age-appropriate expectations } \\
\text { and establishing routines. }\end{array}$ & $\begin{array}{l}\text { Pre-post design } \\
\text { AAPI-II, } \\
\text { Nurturing Quiz } \\
\text { (NQ), family } \\
\text { social history } \\
\text { questionnaire }\end{array}$ & $\begin{array}{l}\text { Increase in empathy } \\
\text { and knowledge of } \\
\text { positive discipline } \\
\text { techniques; decrease } \\
\text { in role reversals, } \\
\text { inappropriate } \\
\text { expectations, belief in } \\
\text { corporal punishment } \\
\text { and oppression of } \\
\text { children's } \\
\text { independence }\end{array}$ \\
\hline
\end{tabular}




$\begin{array}{lll}\text { Gat, 2000 } & 21 \text { females } & \text { Mother/Offspring Life } \\ \text { (parenting } & \text { Development (MOLD) } \\ \text { programs), } 4 & \text { curriculum } \\ \text { (controls), } & \\ \text { record review } & \\ \text { of } 117 & \\ \text { recidivists } & \end{array}$

Gonzalez et al., 2007

\section{Harm,}

Thompson, \& Chambers, 1998

Kennon, 2003
191 females

Topics included

Reintegration issues, establishing positive support networks, the school system, and high-risk behavior in children. Plus a skill-based program focusing on strengthening family relationships and promoting positive behaviors. Duration of program was not noted.

104 females

Inmates participated in 15weel program based on Bavolek and Comstock's (1985) Nurturing Parent curriculum/
66 females
Class met for 12 sessions. Targeted self-esteem, communication, legal knowledge, and parenting
Parenting Skills Test, Interpersonal Reactivity Index (IRI), Prosocial

Reasoning

Objective

Measure- Revised

(PROM-R), recidivism records

Pre-post design Study developed questionnaires assessed parenting attitudes before and after intervention.

AAPI and Index of Self-Esteem (ISE) at pre- and posttest interviews.
No significant

differences among inmates on measures or recidivism rates

Increased confidence in parenting skills, value of parenting, and knowledge of parenting needs. No difference found in negative parenting control, parenting attitudes about drugs and alcohol, parental discipline or child independence.

Women with frequent use of drugs or alcohol showed improvement on ISE scores at posttest. Women with histories of victimization showed lower ISE scores at both pre- and posttest than did nonvictimized participants.

$\begin{array}{ll}\text { SEI, Parental } & \text { Increases in positive } \\ \text { Acceptance } & \text { parenting attitudes, } \\ \text { Rejection } & \text { self-esteem, and legal } \\ \text { Questionnaire } & \text { knowledge. No } \\ \text { (PARQ), legal } & \text { increase in amount of } \\ \text { questionnaire, } & \text { communication } \\ \text { communication } & \text { between mothers and } \\ \text { questionnaire, } & \text { children } \\ \text { program } & \\ \text { satisfaction } & \\ \text { survey. } & \end{array}$




\begin{tabular}{|c|c|c|c|c|}
\hline $\begin{array}{l}\text { Loper \& } \\
\text { Tuerk, } 2011\end{array}$ & $\begin{array}{l}106 \text { females } \\
\text { (waitlist/cont } \\
\text { rol ), } 90 \text { (pre- } \\
\text { post } \\
\text { comparison) }\end{array}$ & $\begin{array}{l}8 \text { session, Parenting From } \\
\text { Inside curriculum, Emphasis } \\
\text { on cognitive-behavioral } \\
\text { skills, developmentally } \\
\text { appropriate communication, } \\
\text { using skills across situations, } \\
\text { collaborating with } \\
\text { caregivers, discussing } \\
\text { substance use and behavior } \\
\text { problems with children. }\end{array}$ & $\begin{array}{l}\text { Pre-post design, } \\
\text { randomized design } \\
\text { with waitlist } \\
\text { control group. } \\
\text { (Large drop- out } \\
\text { rates shown in } \\
\text { both groups.) } \\
\text { Parenting Stress } \\
\text { Index-Modified, } \\
\text { Parenting Alliance } \\
\text { Measure, Brief } \\
\text { Symptom } \\
\text { Inventory (BSI) }\end{array}$ & $\begin{array}{l}\text { No significant } \\
\text { difference between } \\
\text { intervention group } \\
\text { and waitlist on } \\
\text { increased parent- } \\
\text { caregiver alliance or } \\
\text { contact. Both groups } \\
\text { decreased in parenting } \\
\text { stress, mental distress } \\
\text { symptoms, and } \\
\text { increased parent- } \\
\text { caregiver alliance and } \\
\text { letter-writing. }\end{array}$ \\
\hline $\begin{array}{l}\text { McKeown, } \\
1993\end{array}$ & $\begin{array}{l}40 \text { females, } \\
49 \text { control } \\
\text { group }\end{array}$ & $\begin{array}{l}\text { Extended visits for } \\
\text { participants and children } \\
\text { during a 4-month period. }\end{array}$ & $\begin{array}{l}\text { Questionnaire, } \\
\text { institutional } \\
\text { records }\end{array}$ & $\begin{array}{l}\text { Positive qualitative } \\
\text { reaction, decrease in } \\
\text { request for medical } \\
\text { treatment. }\end{array}$ \\
\hline
\end{tabular}
Moore \& 20 females, $\quad$ Mothers Inside Loving Kids Clement, $\quad 20$ waitlist/ (MILK) 1998 control
ISE, AAPI, NQ
No differences between groups.

Sandifer, $\quad 90$ females 2008

$\begin{array}{ll}\text { Showers, } & \begin{array}{l}203 \text { females } \\ \text { with control } \\ 1993\end{array} \\ & \text { group }\end{array}$

12-week, 3 hours per day, twice weekly, curriculumbased with interactive component, topics included Family and child development, discipline, difficult topics, personal growth and child abuse.

Class met 1.5 hours per week, 10 weeks, Modified STEP curriculum
Pre-post design, AAPI-II, Parent-Child Relationships Inventory (PCRI)

Pre-post design, child behavior management survey
Increase in parenting knowledge, skills, and understanding of child needs of completers. No increase in satisfaction of being a parent or communication

Increase on behavior management questionnaire and frequency of letters received from children, and childfocused communication for treatment group No group differences in perceptions of child well-being or concern about child.

\section{Snyder-Joy \& 31 females, Carlo,1998 27 waitlist control}

Visitation experiences enhanced with volunteers providing special activities and child-friendly visitation area. 


$\begin{array}{lll}\text { Surratt, } 200359 \text { females } & \begin{array}{l}\text { Parenting component of } \\ \text { substance-abuse treatment } \\ \text { program }\end{array}\end{array}$

Thompson \& 104 females

Harm, 2000
AAPI-II

Lower levels of Belief in Corporal Punishment for intervention completers

AAPI and ISE at pre- and posttest.
ISE for mothers who had at least some visits from children or frequent letters improved, Improvements for total group on the AAPI were found in expectations, belief in corporal punishment, and parent-child roles. 
Table 2

Difference between Standard Programs and Facility Adaptations

\begin{tabular}{|c|c|c|c|c|}
\hline & \multicolumn{2}{|c|}{ PCIT } & \multicolumn{2}{|c|}{ Partnerships in Parenting } \\
\hline Program & Standard & Adapted & Standard & Adapted \\
\hline Sessions & $13-16$ & 7 & 8 & 7 \\
\hline Session Length & $1-1.5$ hours & 1.5 hours & 2 hours & 1.5 hours \\
\hline Delivery & $\begin{array}{l}\text { Individual- } \\
\text { Family }\end{array}$ & Group & Group & Group \\
\hline Instructor & $\begin{array}{l}1 \text { Lead } \\
\text { therapist, } \\
\text { Optional } \\
\text { cotherapist }\end{array}$ & $\begin{array}{l}1 \text { Instructor } \\
1 \text { Research assistant, } \\
\text { involved in DPICs } \\
\text { Coding }\end{array}$ & $\begin{array}{l}1 \text { Instructor, } \\
\text { Optional } \\
\text { assistants }\end{array}$ & $\begin{array}{l}1 \text { Instructor } \\
1-2 \text { Inmate } \\
\text { assistants, who are } \\
\text { parenting class } \\
\text { graduates }\end{array}$ \\
\hline $\begin{array}{l}\text { Mastery } \\
\text { Requirements }\end{array}$ & Yes & No & No & No \\
\hline $\begin{array}{l}\text { Child In-session } \\
\text { Involvement }\end{array}$ & Yes & No & No & No \\
\hline $\begin{array}{l}\text { Out-of-Session } \\
\text { Work }\end{array}$ & Yes & Yes & Yes & Yes \\
\hline
\end{tabular}


Table 3

Demographic Information as Totals and Percentages across Group and Time

\begin{tabular}{llll}
\hline Group & $\begin{array}{l}\text { Overall } \\
n(\%)\end{array}$ & $\begin{array}{l}\text { PCIT } \\
n(\%)\end{array}$ & $\begin{array}{l}\text { TAU } \\
n(\%)\end{array}$ \\
\hline Total Participants & $82(100 \%)$ & & \\
Pre-treatment & $82(100 \%)$ & $42(51.2 \%)$ & $40(48.7 \%)$ \\
Post-treatment & $69(84.1 \%)$ & $39(51.3 \%)$ & $30(49.1 \%)$ \\
Follow-up & $64(78.0 \%)$ & $35(55.0 \%)$ & $29(35.4 \%)$
\end{tabular}

Ethnicity

White, non-Hispanic

African-American

biracial

\section{Marital Status}

Single, never married

Divorced/Separated

Married

Unmarried Partners

Widowed

Unknown

Education

$$
\begin{aligned}
& 1^{\text {st }}-8^{\text {th }} \text { grade } \\
& 9^{\text {th }}-11^{\text {th }} \text { grade } \\
& 12^{\text {th }} \text { grade }
\end{aligned}
$$

Vocational school or some college

$\begin{array}{lll}76(92.6 \%) & 41(97.6 \%) & 34(85.0 \%) \\ 3(3.7 \%) & 1(2.4 \%) & 2(5.0 \%) \\ 3(3.7 \%) & 0(0 \%) & 3(7.5 \%)\end{array}$

$30(36.6 \%) \quad 15(59.5 \%) \quad 15(37.5 \%)$

$30(36.6 \%) \quad 17(40.5 \%) \quad 13(32.5 \%)$

$9(11.0 \%) \quad 5(11.9 \%) \quad 4(10.0 \%)$

$7(8.5 \%) \quad 4(9.5 \%) \quad 3(7.14 \%)$

$4(4.9 \%) \quad 0(0 \%) \quad 4(10.0 \%)$

$2(2.4 \%) \quad 1(2.4 \%) \quad 1(2.5 \%)$

$\begin{array}{lll}4(4.9 \%) & 2(4.8 \%) & 2(5.0 \%) \\ 48(58.5 \%) & 28(66.7 \%) & 20(50.0 \%) \\ 19(23.2 \%) & 9(21.4 \%) & 10(25.0 \%) \\ 8(9.8 \%) & 1(2.4 \%) & 7(17.5 \%)\end{array}$


Unreported

Employment Status

Unemployed/ Disability

Employed Full Time

Employed Full Time

Unknown

Annual Household Income at Incarceration

Unknown

Under $\$ 15,000$

$\$ 15,001-\$ 25,000$

$\$ 25,001-\$ 40,000$

Over $\$ 40,000$

Total Children

One- Two

Three-Four

Five or more

Child Now Living With

Grandmother

Father

Another family member

Nonfamily member, chosen by courts

Other
$3(3.7 \%)$

$2(4.8 \%)$

$1(2.5 \%)$

$46(56.1 \%) \quad 27(64.3 \%) \quad 19(47.5 \%)$

$19(23.2 \%) \quad 5(11.9 \%) \quad 14(35.0 \%)$

$10(12.2 \%) \quad 8(19.0 \%) \quad 2(5.0 \%)$

$7(8.5 \%) \quad 2(4.8 \%) \quad 5(12.5 \%)$
$56(68.3 \%) \quad 29(69.0 \%) \quad 27(67.5 \%)$

$20(24.4 \%) \quad 10(23.8 \%) \quad 10(25.0 \%)$

$6(7.3 \%) \quad 3(7.1 \%) \quad 3(7.5 \%)$

$46(47.9 \%) \quad 25(50.0 \%) \quad 21(45.7 \%)$

$25(26.0 \%) \quad 13(26.0 \%) \quad 12(26.1 \%)$

$10(10.4 \%) \quad 2(4.0 \%) \quad 8(17.4 \%)$

$8(8.3 \%) \quad 6(12.0 \%) \quad 2(4.3 \%)$

$7(7.3 \%) \quad 4(8.0 \%) \quad 3(6.5 \%)$ 
Table 4

Participant-Child Contact Information

\begin{tabular}{|c|c|c|c|}
\hline & $\begin{array}{c}\text { Overall } \\
\%(n)\end{array}$ & $\begin{array}{l}\text { PCIT } \\
\%(n)\end{array}$ & $\begin{array}{l}\text { TAU } \\
\%(n)\end{array}$ \\
\hline \multicolumn{4}{|c|}{ Primary Caregiver for Children Outside } \\
\hline Yes & $71.0 \%(58)$ & $66.7 \%(28)$ & $75.0 \%(30)$ \\
\hline No & $29.3 \%(24)$ & $33.3 \%(14)$ & $25.0 \%(10)$ \\
\hline \multicolumn{4}{|l|}{ Saw Child on Outside } \\
\hline Every day & $70.7 \%(58)$ & $64.3 \%(27)$ & $77.6 \%(31)$ \\
\hline Several times a week & $12.2 \%(10)$ & $9.5 \%(4)$ & $15.0 \%(6)$ \\
\hline Once a week & $2.4 \%(2)$ & $4.8 \%(2)$ & $0 \%(0)$ \\
\hline At least once per month & $6.1 \%(5)$ & $9.5 \%(4)$ & $2.5 \%(1)$ \\
\hline At least once per year & $2.5 \%(2)$ & $2.5 \%(2)$ & $0 \%(0)$ \\
\hline Less than once per year & $6.2 \%(5)$ & $3.7 \%(3)$ & $5.0 \%(2)$ \\
\hline \multicolumn{4}{|c|}{ Talked about Child in Last Six Weeks } \\
\hline Every day & $64.6 \%(53)$ & $61.9 \%(26)$ & $67.5 \%(27)$ \\
\hline Several times a week & $28.4 \%(23)$ & $31.0 \%(13)$ & $25.0 \%(10)$ \\
\hline Once a week & $3.7 \%(3)$ & $2.4 \%(1)$ & $5.0 \%(2)$ \\
\hline Less than once a week & $1.2 \%(1)$ & $2.4 \%(1)$ & $0 \%(0)$ \\
\hline Once a month & $1.2 \%(1)$ & $0 \%(0)$ & $2.5 \%(1)$ \\
\hline Less than once a month & $1.2 \%(1)$ & $2.4 \%(1)$ & $0 \%(0)$ \\
\hline \multicolumn{4}{|c|}{ Wrote Letter to Child in Last Six Weeks } \\
\hline Every day & $3.7 \%(3)$ & $0 \%(0)$ & $7.5 \%(3)$ \\
\hline Several times a week & $14.6 \%(12)$ & $19.0 \%(8)$ & $10.0 \%(4)$ \\
\hline Once a week & $39.0 \%(32)$ & $40.5 \%(17)$ & $37.5 \%(15)$ \\
\hline Less than once a week & $6.1 \%(5)$ & $2.4 \%(1)$ & $10.0 \%(4)$ \\
\hline Once a month & $20.7 \%(17)$ & $19.0 \%(8)$ & $22.5 \%(9)$ \\
\hline No such contact & $15.9 \%(13)$ & $19.0 \%(8)$ & $12.5 \%(5)$ \\
\hline \multicolumn{4}{|c|}{ Phone Call with Child in Last Six Weeks } \\
\hline Every day & $3.7 \%(3)$ & $4.8 \%(2)$ & $2.5 \%(1)$ \\
\hline Several times a week & $26.8 \%(22)$ & $21.4 \%(9)$ & $33.0 \%(13)$ \\
\hline Once a week & $18.3 \%(15)$ & $21.4 \%(9)$ & $15.0 \%(6)$ \\
\hline Less than once a week & $3.7 \%(3)$ & $2.4 \%(1)$ & $5.0 \%(2)$ \\
\hline
\end{tabular}


Once a month

No such contact

Facility Visitation with Child in Last Six

Weeks

5-6 weeks

3-4 weeks

2 weeks

1 week

No such contact

$\begin{array}{lll}4.9 \%(4) & 4.8 \%(2) & 5.0 \%(2) \\ 42.7 \%(35) & 45.2 \%(19) & 40.0 \%(16)\end{array}$

$3.7 \%(3) \quad 2.4 \%(1) \quad 5.0 \%(2)$

$3.7 \%$ (3) $\quad 4.8 \%(2) \quad 2.5 \%(1)$

$3.7 \%(3) \quad 2.4 \%(1) \quad 5.0 \%(2)$

$12.2 \%(10) \quad 9.5 \%(4) \quad 15.0 \%(6)$

$76.8 \%(63) \quad 81.0 \%(34) \quad 72.5 \%(29)$ 
Table 5

Mean scores on CAP Subscales across Group and Time

\begin{tabular}{|c|c|c|c|}
\hline Subscale & $\begin{array}{l}\text { Overall } \\
M(S D)\end{array}$ & $\begin{array}{l}\text { PCIT } \\
M(S D)\end{array}$ & $\begin{array}{l}\text { TAU } \\
M(S D)\end{array}$ \\
\hline \multicolumn{4}{|c|}{$\begin{array}{l}\text { CAP Abuse scale (normative mean }=91 ; \\
\text { signal detection cut-off }=166 \text { ) }\end{array}$} \\
\hline Pre & $139.5(87.6)$ & $147.3(86.3)$ & $131.5(89.2)$ \\
\hline Post & $125.1(85.4)$ & $121.6(78.9)$ & $129.5(94.1)$ \\
\hline Follow-up & $115.9(87.9)$ & $113.0(77.6)$ & $119.2(99.5)$ \\
\hline \multicolumn{4}{|c|}{ CAP Rigidity scale (normative mean $=10$ ) } \\
\hline Pre & $12.1(11.0)$ & $11.8(10.7)$ & $12.5(11.5)$ \\
\hline Post & $10.9(10.6)$ & $10.0(10.3)$ & $11.9(11.0)$ \\
\hline Follow-up & $10.3(10.7)$ & $9.6(10.3)$ & $11.0(11.2)$ \\
\hline \multicolumn{4}{|c|}{ CAP Distress scale (normative mean $=58$ ) } \\
\hline Pre & $88.5(67.56)$ & $92.4(62.4)$ & $84.3(73.3)$ \\
\hline Post & $77.1(67.8)$ & $72.3(62.5)$ & $83.5(74.7)$ \\
\hline Follow-up & $69.9(66.7)$ & $65.8(57.4)$ & $74.4(76.4)$ \\
\hline \multicolumn{4}{|l|}{ CAP Loneliness scale } \\
\hline Pre & $7.1(5.23)$ & $7.7(4.1)$ & $6.38(6.3)$ \\
\hline Post & $6.5(4.6)$ & $6.5(4.5)$ & $6.58(4.7)$ \\
\hline Follow-up & $6.0(4.7)$ & $5.8(3.9)$ & $6.25(5.4)$ \\
\hline \multicolumn{4}{|c|}{$\begin{array}{l}\text { CAP Problems with Child scale (normative } \\
\text { mean }=2.8 \text { ) }\end{array}$} \\
\hline Pre & $2.6(4.0)$ & $2.6(3.8)$ & $2.6(4.2)$ \\
\hline Post & $1.7(3.3)$ & $2.2(3.7)$ & $1.0(2.8)$ \\
\hline Follow-up & $1.5(3.4)$ & $1.7(3.0)$ & $1.4(3.8)$ \\
\hline
\end{tabular}


Table 6

Mean Positive Mastery Skills during Child-Directed Interaction across Group and Time

\begin{tabular}{llcc}
\hline & \multicolumn{1}{c}{$\begin{array}{c}\text { Pre-treatment } \\
M(S D)\end{array}$} & $\begin{array}{c}\text { Post-treatment } \\
M(S D)\end{array}$ & $\begin{array}{c}\text { Follow-up } \\
M(S D)\end{array}$ \\
\hline $\begin{array}{l}\text { Parent-Child Interaction Therapy } \\
(\mathrm{n}=39)\end{array}$ & $.8(.8)$ & $11.3(9.1)$ & $10.4(7.6)$ \\
Treatment as Usual $(\mathrm{n}=29)$ & $.6(.7)$ & $.8(1.3)$ & $.4(.7)$ \\
\hline
\end{tabular}


Table 7

Negative Mastery Skills during Child-Directed Interaction

\begin{tabular}{llcc}
\hline & \multicolumn{1}{c}{$\begin{array}{c}\text { Pre-treatment } \\
M(S D)\end{array}$} & $\begin{array}{c}\text { Post-treatment } \\
M(S D)\end{array}$ & $\begin{array}{c}\text { Follow-up } \\
M(S D)\end{array}$ \\
\hline $\begin{array}{l}\text { Parent-Child Interaction Therapy } \\
(\mathrm{n}=39)\end{array}$ & $15.9(9.1)$ & $9.3(8.1)$ & $8.3(5.9)$ \\
$\begin{array}{l}\text { Treatment as Usual (n=29) } \\
\text { 14 }\end{array}$ & $14.2(8.7)$ & $18.8(14.0)$ & $16.7(12.9)$ \\
\hline
\end{tabular}


Table 8

Mean Percentage of Effective Command Sequences during Parent-Directed Interaction

\begin{tabular}{lllc}
\hline & \multicolumn{1}{c}{$\begin{array}{c}\text { Pre-treatment } \\
M(S D)\end{array}$} & $\begin{array}{c}\text { Post-treatment } \\
M(S D)\end{array}$ & $\begin{array}{c}\text { Follow-up } \\
M(S D)\end{array}$ \\
\hline $\begin{array}{l}\text { Parent-Child Interaction Therapy } \\
(\mathrm{n}=39)\end{array}$ & $0.0(0.0)$ & $9.6(18.3)$ & $6.7(17.9)$ \\
Treatment as Usual (n=29) & $0.0(0.0)$ & $1.4(6.3)$ & $1.6(4.5)$ \\
\hline
\end{tabular}


Table 9

Mean Percentage of Compliance-Contingent Labeled Praise during Parent-Directed Interaction across Group and Time

\begin{tabular}{llll}
\hline & \multicolumn{1}{c}{$\begin{array}{c}\text { Pre-treatment } \\
M(S D)\end{array}$} & $\begin{array}{c}\text { Post-treatment } \\
M(S D)\end{array}$ & $\begin{array}{c}\text { Follow-up } \\
M(S D)\end{array}$ \\
\hline $\begin{array}{l}\text { Parent-Child Interaction Therapy } \\
(\mathrm{n}=39)\end{array}$ & $1.1(4.1)$ & $28.9(36.5)$ & $45.4(63.4)$ \\
Treatment as Usual (n=29) & $2.7(7.0)$ & $6.9(3.7)$ & $7.1(4.7)$ \\
\hline
\end{tabular}


Table 10

Mean Scores on AAPI-II Inappropriate Expectations across Group and Time

\begin{tabular}{llcc}
\hline & \multicolumn{1}{c}{$\begin{array}{c}\text { Pre-treatment } \\
M(S D)\end{array}$} & $\begin{array}{c}\text { Post-treatment } \\
M(S D)\end{array}$ & $\begin{array}{c}\text { Follow-up } \\
M(S D)\end{array}$ \\
\hline $\begin{array}{l}\text { Parent-Child Interaction Therapy } \\
(\mathrm{n}=41)\end{array}$ & $19.7(5.1)$ & $20.9(3.0)$ & $22.0(3.5)$ \\
Treatment as Usual $(\mathrm{n}=32)$ & $20.6(2.9)$ & $22.7(3.8)$ & $23.0(4.2)$
\end{tabular}

Note. Higher scores indicate more appropriate expectations of child development. 
Table 11

Mean Scores of PIP Knowledge of Parenting Topics

\begin{tabular}{llcc}
\hline & $\begin{array}{c}\text { Pre-treatment } \\
M(S D)\end{array}$ & $\begin{array}{c}\text { Post-treatment } \\
M(S D)\end{array}$ & $\begin{array}{c}\text { Follow-up } \\
M(S D)\end{array}$ \\
\hline $\begin{array}{l}\text { Parent-Child Interaction Therapy }(\mathrm{n} \\
=41)\end{array}$ & $165.4(50.0)$ & $147.1(47.8)$ & $139.8(38.2)$ \\
Treatment as Usual $(\mathrm{n}=32)$ & $144.2(43.8)$ & $138.8(68.1)$ & $146.5(66.8)$
\end{tabular}

Note. Scores calculated based on each item score difference from lead teacher's rated ideal 
Table 12

Mean Scores of PSI Total Stress across Group and Time

\begin{tabular}{lccc}
\hline & $\begin{array}{c}\text { Pre-treatment } \\
M(S D)\end{array}$ & $\begin{array}{c}\text { Post-treatment } \\
M(S D)\end{array}$ & $\begin{array}{c}\text { Follow-up } \\
M(S D)\end{array}$ \\
\hline $\begin{array}{l}\text { Parent-Child Interaction Therapy } \\
(\mathrm{n}=41)\end{array}$ & $228.2(29.6)$ & $219.9(31.8)$ & $215.1(38.2)$ \\
Treatment as Usual (n=32) & $220.4(37.8)$ & $214.1(48.2)$ & $212.9(50.7)$ \\
\hline
\end{tabular}


Table 13

Mean Scores on PSI Competency-Related Stress across Group and Time

\begin{tabular}{llcc}
\hline & \multicolumn{1}{c}{$\begin{array}{c}\text { Pre-treatment } \\
M(S D)\end{array}$} & $\begin{array}{c}\text { Post-treatment } \\
M(S D)\end{array}$ & $\begin{array}{c}\text { Follow-up } \\
M(S D)\end{array}$ \\
\hline $\begin{array}{l}\text { Parent-Child Interaction Therapy } \\
(\mathrm{n}=41)\end{array}$ & $35.7(8.5)$ & $32.0(6.7)$ & $31.2(6.5)$ \\
Treatment as Usual (n=32) & $30.5(7.7)$ & $29.5(7.8)$ & $29.1(8.6)$ \\
\hline
\end{tabular}


Table 14

Child Abuse Potential Inventory Signal -Detection Cutoff with and without Elevated Lie Scales

\begin{tabular}{|c|c|c|c|}
\hline Group & $\mathrm{N}$ & Below & Above \\
\hline \multicolumn{4}{|c|}{ Elevated Lie Scores Included } \\
\hline \multicolumn{4}{|l|}{ Overall } \\
\hline Pre & 82 & $67 \%(55)$ & $33 \%(27)$ \\
\hline Post & 70 & $70 \%(49)$ & $30 \%(21)$ \\
\hline Follow-up & 59 & $75 \%(44)$ & $25 \%(15)$ \\
\hline \multicolumn{4}{|l|}{ PCIT } \\
\hline Pre & 42 & $67 \%(28)$ & $33 \%(14)$ \\
\hline Post & 39 & $74 \%(29)$ & $26 \%(10)$ \\
\hline Follow-up & 31 & $81 \%(25)$ & $19 \%(6)$ \\
\hline \multicolumn{4}{|l|}{ TAU } \\
\hline Pre & 40 & $68 \%(27)$ & $33 \%(13)$ \\
\hline Post & 31 & $65 \%(20)$ & $35 \%(11)$ \\
\hline Follow-up & 28 & $68 \%(19)$ & $32 \%(9)$ \\
\hline \multicolumn{4}{|c|}{ Elevated Lie Scores Removed } \\
\hline \multicolumn{4}{|l|}{ Overall } \\
\hline Pre & 61 & $59 \%(36)$ & $41 \%(25)$ \\
\hline Post & 56 & $66 \%(37)$ & $32 \%(18)$ \\
\hline Follow-up & 46 & $70 \%(32)$ & $30 \%(14)$ \\
\hline \multicolumn{4}{|l|}{ PCIT } \\
\hline Pre & 33 & $58 \%(19)$ & $42 \%(14)$ \\
\hline Post & 31 & $74 \%(23)$ & $26 \%(8)$ \\
\hline Follow-up & 24 & $79 \%$ (19) & $21 \%(5)$ \\
\hline \multicolumn{4}{|l|}{ TAU } \\
\hline Pre & 28 & $61 \%(17)$ & $39 \%(11)$ \\
\hline Post & 24 & $58 \%(14)$ & $42 \%(10)$ \\
\hline Follow-up & 22 & $59 \%(13)$ & $41 \%(9)$ \\
\hline
\end{tabular}

Note. Scores falling above and below the Abuse scale signal detection cutoff of 166. 
Table 15

Means Scores on CAP Abuse Score across Group and Time

\begin{tabular}{llcc}
\hline & $\begin{array}{c}\text { Pre-treatment } \\
M(S D)\end{array}$ & $\begin{array}{c}\text { Post-treatment } \\
M(S D)\end{array}$ & $\begin{array}{c}\text { Follow-up } \\
M(S D)\end{array}$ \\
\hline $\begin{array}{l}\text { Parent-Child Interaction Therapy } \\
(\mathrm{n}=41)\end{array}$ & $145.0(85.8)$ & $118.8(77.4)$ & $109.1(79.5)$ \\
Treatment as Usual $(\mathrm{n}=32)$ & $136.3(96.9)$ & $127.7(95.8)$ & $125.1(104.5)$ \\
\hline
\end{tabular}


Table 16

Mean Scores on AAPI-II Lack of Empathetic Regard across Group and Time

\begin{tabular}{llcc}
\hline & $\begin{array}{c}\text { Pre-treatment } \\
M(S D)\end{array}$ & $\begin{array}{c}\text { Post-treatment } \\
M(S D)\end{array}$ & $\begin{array}{c}\text { Follow-up } \\
M(S D)\end{array}$ \\
\hline $\begin{array}{l}\text { Parent-Child Interaction Therapy } \\
(\mathrm{n}=41)\end{array}$ & $40.4(4.4)$ & $43.9(3.8)$ & $44.0(4.2)$ \\
Treatment as Usual $(\mathrm{n}=32)$ & $40.7(4.0)$ & $43.9(5.3)$ & $43.6(5.0)$ \\
\hline
\end{tabular}

Note. Higher scores indicate more empathetic regard. 
Table 17

Mean scores on AAPI-II Belief in Corporal Punishment across Group and Time

\begin{tabular}{llcc}
\hline & \multicolumn{1}{c}{$\begin{array}{c}\text { Pre-treatment } \\
M(S D)\end{array}$} & $\begin{array}{c}\text { Post-treatment } \\
M(S D)\end{array}$ & $\begin{array}{c}\text { Follow-up } \\
M(S D)\end{array}$ \\
\hline $\begin{array}{l}\text { Parent-Child Interaction Therapy } \\
(\mathrm{n}=41)\end{array}$ & $39.5(10.2)$ & $43.6(5.5)$ & $44.0(5.6)$ \\
Treatment as Usual $(\mathrm{n}=32)$ & $43.7(8.9)$ & $43.1(8.2)$ & $43.4(7.7)$ \\
\hline
\end{tabular}

Note. Higher scores indicate greater endorsement of alternative parenting techniques. 
Table 18

Mean Scores of TAI Treatment Acceptability across Group and Time

$\begin{array}{cc}\text { Post-treatment } & \text { Follow-up } \\ M(S D) & M(S D)\end{array}$

Parent-Child Interaction Therapy $(n=42)$

$38.4(4.6)$

$38.1(5.1)$

Treatment as Usual $(\mathrm{n}=31)$

$35.4(6.1)$

$34.8(7.4)$ 
Appendix A: Dissertation Wave Diagram 


\section{Dissertation Wave Diagram}

Wave Pre=30

Wave 1

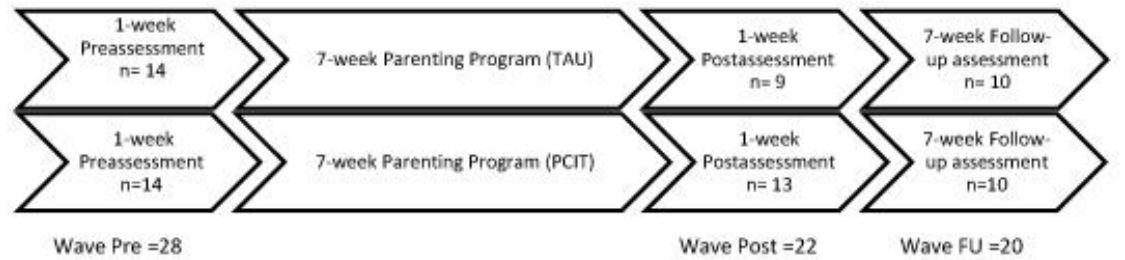

Wave 2

Wave Pre =24

Wave 3 
Appendix B: Treatment as Usual Treatment Description 


\section{Expectations and child development.}

During Class 1, participants are encouraged to think about current parenting concerns and challenges, their goals and expectations for the group, and the strengths and skills that they may contribute to the class. Class two emphasizes child development, common parenting issues and guidance strategies at different developmental stages, and parental expectations.

\section{Communication.}

In Class 3 and 4, family communication is addressed through the teaching of active listening and building understanding. Specific techniques for conveying acceptance and emotional support during listening and speaking are discussed. For example, "I-Messages" are introduced as a strategy for communicating clearly about feelings and for setting limits and making requests.

\section{Child behavior and discipline.}

In Classes 5 and 6, child behavior and sensible discipline are emphasized. Participants are introduced to strategies for increasing desired child behaviors through the use of praise, reinforcement, setting limits, redirection, and modeling. Ineffective methods of handling misbehavior and communication skills for providing child guidance are also discussed. Further focus is given to techniques for effective and fair discipline (e.g., ignoring, timeout, and natural and logical consequences). Lastly, participants are taught the reasons for children's misbehavior, common discipline problems, and recommended solutions.

\section{Self-care for parents.}

Class 7 acknowledges parental stress, insecurity, and low sense of self-esteem experienced by parents who feel overwhelmed by parenting responsibilities. Participant self-care is promoted, and participants are asked to pay attention to the impact of not caring for themselves. Specifically, assertiveness, affirmations, time management, and other strategies for dealing with negative "selftalk" are discussed. 


\section{Problem-solving.}

Class 8 emphasizes problem-solving, planning, and encouraging resilience in children. Parents are introduced to a problem-solving model and are taught to use this model in future parenting challenges. Class 8 is designed to prepare parents for generalizing class information to real-life situations.

\section{Extra meetings (optional component).}

This curriculum further allows the option of holding extra class meetings to expand the topics covered in the structured sessions. Suggestions such as showing "trigger" films with sequential discussion of parenting situations and responses; providing "hands-on" directions for specific parenting tips and techniques (e.g., construct incentive charts or games for encouraging positive behaviors); teach parents how to organize and hold family meetings; role-play and practice problem-solving and communication skills; and discussing actual use of parenting skills with children out of session.

\section{Modeling and role play (optional component).}

Group instructors are encouraged to model appropriate communication skills and guidance techniques. Role play is also used extensively in the structured sessions to help participants practice new skills and become comfortable using these skills. Parents are not required to participate in role play if they feel uncomfortable and may discontinue role plays at any time. 
Appendix C: Treatment as Usual Outline of Session Material 
NAME:

Date Ended:

\section{Partnerships in Parenting Outline of Session Material}

1. Orientation Packet

2. 3 Video Series - Successful Parenting

A. Lecture of Self Esteem and how to bolster it in our children

I. Video 1-"Self-Esteem is the Key"

ii. Personal Plan (Graphic Organizer)

B. Lecture of Communication (Verbal/Nonverbal)

I. Video 2 "Communication is Crucial"

II. Personal Plan (Graphic Organizer)

III. Role Play

C. Lecture on Discipline - Discipline vs. Punishment

I. Positive and negative reinforcement

II. Behavior Modification / Target Behaviors

III. Video 3 "Discipline Makes a Difference"

IV. Personal Plan (Graphic Organizer)

V. Discipline vs. Punishment - Page 45 in Parenting Booklet

3. Family Origins and Roles (Pages 1-9 in Parenting Booklet)

A. Family Tree (exercise)

4. Family Rules and Responsibilities (Pages 38-44 in Parenting Booklet)

5. Domestic Violence and Children

A. Child Abuse Quiz 
B. Video: Domestic Violence \& Children - Films for the Humanities \& Science

C. The Developmental Impact of Trauma --- Power Point

6. Developmental Milestones - Power Point

7. Your Present Family \& the Ripple Effect (Pages 28-33 in Parenting Booklet)

A. Video: Family Reunification Video: Reuniting with Family \& Exercise

B. Video: Family Reunification Video: Forgiveness \& Exercise

8. Writing Assignment - 3 Pages

A. Write On: How have I, or will I deal with forgiveness with:

1. My Children 2. Others 3. Myself

B. Who am I Now? (1 page front and back)

9. A Work in Progress \& Positive Self-Talk (Pages 22-27 in Parenting Booklet)

A. Video: Parenting From Prison: What does it mean to be a Parent? Exercise

B. Video: Parenting From Prison: Rights \& Responsibilities. Exercise

C. Video: Parenting From Prison: Keeping in Touch. Exercise

D. Video: Parenting From Prison: Going Home. Exercise

Practical Advice and a Message for Going Home

10. VIDEO
A. Video: Troop 1500
B. Video: Hard Straight
C. Video: When the Bough Breaks 
Appendix D: Participant Information Form 


\section{Participant Information Form}

1) When I was incarcerated with my current offense my child was

2) How many months of experience have you had providing parenting on a daily basis for your child?

3) I am __ years old.

4) My children are what age (list all children):

Child 1: years Child 4:

Child 2: _ _ years Child 5:

years

Child 6:

Child 7:___ years

Child 8: ___ years

\section{Check box of all that apply}

5) I have a child between age 2-12 years who is a:

Boy

Girl

6) My race:

African-American

Asian

White

Hispanic

Other

7) What is the highest level in school you have completed?

$1-8^{\text {th }}$ grade

$9^{\text {th }}$ grade

$10^{\text {th }}$ grade

$12^{\text {th }}$ grade

Vocational school or some college

College graduate

Graduate or professional school

8) When I was on the outside, I was responsible for my child's day-to-day care.

Yes

No

9) My child is now living with:

Grandmother

Father

Another family member

Not a family member chosen by courts (e.g., foster care, youth home)

Other:

10) When I was on the outside, I saw my child:

Every day

Several times a week

Once a week

Less than once a week

Once a month 
Less than once a month

One time per year

Less than once a year

11) In the last 6 weeks, in conversations with other people, I talked about my child:

Every day

Several times a week

Once a week

Less than once a week

Once a month

Less than once a month

12) During the last 6 weeks, I have written to my child:

Every day

Several times a week

Once a week

Less than once a week

Once a month

$\square \quad$ No such contact

13) During the last 6 weeks, I have talked with my child on the telephone:

Every day

Several times a week

Once a week

Less than once a week

Once a month

$\square \quad$ No such contact

14) During the last 6 weeks, I have seen my child during visitation:

$\square$ 5-6 weeks

$\square$ 3-4 weeks

$\square 2$ weeks

$\square \quad 1$ week

$\square \quad$ No such contact 
Appendix E: Child-Directed Interaction Coding Sheet 


\begin{tabular}{|c|c|c|c|c|c|c|c|c|c|c|c|c|c|c|c|c|}
\hline & 1 & 2 & 3 & 4 & 5 & 6 & 7 & 8 & 9 & 10 & 11 & 12 & 13 & 14 & 15 & \\
\hline UP & & & & & & & & & & & & & & & & UP \\
\hline LP & & & & & & & & & & & & & & & & LP \\
\hline $\mathrm{QU}$ & & & & & & & & & & & & & & & & $\mathrm{QU}$ \\
\hline $\mathrm{RF}$ & & & & & & & & & & & & & & & & $\mathrm{RF}$ \\
\hline $\mathrm{BD}$ & & & & & & & & & & & & & & & & BD \\
\hline NTA & & & & & & & & & & & & & & & & NTA \\
\hline $\mathrm{COM}$ & & & & & & & & & & & & & & & & $\mathrm{COM}$ \\
\hline TA & & & & & & & & & & & & & & & & TA \\
\hline & 16 & 17 & 18 & 19 & 20 & 21 & 22 & 23 & 24 & 25 & 26 & 27 & 28 & 29 & 30 & \\
\hline UP & & & & & & & & & & & & & & & & UP \\
\hline LP & & & & & & & & & & & & & & & & LP \\
\hline $\mathrm{QU}$ & & & & & & & & & & & & & & & & $\mathrm{QU}$ \\
\hline $\mathrm{RF}$ & & & & & & & & & & & & & & & & $\mathrm{RF}$ \\
\hline $\mathrm{BD}$ & & & & & & & & & & & & & & & & $\mathrm{BD}$ \\
\hline NTA & & & & & & & & & & & & & & & & NTA \\
\hline $\mathrm{COM}$ & & & & & & & & & & & & & & & & $\mathrm{COM}$ \\
\hline TA & & & & & & & & & & & & & & & & $\mathrm{TA}$ \\
\hline
\end{tabular}


Appendix F: Parent-Directed Interaction Coding Sheet 
PDI Coding Sheet

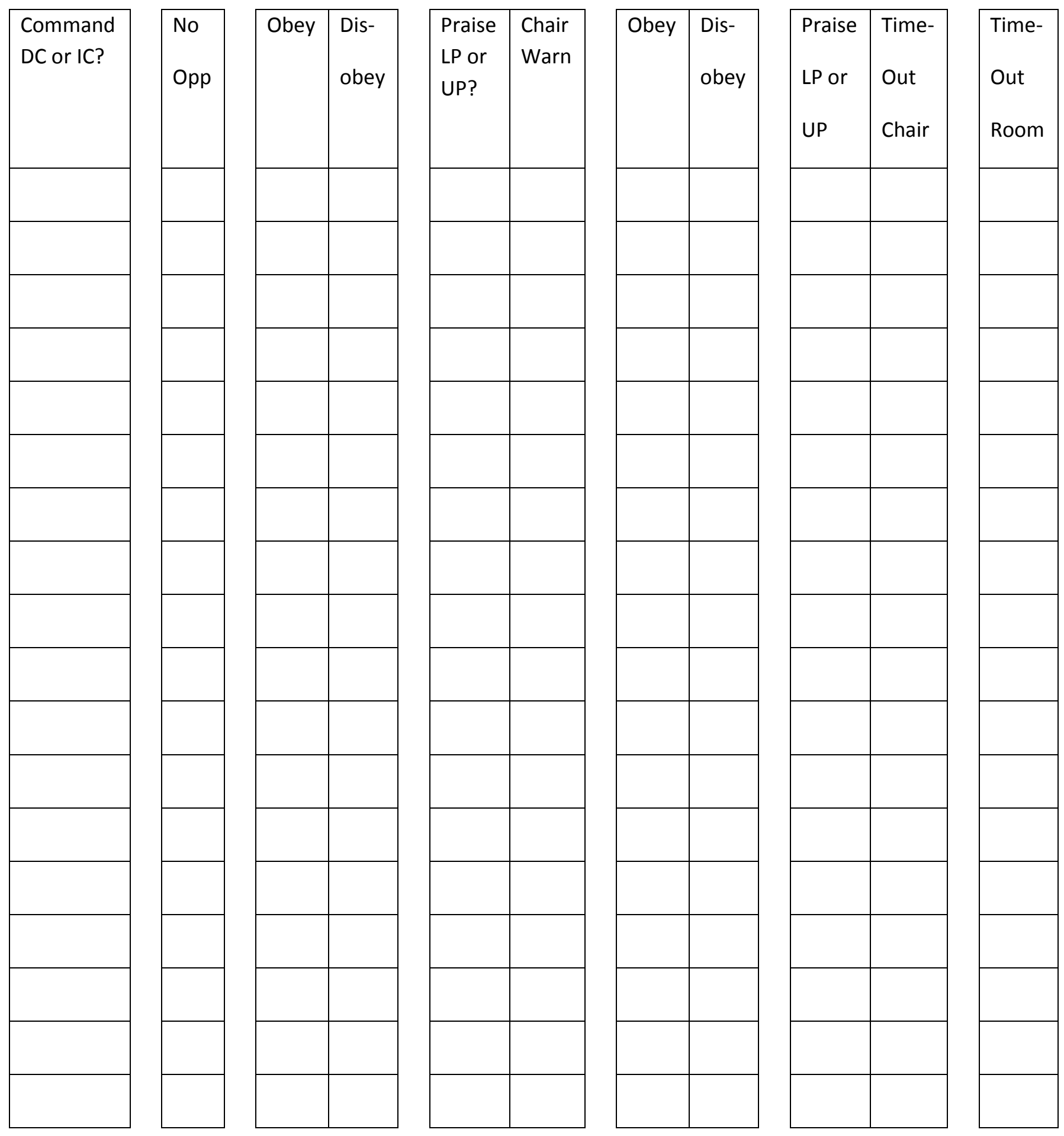


Appendix G: Manipulation Integrity Checklist of Child Play Behavior 


\section{Child Play Behavior Checklist}

- Compliance with $\mathbf{3 0 - 7 0 \%}$ of commands

\begin{tabular}{|l|l|l|c|}
\hline COMMAND & COMPLIANCE & NONCOMPLIANCE & $\begin{array}{c}\text { NO } \\
\text { OPPORTUNITY }\end{array}$ \\
\hline & & & \\
& & & \\
\hline
\end{tabular}

- 15 Prosocial Statements

- Majority of Prosocial Statements

\begin{tabular}{|l|l|}
\hline Positive Talk (PT) & Negative Talk (NTA) \\
\hline & \\
& \\
\hline
\end{tabular}

- 1 Annoying or obnoxious sequence lasting 15-45 secs

\begin{tabular}{|l|l|}
\hline Annoy/Obnoxious & Time \\
\hline & \\
& \\
\hline
\end{tabular}


Appendix H: Child Play Behavior Checklist 


\section{Child Behavior Script}

- Compliance with 30-70\% of commands

- 15 Prosocial Statements

- Majority of Prosocial Statements

- 1 Annoying or obnoxious sequence lasting 15-45 secs -[CHOOSE 1]
○ Tantrum
○ Toy tapping
○ Repeating "Bad word"
- Burping/Farting Noises
○ Throwing Toy on floor
- Scribble on paper
- Yell, scream, squeak

\section{Complete 4}

- Play with truck

- Share toy

- Color with Crayon

- Build Tower

- Build Fence

- Pretend to eat food

\section{Complete 4}

- Laugh

- Sing a 1-line song

- Make animal noise

- Say Statement about Self: "I'm funny!" or "I'm silly worm!"

- Say Statement that is Incorrect: "I've got 3 eyes!" or "My hair is blue!"

- Say Statement about Toy: "Car go vroom vroom vroom" or "Horsies goNeeeigh!"

- Say Mistake statement: “Oopsies! Or Ought O Spaghettis!”

\section{Complete 4}

- Ask a question

- Show parent toy

- Tell parent what you are doing

- Talk about fence

- Talk about Tower

- Talk about favorite color 